\title{
Using impedance cardiography to examine changes in hemodynamic parameters during heart rate biofeedback
}

Jeffrey Louis Goodie

West Virginia University

Follow this and additional works at: https://researchrepository.wvu.edu/etd

\section{Recommended Citation}

Goodie, Jeffrey Louis, "Using impedance cardiography to examine changes in hemodynamic parameters during heart rate biofeedback" (1999). Graduate Theses, Dissertations, and Problem Reports. 722.

https://researchrepository.wvu.edu/etd/722

This Thesis is protected by copyright and/or related rights. It has been brought to you by the The Research Repository @ WVU with permission from the rights-holder(s). You are free to use this Thesis in any way that is permitted by the copyright and related rights legislation that applies to your use. For other uses you must obtain permission from the rights-holder(s) directly, unless additional rights are indicated by a Creative Commons license in the record and/ or on the work itself. This Thesis has been accepted for inclusion in WVU Graduate Theses, Dissertations, and Problem Reports collection by an authorized administrator of The Research Repository @ WVU. For more information, please contact researchrepository@mail.wvu.edu. 
Using Impedance Cardiography to Examine Changes in Hemodynamic Parameters During Heart Rate Biofeedback

\author{
Jeffrey L. Goodie
}

Master's thesis submitted to the Eberly College of Arts and Sciences of West Virginia University in partial fulfillment of the requirements of the degree of

\author{
Master of Arts \\ in \\ Psychology
}

Kevin Larkin, Chair

Daniel W. McNeil

David Schaal

1998

Morgantown, WV

Keywords: Impedance Cardiography, Biofeedback, Cardiovascular

Copyright 1998, Jeffrey L. Goodie 


\begin{abstract}
Cardiovascular disease is the leading cause of death throughout the industrialized world. Previous studies have suggested that individuals demonstrating exaggerated cardiovascular responses to stressors are at a greater risk of developing cardiovascular disease compared to those with smaller responses. Reducing cardiovascular responses to stressors may help to reduce one's risk of developing cardiovascular disease. Heart rate (HR) feedback training is one method that researchers have used to reduce HR responses to stressors. The present study was designed to examine the underlying hemodynamic changes that accompany $\mathrm{HR}$ response reduction to a stressor following HR feedback training. Twenty-five healthy college males were assigned to either a HR feedback training group (FB+) or a control group (FB-) and were presented with a videogame and mental arithmetic challenge, as HR, blood pressure, and impedance cardiographyderived measures were recorded. During the training sessions, the FB+ group received HR feedback and the FB- group was not provided with HR feedback while playing the videogame. Results revealed that those in the FB+ group demonstrated significantly lower HR, systolic blood pressure, stroke volume, and total peripheral resistance responses to the post-training compared to the pre-training videogame. There was no evidence that the acquired skills generalized to the mental arithmetic task. Overall, these results suggest that HR feedback training is an effective method for reducing cardiovascular responding to a stressor; however, the generalizability of this effect remains questionable.
\end{abstract}




\section{Acknowledgements}

This research project was supported by a grant from the West Virginia University Department of Psychology Alumni Fund. I would like to thank the generous alumni who make this fund possible.

Although one individual appears as the author of this document, this project would not have been possible without the assistance of many other individuals. First, I want to express my gratitude for my advisor, and chairperson of my thesis committee, Kevin Larkin. Kevin was instrumental in helping to generate ideas for this project and assisting with problem solving throughout the course of the study. He provided extensive and useful comments that were instrumental for shaping this document. I would also like to thank my committee members Dan McNeil and David Schaal, who provided valuable input into the design of the study and the interpretation of the results. I would also like to thank my research assistant Emily Daley, who helped to contact and run participants. I am very thankful for the assistance provided by Tom Debski and Michael Eddy at the University of Pittsburgh, who freely gave time and advice on how to set-up the impedance cardiograph and then install and operate the software. I am also thankful for the assistance provided by Dan Hollander, Lynda Ciano-Federoff, and Carl Lejuez, who all sacrificed their time and effort to the monumental effort required for setting up the impedance cardiograph.

Finally, I would like to thank my loving wife Mary and son Alex. Without their patience, support, and encouragement this endeavor would have never been possible. 


\section{Table of Contents}

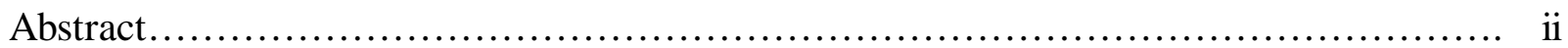

Acknowledgements..........................................................

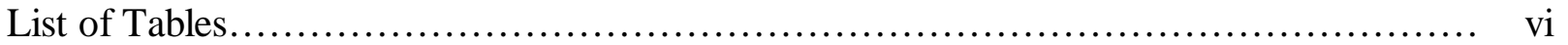

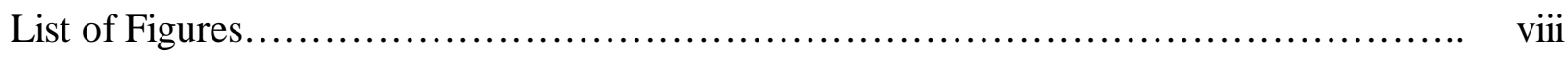

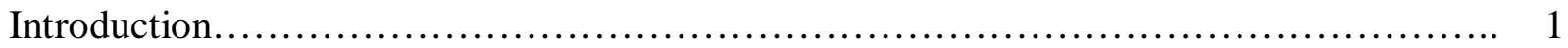

The Cardiovascular Reactivity Hypothesis............................... 2

Reducing Cardiovascular Reactivity...................................... 5

Review of Investigations Examining HR Feedback Training to Reduce

Cardiovascular Reactivity to Stress During Stress Presentation ................... 7

Statement of the Problem...................................................... 14

Hypotheses............................................................ 17

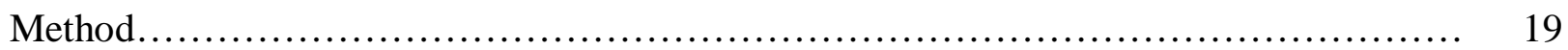

Participants........................................................ 19

Tasks................................................................. 20

Cardiovascular Measures............................................... 21

Procedures............................................................. 23

Data Reduction and Analysis........................................... 26

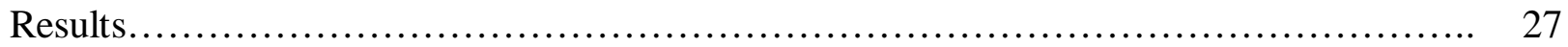

Cardiovascular Measures During the Pre-Training Baseline Periods.............. 27

Cardiovascular and Behavioral Responses to the Pre-Training Videogame

Presentation...................................................... 28

Cardiovascular Responses to the Pre-Training Mental Arithmetic Task............ 28 
Change in Cardiovascular and Behavioral Responses from Pre- to Post-Training

During the Videogame

Changes in Cardiovascular Responses from Pre- to Post-Training During the Mental Arithmetic Task

Cardiovascular Changes Associated with FB+_MAP+ and FB+_MAP-Subjects

from Pre-training to Post-training Videogame Presentations.

Discussion.

Heart Rate Responses to the Videogame. 36

Blood Pressure Responses to the Videogame.

PEP, SV, CI, and TPR responses to the Videogame.

Behavioral Responses During the Videogame.

Cardiovascular responses to the Mental Arithmetic Challenge

FB+_MAP+ and FB+_MAP-Cardiovascular Responses to the Videogame.......... 46

Limitations and Future Directions......................................... 50

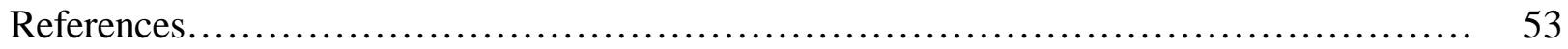

Appendix A............................................................... 61

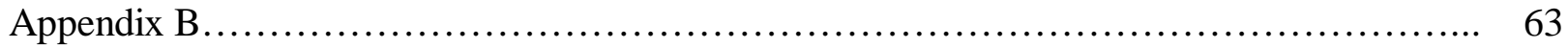

Appendix C............................................................. 64

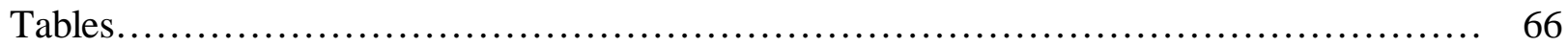

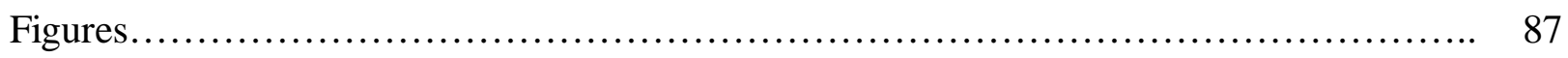

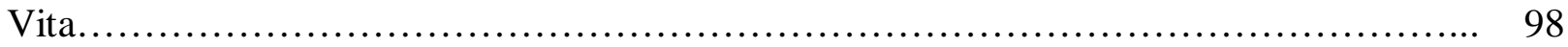




\section{List of Tables}

Table 1. Demographic Information for Participants in the FB+ and FB- Groups.......... 64

Table 2. Summary of Analyses of Variance Results Comparing FB+ $(\mathrm{N}=12)$ and FB- $(\mathrm{N}=$

13) During Pre-Training Baseline and Task Periods.............................. 65

Table 3. Videogame Scores During Pre-Training, Training, and Post-Training Phases...... 66

Table 4. Adjusted Mean and Standard Error of FB+ $(\mathrm{N}=12)$ and FB- $(\mathrm{N}=13)$ Groups

During Post-Training Baselines and Tasks........................................ 67

Table 5. Repeated Measures Analysis of Covariance for HR during the Videogame and

Mental Arithmetic................................................................ 68

Table 6. Repeated Measures Analysis of Covariance for SBP during the Videogame and

Mental..............................................................................

Table 7. Repeated Measures Analysis of Covariance for DBP during the Videogame and

Mental Arithmetic.

Table 8. Repeated Measures Analysis of Covariance for PEP during the Videogame and

Mental

Table 9. Repeated Measures Analysis of Variance for SV during the Videogame and Mental

Arithmetic

Table 10. Repeated Measures Analysis of Variance for CI during the Videogame and Mental

Arithmetic

Table 11. Repeated Measures Analysis of Variance for TPR during the Videogame and Mental Arithmetic.

Table 12. Repeated Measures Analysis of Variance of Performance Scores during the 
Videogame.

Table 13. FB+_MAP+ and FB+_MAP-Cardiovascular Change from Baseline to Pre-

training and Post-training Videogame Presentations.

Table 14. Repeated Measures Analysis of Variance for HR Comparing the FB+_MAP+ and FB+_MAP-Groups During the Videogame.

Table 15. Repeated Measures Analysis of Variance for MAP Comparing the FB+ _MAP+ and FB+_MAP-Groups During the Videogame.

Table 16. Repeated Measures Analysis of Variance for SBP Comparing the FB+_MAP+ and FB+_MAP- Groups During the Videogame

Table 17. Repeated Measures Analysis of Variance for DBP Comparing the FB+ _MAP+ and FB+_MAP- Groups During the Videogame.

Table 18. Repeated Measures Analysis of Variance for PEP Comparing the FB+_MAP+ and FB+_MAP- Groups During the Videogame

Table 19. Repeated Measures Analysis of Variance for SV Comparing the FB+ _MAP+ and FB+_MAP-Groups During the Videogame.

Table 20. Repeated Measures Analysis of Variance for CI Comparing the FB+_MAP+ and FB+_MAP-Groups During the Videogame.

Table 21. Repeated Measures Analysis of Variance for TPR Comparing the FB+ _MAP+ and FB+_MAP-Groups During the Videogame 


\section{List of Figures}

Figure 1. Flow chart of experimental procedures

Figure 2. Heart Rate for FB+ and FB- groups during pre-training, training, and posttraining periods.

Figure 3. Videogame scores for FB+ and FB- groups during pre-training, training, and post-training videogame presentations

Figure 4. Systolic blood pressure for FB+ and FB- groups during pre- and post-training periods.

Figure 5. Diastolic blood pressure for FB+ and FB- groups during pre- and post-training periods.

Figure 6. Pre-ejection period for FB+ and FB- groups during pre- and post-training periods

Figure 7. Stroke volume changes for FB+ and FB- groups during pre- and post-training periods.

Figure 8. Cardiac index changes for FB+ and FB- groups during pre- and post-training periods

Figure 9. Total peripheral resistance changes for FB+ and FB- groups during pre- and post-training periods.

Figure 10. Cardiovascular changes for $\mathrm{FB}+$ _MAP+ group during pre- and post-training periods

Figure 11. Cardiovascular changes for $\mathrm{FB}+$ _MAP-group during pre- and post-training periods. 


\section{Introduction}

Every minute one person dies from coronary heart disease, arguably the foremost health problem in the United States and other industrialized Western countries (Smith \& Leon, 1992). Coronary heart disease typically develops over many years through a process of coronary artery atherosclerosis, the narrowing of the coronary arteries. The narrowing of these arteries, which provide the heart with its own blood supply, develops through a buildup of atherosclerotic plaque, containing excess cholesterol and lipids, and hardened by calcium deposits. The atherosclerotic plaque tends to form in areas where the artery lining, the endothelium, is damaged (Haudenschild, Prescott, \& Chobanian, 1980; Ross, 1981). Injury to the endothelium often occurs in areas where the turbulence of the blood flow increases, such as at branches and bends of the artery proximal to the heart (e.g., coronary arteries, carotid arteries). When the accumulation of atherosclerotic plaque is sufficient, a heart attack (i.e., myocardial infarction) occurs if the blockage is in the coronary arteries, or a stroke occurs if the blockage is in the carotid arteries.

Hereditary, physical, and psychosocial factors interact to promote the development of atherosclerotic plaque responsible for coronary heart disease and stroke. Some risk factors such as age and family history of heart disease are beyond the control of the individual. However, other risk factors such as serum cholesterol levels, lipoprotien ratios, and smoking can be affected by lifestyle practices (Blackburn \& Jacobs, 1984; Jenkins, 1988; Schwartz, 1987). Despite the effort that has led toward the identification of these cardiac risk factors, the three leading risk factors, hypertension, serum cholesterol levels, and smoking, only account for about half of the variance in the prediction of the development of coronary heart disease (Jenkins, 1988). Consequently, researchers have expanded their efforts to examine psychosocial and behavioral 
factors, such as depression (Appels \& Mulder, 1984), social support (Kaplan, Salonen, Cohen, Brand, Syme \& Puska, 1988), and hostile personality characteristics (Dembroski \& Czajkowski, 1989; Smith \& Frohm, 1985), which may influence the disease process. How an individual responds to stress has been one of the more widely studied behavioral risk factors thought to be important in predicting coronary heart disease and stroke.

Individuals typically exhibit characteristic responses to situations associated with high levels of stress marked by sympathetic nervous system (SNS) involvement, cardiovascular activation, and release of neuroendocrine stress hormones, such as cortisol and norepinephrine. This SNS activation involves increased heart rate (HR) and blood pressure (BP) circulation to muscle tissue, while blood flow to nonessential emergency systems (e.g., the digestive system) is decreased. Although adaptive, the increased demands placed on the cardiovascular system in response to stress may lead to the development of pathogenic cardiovascular responses including atherosclerotic lesions, particularly when this cardiovascular activation is magnified (Kaplan, Pettersson, Manuck, \& Olsson, 1991; Smith \& Leon, 1992). The hypothesis that exaggerated HR and $\mathrm{BP}$ reactions to environmental stimuli are associated with coronary heart disease and stroke endpoints is known as the cardiovascular reactivity hypothesis.

\section{The Cardiovascular Reactivity Hypothesis}

It has been well established that some individuals experience excessive cardiovascular reactions (i.e., $\mathrm{HR}$ and $\mathrm{BP}$ ), compared to others, when encountering challenging, engaging, or aversive stimuli (Manuck, Kasprowicz, Monroe, Larkin, \& Kaplan, 1989). The magnitude of these cardiovascular reactions to standardized stressors has been shown to be reliable across periods as long as months and even years (Barnett, Hines, Schirger, \& Gage, 1963; Keys et al., 1971; Menkes et al., 1989; Wood, Sheps, Eleback, \& Schirger, 1984). The cardiovascular 
reactivity hypothesis, in its most basic form, states that persons with exaggerated cardiovascular responses are at greater risk for coronary heart disease than those demonstrating smaller cardiovascular responses. Animal models, case control research using cardiac patients, and prospective human studies have all supported the relation between cardiovascular reactivity to stress and coronary heart disease (Manuck, 1994; Manuck, Kaplan, \& Clarkson, 1983).

Manuck et al. (1983) examined the cardiovascular reactivity hypothesis in 26 male, cynomolgus monkeys. The experimental animals were exposed to a stressor, a monkey glove representing the threat of capture, while HR was monitored. The participants had been fed a diet with a fat and cholesterol composition that was similar to the diets of North American men. The monkeys exhibiting the largest HR reactions to the stressor, compared to a previous baseline assessment, exhibited more atherosclerosis than those monkeys with the lowest levels of HR reactivity to the stressor. In fact, high HR reactors exhibited almost twice the coronary atherosclerosis as the low HR reactors. Using similar research procedures Manuck replicated his findings in a sample of female, cynomolgus monkeys (Manuck, Muldoon, Kaplan, Adams, \& Polefrone, 1989).

Case control studies have retrospectively examined cardiovascular reactivity responses to a variety of stressors (e.g., mental arithmetic, structured Type A interview, and American history quiz) in human participants with and without coronary heart disease. Studies have generally found a positive relation between higher levels of BP reactivity to stressors and the development of coronary heart disease (Corse, Manuck, Cantwell, Giordani, \& Matthews, 1982; Dembroski, MacDougall, \& Lushene, 1979; Krantz, Schaeffer, Davia, Dembroski, MacDougall, \& Schaffer, 1981; Sime, Buell, \& Eliot, 1980). As an example, Corse et al. (1982) studied 58 adult males, 34 of whom had a history of coronary heart disease, but were free of beta-adrenergic blocking 
medication and were normotensive. Participants were exposed to three cognitive tasks: a concept formation task, mental arithmetic and a picture completion task based on test items from the Wechsler Scales. Coronary heart disease participants demonstrated significantly higher DBP reactivity to the stressors than their non-coronary heart disease counterparts.

Prospective human studies also have generally supported the reactivity hypothesis.

Menkes et al. (1989) reported a longitudinal study examining cardiovascular reactivity to the cold pressor task and the development of hypertension. Between 1948-1964, 910 medical students underwent the cold pressor test while their HR and BP reactivity from baseline to task were recorded. Using self-reported health status from the participants 20-36 years later, the researchers found that 105 participants had developed hypertension. Although no association between either DBP or HR reactivity and onset of hypertension was found, participants who demonstrated exaggerated SBP reactivity to the cold pressor test were at an increased risk ( $R R=$ 1.7-2.8) of developing hypertension 20 years later. Other studies (Barnett et al., 1963; Keys et al., 1971; Wood et al., 1984) following participants for at least 20 years, have also found that participants identified as hyper-reactors to the cold pressor task have demonstrated an increased risk for developing hypertension or coronary heart disease later in life. Some prospective studies (Eich \& Jacobsen, 1967; Harlan, Osborne, \& Graybiel, 1964; Armstrong \& Rafferty, 1950; Thacker, 1940) have failed to find significant correlations between cold pressor reactivity and hypertension. However, these results may be difficult to interpret because the researchers did not follow participants until they reached the age of 45 or 50 , ages when hypertension and coronary heart disease are most likely to occur (Menkes et al., 1989).

A recent prospective study used ultrasonography to detect the progression of atherosclerosis in individuals whose cardiovascular reactivity was assessed using a coping task 
(Barnett, Spence, Manuck \& Jennings, 1997). The researchers found that higher SBP reactors to a Stroop color-word interference task also demonstrated greater accumulation of atherosclerotic plaque in the carotid arteries than low SBP reactors over two years following the test trial. In this study, SBP reactivity was the best predictor of atherosclerotic plaque development among all traditional risk factors, including HDL/LDL ratio, body mass index, age, and initial extent of the plaque development.

In a recent review of the literature examining the cardiovascular reactivity hypothesis, Manuck (1994) concluded that it was premature to consider cardiovascular reactivity an established risk factor for coronary heart disease or hypertension. However, the extensive clinical, experimental, and epidemiological data have suggested that cardiovascular reactivity to stress is significantly associated with the development of cardiovascular disease.

\section{Reducing Cardiovascular Reactivity}

In view of the potential negative consequences of exaggerated cardiovascular reactivity to stress, it would seem desirable to develop and test methods to control and moderate HR and/or physiological responses to challenging, engaging, or aversive stimuli. Moderating cardiovascular reactivity, like eliminating smoking, increasing exercise, or reducing sodium and fat intake, may reduce one's risk for developing coronary heart disease and hypertension. Researchers have examined several methods aimed at reducing one's physiological reaction to stress, including cognitive (Grimm \& Kanfer, 1976; Houston \& Holmes, 1976), behavioral (Ewart, Burnett, \& Taylor, 1983; Kirsch \& Henry, 1979) and physiological interventions (Goleman \& Schwartz, 1976; Lehrer, 1978; Sawada \& Steptoe; 1988). These studies examining the efficacy of methods to reduce cardiovascular response to stress typically involve random assignment of participants to a control group or a treatment group. The procedure generally includes three phases: pre- 
training, training, and post-training. In the pre-training phase, HR or BP measures are assessed while the participant is at rest and during exposure to a standardized stressor (e.g., shock, cold pressor, MA). Change scores from the resting state to the presentation of the stressor provide an initial estimate of cardiovascular reactivity. Next, during the training phase, individuals in the treatment group receive instruction in the method designed to reduce their cardiovascular response (e.g., cognitive intervention, relaxation, biofeedback) while control participants receive no training. In some investigations, participants have received training while at rest (Blanchard \& Young, 1972; Hatch, 1980; Manuck, Levenson, Hinrichsen, \& Gryll, 1975), while in other studies, training was conducted while participants engaged in a physical or mental task (Larkin, Manuck, \& Kasprowicz, 1990; Perski \& Engle, 1980; Sirota, Schwartz, \& Shapiro, 1974). Finally, in the post-training phase of these studies, participants in both groups are re-exposed to the stressor and a second estimate of cardiovascular responsivity is calculated. Researchers can then compare change in cardiovascular response magnitude of those in the treatment group with control participants to determine whether training affected cardiovascular responding.

Research examining the efficacy of the various non-pharmacological methods to decrease HR responses to stress has resulted in discrepant findings. Some studies demonstrated that nonpharmacological methods effectively decrease HR responses (Goleman \& Schwartz, 1976; Grimm \& Kanfer, 1976; Kirsch \& Henry, 1979; Larkin, Manuck, \& Kasprowicz, 1989) and others have failed to support this contention (e.g., Ahles, Blanchard, \& Leventhal, 1983; Falkowski \& Steptoe, 1981; Green, Webster, Beiman, Rosmarin, \& Holliday, 1981; Jorgenson, Houston, \& Zurawski, 1981; Sharpley, 1989). Although it is beyond the scope of this paper to review the entire body of literature pertaining to the effectiveness of these methods for reducing cardiovascular reactivity to stress, two findings are important to highlight. First, HR biofeedback 
has been shown to reduce HR reactivity to a stressor more consistently than other interventions (e.g., cognitive restructuring, relaxation therapy). Second, interventions that involved training during the presentation of a stressor (e.g., Ainslie \& Engel, 1974; Larkin et al., 1989; Larkin, Zayfert, Veltum, \& Abel, 1992; Sirota et al., 1974), rather than during periods of rest (e.g., Bennett, Holmes, \& Frost, 1978; Blanchard \& Young, 1972; Caroll \& Evans, 1981; Hatch, 1980; Manuck, et al., 1975), have been more effective at reducing HR reactivity to stress. Although these findings have been consistently observed, the role of training during stressor presentation has rarely been examined empirically. Bentham and Glaros (1982) conducted the only published study to date directly comparing training during a stressor and at rest. Using pulse transit time feedback, the researchers found that only those participants trained during the stressor demonstrated reductions in cardiovascular reactivity to stress (increased pulse transit time). Participants in a no treatment group and those trained during rest showed no change in cardiovascular reactivity to stress. Based on these findings, coupled with the observations from the literature using HR feedback to reduce HR reactivity to stress, it is evident that the most promising method to date for obtaining reductions in behaviorally-elicited cardiovascular responsivity is HR feedback training during the presentation of a stressor.

$\underline{\text { Review of Investigations Examining HR Feedback Training to Reduce Cardiovascular Reactivity }}$ to Stress During Stress Presentation

Early investigations of HR feedback conditioning were conducted on monkeys. Ainslie and Engel (1974) examined whether an operant conditioning paradigm could be used to control a monkey's HR response to an impending electrical shock. Using two different auditory stimuli (2 second clicks and 20 second clicks) the researchers paired one set of clicks with an impending electric shock and the other click set served as a neutral stimulus (i.e., no shock followed). The 
monkeys showed a HR and SBP increase to the clicks associated with the shock. Then, using operant conditioning, 4 monkeys were trained to reduce their HR to avoid the shock, while the other 2 monkeys were taught to increase their HR. Once the monkeys had reliably learned the appropriate response, a procedure began in which the monkeys were shocked if the appropriate HR was not maintained. The monkeys taught to slow their HR were shocked if their HR exceeded the threshold established by the experimenter. The monkeys taught to accelerate their HR received a shock if their HR decreased below the threshold established by the experimenter. The monkeys in each group learned to maintain appropriate HR levels. Other studies by Engel and colleagues (Engel \& Chism, 1967; Engel \& Gottlieb, 1970; Engel \& Hansen, 1966) using avoidance paradigms in monkeys have also shown that increases and decreases in HR could be obtained using lights to signal the participant and to provide HR feedback.

In the first study of this type using humans, Sirota et al. (1974) used a conditioning paradigm to examine the use of biofeedback to reduce an anxiety and fear reaction. Although, the researchers did not conduct a pre-treatment evaluation of HR reactivity to shock, their study provides important evidence about the efficacy of HR biofeedback training. Throughout half of 72 trials, twenty women were administered mild shocks preceded by a warning signal (the other trials were no shock conditions). During the first 48 trials, participants were provided with HR feedback; half of the women were asked to increase their HR and the others were asked to decrease their HR. In both conditions, the women were successful at controlling their HR responses to the shock. These findings were replicated in a second sample of participants (Sirota et al., 1974).

Two other studies employing HR feedback training used physical tasks as stressors (Goldstein, Ross, \& Brady, 1977; Perski \& Engel, 1980). Goldstein et al. provided 8 of 18 
participants with HR biofeedback training while the participants walked on a treadmill at $2.5 \mathrm{mph}$ with a $6 \%$ incline. The participants were trained during weekly sessions that included five 10minute trials. After 25 sessions ( 5 weekly meetings), the HR biofeedback participants reduced their HR reactivity response to exercise more effectively than control participants. The researchers also found that SBP was reduced among individuals receiving HR feedback training. However, when the control group was provided with HR feedback for the last five sessions, these participants were unable to significantly lower their HR during the treadmill exercise. The authors suggested that because participants in the experimental group had higher HRs prior to HR feedback training compared to the control group participants, experimental participants were better able to reduce their HR than control participants. Furthermore, the control group participants may have experienced less initial success at reducing HR and therefore received less reinforcement. Consequently, the inability of the control group to reduce HR using HR feedback training may have been related to lesser reinforcement received during their initial training trials.

In attempt to partially replicate Goldstein et al.'s (1977) findings, Perski and Engel (1980) employed a bicycle ergometer task with 10 participants, five were provided with HR biofeedback and five served as control participants. Five, 45-minute sessions were devoted to the experimental participants receiving HR feedback while pedaling the bicycle ergometer. Control participants did not receive HR feedback during the first five sessions. The researchers did not obtain a pre-training measure of HR or BP reactivity to the exercise task. Instead, the researchers obtained a resting HR and SBP prior to each session and then calculated the HR and SBP change that occurred in response to the exercise task. During two final sessions, the experimental participants did not receive HR feedback, but were asked to reduce their HR while pedaling, using whatever skills they had learned in prior sessions. As in Goldstein et al.'s (1977) study, control 
participants were then provided with HR feedback during an additional five sessions.

Although Perski and Engel (1980) found that participants using HR biofeedback could significantly reduce their HR reactivity to the exercise task, the researchers did not find any significant differences for SBP response. Perski and Engel also found that control participants were able to significantly reduce their HR reactivity to the exercise task when provided with biofeedback, results that are contrary to Goldstein et al.'s (1977) findings.

Not all studies have shown biofeedback to be an effective method of reducing HR reactivity to a stressor. Bouchard and Labelle (1982) examined participants' abilities to decelerate $\mathrm{HR}$ in the presence of a psychological coping stressor, exposure to ischemic arm pain using a BP cuff inflated to $10 \mathrm{~mm} \mathrm{Hg}$ above SBP. Participants in the feedback group learned to reduce their HR through a shaping procedure, provided with HR feedback during the task. Control participants were instructed to decrease their HR but they were not given feedback during the task. The researchers found that the magnitude of HR reduction in response to the stressor at post-training was comparable between the control and feedback groups. These negative findings may in part be explained by the type of stressor employed. In contrast to studies using stressors in which the participants had some degree of control (i.e., active-coping tasks), Bouchard and Labelle used ischemic arm pain, which the participant could not control (i.e., a passive-coping task), possibly reducing the effectiveness of the biofeedback training.

Larkin and colleagues conducted a series of studies that also demonstrated the effectiveness of HR biofeedback, compared to a control group, during exposure to a videogame stressor (Larkin et al., 1989; Larkin et al., 1990; Larkin, Zayfert, Veltum, \& Abel, 1992). Larkin et al. (1989) assigned 20 male participants, who demonstrated at least a 2-bpm HR increase in response to a videogame challenge to either a no-feedback or a HR feedback training group. 
After obtaining pre-training HR reactivity scores to the videogame, participants in the experimental group were provided with HR feedback and instructed to reduce their HR. The score that the participants earned on the game was also contingent on their ability to reduce their HR. Feedback was discontinued and participants in both groups were told to use the skills they had learned during training while playing a final videogame. The results showed that the feedback group exhibited lower post-training HR reactions to the videogame compared to the control group.

In a second study, Larkin et al. (1990) compared HR responses to the same videogame in males placed into one of four groups: no instructions, instructions to maintain a low HR, instructions to maintain a low HR using HR feedback, and a fourth group that received instructions to decrease HR, HR feedback, and was provided with bonus points for successfully maintaining a low HR and had points deducted for poor HR control. Resting HR and BP were measured during pre-training and post-training periods as well as HR and BP reactions to playing the videogame. Participants who received feedback and the score contingency maintained the lowest HR during the post-training task in contrast to the three comparison groups. Interestingly, although the HR response was reduced to almost zero in $40 \%$ of the participants in the feedback condition, the mean $\mathrm{BP}$ response at post-training was almost identical to the pressor response demonstrated prior to the feedback training (Manuck, 1994). For all participants, no changes in SBP or DBP reactivity to the videogame were observed regardless of group assignment.

Larkin et al. (1992) used the same videogame stressor to examine the effects of the score contingency in the HR biofeedback training procedure. Participants included 48 males who demonstrated at least a 4-bpm increase during a pre-training presentation of the videogame and a mental arithmetic challenge. Participants either did (FB+) or did not (FB-) receive biofeedback 
and were reinforced through a game score contingency including both HR reduction and game performance $(\mathrm{SC}+)$ or game performance alone (SC-). Results revealed a main effect for score contingency. Individuals in the $\mathrm{SC}+$ groups exhibited lower HR reactivity to the videogame during the post-training session than did SC-participants. No significant differences were observed between FB+ and FB- participants. Although these results appear to suggest that HR feedback was not important, as the authors discuss, individuals in the $\mathrm{SC}+$ groups were given indirect feedback after each game when their HR reactivity-adjusted score was displayed. Although no significant differences in SBP or DBP were found between groups at either pre- or post-training, FB+ individuals demonstrated significantly lower DBPs than FB- participants during training trials.

Larkin, Zayfert, Abel, \& Veltum (1992) investigated whether feedback training would generalize: (a) to sessions conducted one week later, and (b) to a mental arithmetic task that was not used during feedback training. HR reactivity to the videogame and mental arithmetic task was assessed in 8 experimental and 8 control participants. Participants in the experimental group were trained using five HR biofeedback training trials and participants in the control group were simply instructed to lower HR without feedback. Following training, participants were again exposed to the videogame and mental arithmetic tasks and instructed to use whatever skills they had learned to lower their HR. One week later participants returned and were provided with the same instructions as during the post-training session. Results showed that those participants trained to reduce their HR using biofeedback, compared to control group participants, demonstrated significantly less HR reactivity to both the videogame and mental arithmetic tasks during the posttraining and one-week follow-up sessions. These findings suggest that HR reductions obtained with biofeedback training can generalize to tasks not used in training as well as across time. 
Sharpley (1994) also provided evidence that individuals who learned to reduce HR with biofeedback were able to generalize what they learned to non-laboratory situations. Sharpley (1994) demonstrated that individuals who received biofeedback, imagery, and breathing training reduced HR reactivity to mental stress more than control participants. Treatment group participants received five weeks of HR biofeedback training during a laboratory mental arithmetic stressor. HR reactivity was assessed for the mental arithmetic task three times prior to training and three times following training. Work HR reactivity (i.e., HR changes recorded during a person's daily activities while behavioral observations were made by an observer) were assessed two times prior to HR biofeedback training and two times following training. The treatment group showed significantly lower HR responses to the mental arithmetic task during all three post-training sessions and demonstrated smaller HR reactivity during work than the control group. According to the authors, $95 \%$ of the participants who received biofeedback training reported that they continued to use the training 2.5 years later.

In summary, 13 of the 14 studies that have examined the effects of HR feedback training upon cardiovascular reactivity to stress have demonstrated that HR biofeedback can reliably reduce an exaggerated $\mathrm{HR}$ response to a stressor when participants are trained to reduce their $\mathrm{HR}$ in the presence of a stressor. Further, these reductions appear to generalize to HR reactions to other tasks on which the participant was not trained (Larkin et al., 1992) and to HR reactions to daily work situations (Sharpley, 1994). Of the investigations that have assessed the effect of HR feedback training on BP reactivity to stress, the majority of studies have found no change in BP (Larkin et al., 1990; Larkin et al., 1992; Perski \& Engle, 1980). Only Goldstein et al. (1977) found reductions in SBP during HR feedback training. In an additional analysis of the effects of HR feedback training on BP reactivity, Manuck (1994) reanalyzed data from the study conducted 
by Larkin, et al. (1990). Manuck reported that in 6 out of 17 participants in the HR feedback group, the pre-training mean BP response was equal to the post-training values. In these participants an increased DBP response to the task was observed between pre- and post-training sessions. Based upon these findings, Manuck concluded that HR feedback training may reduce HR reactions to stress via an increased DBP compensatory response to stress. If this is true, training in HR feedback may not result in reduced risk for coronary heart disease but rather result in alterations in the patterning of the cardiovascular response.

\section{Statement of the Problem}

Although HR reactions to stress can apparently be altered using HR feedback training, little is known regarding the overall benefit of HR feedback training for reducing risk for heart disease. In fact, based upon the lack of altered BP reactivity observed in most of the studies of this nature and the fact that increased BP reactivity has been observed in a subset of persons receiving HR feedback training, it is possible that no benefit to the cardiovascular system exists with HR feedback training. Rather, HR feedback may result in shifting what initially was a cardiac response (i.e., increased $\mathrm{HR}$ response) to a more peripheral response (i.e., increased DBP response). Changes among cardiovascular measurement parameters in response to changes in HR are not uncommon. In fact, several self-regulatory alterations in the cardiovascular system are known to occur when HR fluctuates (e.g., arterial pressure, blood flow) (Rushmer, 1989). The cardiovascular system is a very plastic system that is composed of a variety of hemodynamic parameters including $\mathrm{BP}$, cardiac output $(\mathrm{CO})$, total peripheral resistance (TPR), stroke volume (SV), and HR. BP is a function of $\mathrm{CO}$, the amount of blood (in liters) the heart pumps per minute, and TPR, the total resistance to blood flow in the circulatory system. $\mathrm{CO}$ is a function of $\mathrm{SV}$, the amount of blood ejected from the heart, and HR, the rate at which the heart is pumping. 
Changes in one hemodynamic component of the system are generally compensated through changes in other hemodynamic components of the system. Consequently, it is necessary to measure a variety of hemodynamic parameters to completely understand changes in the cardiovascular system. Measuring HR, BP, and SV allows researchers to examine complex changes in the hemodynamics of the cardiovascular system and provide information about $\mathrm{CO}$ and TPR.

Although HR and BP have been traditionally measured using noninvasive techniques (e.g., ECG electrodes, BP cuffs), invasive techniques, such as the Fick and indicator dilution methods, are typically used to obtain measures of SV and CO. The Fick method estimates CO based on the principle that a fixed amount of $\mathrm{O}_{2}$ requires a fixed flow for circulation (Tursky \& Jamner, 1982). Therefore, measuring $\mathrm{CO}$ using the Fick method requires that the $\mathrm{O}_{2}$ consumed by the participant is assessed and divided by the arterial-venous $\mathrm{O}_{2}$ concentration difference, which is obtained from blood samples. The indicator dilution method of determining $\mathrm{CO}$ involves the injection of a known amount of dye into a systemic vein on the right side of the heart (Tursky \& Jamner). Then using blood samples drawn at a constant rate from the brachial or femoral arteries, researchers can determine the concentration of the dye and the time required for dye concentration to change. Using these parameters, researchers can then calculate CO. Due to the invasive nature of these procedures and associated risks, it is not optimal for investigations of cardiovascular reactions to stress. Impedance cardiography provides an alternative, noninvasive method of measuring CO. SV and CO measures obtained through impedance cardiography have been shown to be both reliable and valid (Goldstein, Cannon, Zimlichman, \& Keiser, 1986; Miller \& Horvath, 1978; Mohapatra, 1981). Inter-task consistency (Kasprowicz, Manuck, Malkoff, \& Krantz, 1990; Sherwood, Dolan, \& Light, 1990; Turner, Sherwood, \& Light, 1991) and temporal stability 
(Kamarck, Jennings, Pogue-Geile, \& Manuck, 1994; Kasprowicz et al., 1990; Sherwood, Turner, Light, \& Blumenthal, 1990) have been demonstrated for both estimates of CO and TPR. Impedance cardiography derived measures have allowed researchers to examine hemodynamic responses associated with different tasks. In a traditional fight or flight response, $\mathrm{CO}$ increases while TPR decreases, a compensatory response that is thought to be primarily mediated by $\beta$-adrenergic activity (Sherwood \& Turner, 1995). Such a response has been associated with tasks in which the participants have control, or are lead to believe that they have control (e.g., "active coping" tasks such as speech tasks or videogames) (Obrist et al., 1978). During tasks in which participants do not have instrumental control (e.g., passive coping tasks like the cold pressor or inescapable shocks), however, individuals exhibit increased TPR with little or no change in $\mathrm{CO}$, a response that is believed to involve $\alpha$-adrenergic receptors which mediate vasoconstriction.

Researchers have found that DBP changes tend to be more closely associated with vascular rather than cardiac responses (Obrist et al, 1978; Sherwood \& Turner, 1995). In light of this observation, the findings reported by Manuck (1994) seem to suggest that participants may have changed their cardiac response to a vascular response during a task that is normally associated with cardiac responding. This suggestion, however, is merely speculative since impedance cardiography was not used to measure hemodynamic alterations that occur concomitant to HR response changes with biofeedback in these studies.

The purpose of this study was to replicate previous works by Larkin and colleagues (Larkin, 1989, 1990, 1992) examining the utility of HR feedback for reducing HR reactivity to a videogame challenge. Generalizability of HR reduction skills also were examined using a mental arithmetic task. In addition to measuring $\mathrm{HR}$ and $\mathrm{BP}$ responses, hemodynamic parameters of SV, 
$\mathrm{CO}$, and TPR were obtained via impedance cardiography during the HR biofeedback assessment and training protocol. As with previous investigations, half of the participants received HR feedback training accompanied by the score contingency in which the game score was partly determined by game performance and partly determined by success at achieving HR reduction. The remaining participants served as control participants who did not receive HR feedback training.

\section{Hypotheses}

1a. Based on the literature examining HR biofeedback training it was predicted that, compared to control participants, participants who received HR feedback woud demonstrate a smaller HR response to the videogame stressor and mental arithmetic during the post-training assessment.

1b. No significant difference in SBP or DBP responding was expected between the control and experimental groups at the post-training assessment.

2a. It was hypothesized, based on Manuck's (1994) findings, that individuals demonstrating at least a 4-bpm decrease in HR reactivity to the videogame and a mean $\mathrm{BP}$ change smaller than $2 \mathrm{~mm} \mathrm{Hg}$, when comparing pre and post-training measures, would exhibit an increased DBP response at post-training.

2b. These participants were also expected to demonstrate greater TPR and lower CO response at post-training than other experimental and control participants.

3. During training trials, it was expected that participants in the experimental group would demonstrate lower HR responses to the videogame compared to control participants. 
4. No group differences in game performance either at pre- or post-treatment were hypothesized. 
Methods

\section{Participants}

\section{$\underline{\text { Participant Demographics }}$}

Forty-six male students at West Virginia University were recruited for the study. Because males and females have been shown to have different hemodynamic response patterns to stressors (e.g., females have greater HR and cardiac output responses to stress compared to males (Girdler, Turner, Sherwood, \& Light, 1990; Allen, Stoney, Owens, \& Matthews, 1993), only males were

recruited for this study. Data from twenty-one participants (46\%) were not used for the following reasons: twelve were dropped due to technical problems (e.g., insufficient BP readings for analyses or impedance cardiography data during videogame task); three participants were dropped because of inadequate HR reactivity to the initial presentation of the videogame (i.e., HR changed less than $+2.0 \mathrm{bpm}$ from baseline); three subjects were dropped from the FB+ group because their average HR failed to decrease by more than two beats between the pre-training videogame presentation and the final presentation of the videogame during the training session (i.e., they failed to use HR feedback effectively); and three participants were eliminated from the FB- group because they demonstrated an unusually large HR habituation to the videogame (i.e., HR decreased by $10 \mathrm{bpm}$ or more during the training). Data from the remaining 25 participants were used for analysis, 12 in the FB+ group and 13 in the FB- group.

Individuals taking cardiovascular-reactive drugs (e.g., decongestants, asthma medication or beta-blockers) or who had a history of cardiovascular disease were excluded from the study. Participants were asked not to consume alcohol or smoke for 3 hours, as well as avoid exercise for 1 hour prior to coming to the lab.

Participants were matched across the FB+ and FB- groups on the basis of their race, 
family history of hypertension, and smoking status. As Table 1 shows, the FB+ and FB- groups were not statistically different across most demographic variables, including age, BMI, years of education, and the frequency of alcohol, drug, and tobacco use. Those in FB- group rated their videogame ability higher than those in the FB+ group. The participants in the FB+ and FBgroups were predominately Caucasian, although two African Americans were assigned to the FBgroup. An equal number of participants from both groups $(\underline{\mathrm{N}}=9)$ denied a family history of heart disease or high blood pressure.

In return for participating, the male volunteers were awarded extra credit in their psychology course. In order to maintain interest in the videogame, and as possible additional compensation, participants earned chances in a lottery based on their performance on the videogame (i.e., higher scores resulted in more lottery chances). The lottery awarded a $\$ 50$ first prize, a $\$ 30$ second prize, and a $\$ 10$ third prize. A $\$ 20$ award was also provided to the individual who obtained the highest videogame score of all participants during the entire experiment. $\underline{\text { Tasks }}$

Videogame. The Sno-Cat videogame, used as the stressor in this study, required participants to steer an image of a motorized snowmobile up a snow-covered mountain, while avoiding trees that randomly appear in its path. The participant controlled the horizontal movements of the Sno-Cat as well and could slow it down using the firebutton as a brake. The overall speed of the Sno-Cat, however, could not be controlled by the participant. The Sno-Cat videogame was presented using a Commodore 64 computer using a Commodore 1541 disk drive, and a Commodore color monitor (Model 1802). Participants controlled the movements of the Sno-Cat using a Pointmaster Pro joystick with a firebutton. Scores after each trial were printed using a Commodore 1525 graphic printer. The Sno-Cat program also provided HR feedback to 
those individuals in the experimental group by changing the background colors of the screen.

Mental arithmetic. The mental arithmetic task required that participants count backwards by $17 \mathrm{~s}$ from a four-digit number verbally presented to them. The task lasted 4 minutes and a new four-digit number was presented at the beginning of each minute of the task. Participants were asked to work as quickly and accurately as possible.

\section{$\underline{\text { Cardiovascular Measures }}$}

Heart rate. A finger photoplethysmogram (Lafayette, Model \#76624) provided a measure of HR during the videogame training periods. The device was placed on the middle finger of the participant's non-dominant hand. Pulse waves were translated into beats per minute by a Lafayette Heart Rate Monitor (Model \#77067). In order to provide HR feedback, the HR monitor was connected to a Schmitt Trigger (Lafayette Model \#76729) attached to the Commodore 64 computer through the orange and black leads of an Atari joystick plugged into control port \#2 of the computer. For HR feedback training, HR values were programmed into the Heart Rate Monitor. When the participant's HR exceeded the criterion value entered into the Heart Rate Monitor by at least $1 \mathrm{bpm}$, a signal was sent to the Schmitt Trigger, which closed the relay. When the individual's HR was below the criterion level by at least $1 \mathrm{bpm}$, the Schmitt Trigger relay remained open. The Sno-Cat program, which checked the status of the relay over a 5-second period, then provided the appropriate feedback to participant. If the relay remained closed during those 5 seconds, the background color of the screen turned red to indicate increased HR. If the relay remained open during those 5 seconds, the background turned blue to indicate that the participant's HR was below the criterion. If the relay alternated between open and closed during those 5 seconds the background turned white, indicating that the participant's HR was equal to the established criteria. 
Blood pressure. An IBS BP monitor was used to assess SBP and DBP. During the preand post-training sessions, described in the following procedure section, the BP cuff was fastened around the participant's non-dominant arm and inflated every 2 minutes to provide BP values. During the training period, the cuff was switched to the dominant arm to allow the finger photoplethysmogram, which was attached to the non-dominant arm, to obtain readings. A microphone inside of the cuff detected Korotkoff sounds from the brachial artery and provided an estimate of BP, which was digitally displayed and recorded by the experimenter.

Measures of SV, CO, and TPR. The Minnesota Impedance Cardiograph (Model \#304B) was used to obtain measures of SV, CO and TPR (and HR during pre- and post-training assessment). Measurement involved the placement of four strips of surface tape electrodes, two around the neck and two around the abdomen, three EKG electrodes, and a heart sounds microphone positioned over the heart between two ribs. The impedance cardiograph transmitted a constant electrical current $(100 \mathrm{~Hz})$ through the thorax of the participant and detected resistance to the electrical flow. The resistance measure reflected changes in volume due to respiration and blood flow (i.e., ejection of blood from the heart). Impedance cardiography works on the basic principle of $\mathrm{V}=\mathrm{IR}$, where $\mathrm{V}$ is voltage, $\mathrm{I}$ is current, and $\mathrm{R}$ is resistance. A known current is sent through the thoracic region of the individual. The voltage then varies proportionally to the changes in the resistance caused by shifts of the blood volume. Estimates of stroke volume (SV) were calculated by the formula $\mathrm{SV}=\mathrm{rho}_{\mathrm{b}}\left(\mathrm{L} / \mathrm{Z}_{0}\right)^{2}(\mathrm{LVET})(\mathrm{dz} / \mathrm{dt})$ which was developed by Kubicek, Karnegis, Patterson, Witsoe, and Mattson (1966). In this formula rhob is the blood resistivity, $\mathrm{L}(\mathrm{cm})$ is the distance between the recording electrodes, $\mathrm{Z}_{0}$ is the baseline impedance between the recording electrodes (ohms), LVET is the left-ventricular ejection time (sec), and $\mathrm{dz} / \mathrm{dt}$ is the absolute value of the rate of change, the slope, in the impedance waveform 
(Sherwood, Allen, Fahrenberg, Kelsey, Lovallo, \& van Dooren, 1990).

The dz/dt signal, was ensemble averaged over each 1 minute period to eliminate respiratory artifact, leaving a measure of stroke volume (in $\mathrm{ml}$ ), the amount of blood ejected from the heart during each beat. Cardiac output (in liters/min) was obtained by multiplying stroke volume and $\mathrm{HR}$. Estimated peripheral resistance (in $\mathrm{mm} \mathrm{Hg} / \mathrm{liters} / \mathrm{min}$ ) was obtained by dividing mean arterial pressure by $\mathrm{CO}(\mathrm{TPR}=$ mean $\mathrm{BP} / \mathrm{CO})$. The impedance cardiograph also provides a measure of pre-ejection period (PEP), which corresponds to isovolumic contraction of the left ventricle (Sherwood et al., 1990). PEP is inversely related to sympathetic influences of HR; therefore, a shorter PEP period indicates greater sympathetic activation. PEP was measured from the onset of the Q-wave on the ECG waveform to the onset of left-ventricular ejection, which is the B-point on the dz/dt waveform. The impedance cardiograph waveforms were transmitted to an IBM compatible computer for display, ensemble scoring, and recording purposes.

\section{Procedures}

A flow chart of the procedures is provided in Figure 1. Individuals who volunteered for the study, and met acceptance criteria, were asked to come to a psychophysiology laboratory in Oglebay Hall. Informed consent was obtained from all participants and a general summary of the study was provided. A demographics questionnaire (Appendix A) was then administered and compliance with pre-session instructions was assessed. Participants were assigned to either the control or experimental group. Participants were asked to sit in a comfortable chair while the impedance cardiograph leads, finger photoplethysmogram, heart sounds microphone, ECG electrodes, and BP cuff were attached.

Pre-training. After the equipment was attached and tested for signal clarity, participants were asked to rest quietly for a 10-minute habituation period. During this time, no measures were 
obtained. After 10 minutes, a 6-minute baseline commenced. Participants were asked to keep their eyes open during all baseline periods. Hemodynamic parameters were measured continuously and BP measures were obtained every two minutes. Measurement of cardiovascular parameters continued in an identical fashion throughout all resting pre-training and post-training tasks.

Following the 6-minute baseline, the instructions for the videogame task were presented and the contingencies for obtaining lottery entries were explained. The participants then played two 2-minute games. A 6-minute rest phase followed the pre-training videogame set. The instructions for the mental arithmetic task were presented, followed by the 4-minute mental arithmetic task. During the mental arithmetic task, participants were presented with a 4-digit number at the beginning of each minute (i.e., 4 numbers).

Training. For the participants receiving feedback, the experimental participants, the average HR for the last two minutes of the pre-training videogame was calculated. This value was entered into the Heart Rate Monitor and served as the criterion HR value for the first block of training trial games. Participants were instructed to reduce their HR below the criterion level, using the color feedback on the monitor, which showed participants when they were above, equal, or below the criterion HR level. In order to maximize engagement with the game and compliance with instructions, a special point contingency was programmed into the game. For every 5 seconds that the HR was below the criterion, 500 points was added to the final score. Likewise, 500 points were deducted from the score for every 5 seconds that participant's HR was above the criterion. Participants in the control group did not receive feedback or instructions to reduce their HR. Control participants were told to ignore the background colors of the videogame, which changed randomly among blue, white, and red. 
A total of five, 6-minute training blocks of the Sno-Cat videogame, labeled A, B, C, D, E, was presented to each group with a 1-minute rest period between each block. At the beginning of each block of games, the average HR from the last 2-minute game of the preceding training trial block was calculated for the feedback group and served as a new HR criterion. Prior to each block of games, participants were provided a target goal 100 points higher than the previous block of games. For each goal attained, participants earned 1 chance in the lottery.

During the training trials, the blood pressure cuff was attached to the dominant arm of the participant (i.e., the arm used to manipulate the joystick) in order to allow the finger photoplethysmogram to obtain continuous HR readings. Due to erroneous noise that was produced by arm-movement while the participant played the game, BP readings during the training trials were determined to be invalid, and therefore were not analyzed.

Post-training. After the completion of the five blocks of videogame playing in the training phase, all participants were asked to rest for a 6-minute baseline period while physiological measures were assessed. Two 2-minute videogames and the mental arithmetic task (using different numbers) were again presented. A 6-minute resting period was presented between the presentation of the tasks. All participants, control and experimental, were asked to use whatever skills they may have learned during the previous sessions of game playing to obtain the highest scores possible. However, no feedback was provided to either group. Participants were told again the point criterion required for obtaining additional lottery entries during this final videogame presentation. A final 6-minute rest period followed the completion of the mental arithmetic task.

Following the post-training phase, the physiological recording instrumentation was removed. Participants completed a questionnaire about their videogame use (Appendix B), 
informed of the number of lottery entries that they earned, and debriefed about the purpose of the study. The entire session lasted 2.5 - 3 hours.

\section{Data Reduction and Analysis}

For each cardiovascular parameter, data were averaged for each 6-minute rest period and for each 4-minute presentation of the videogame and 4-minute mental arithmetic task during the pre- and post-training videogame presentations. SBP and DBP values were considered to be erroneous and were deleted based on the criteria described by Marler, Jacob, Lehoczky and Shapiro (1988): SBP < $70 \mathrm{mmHg}$ or $>250 \mathrm{mmHg}$, DBP < $45 \mathrm{mmHg}$ or $>150 \mathrm{mmHg}$, SBP/DBP $<[1.065+(0.00125 \times \mathrm{DBP})]$ or $>3$. Because $\mathrm{SV}$ and $\mathrm{CO}$ vary proportionally between individuals based on the person's size, SV and CO were converted into stroke index and cardiac index by dividing the parameter by body surface area (bsa) where bsa $=\left(\left(\right.\right.$ weight $\left.(\mathrm{kg})^{0.425}\right) *$ (height $\left.\left.(\mathrm{cm})^{0.725}\right) * .007184\right)$. For the training trials, the HR was averaged for each of the five trials (i.e., 6 minutes of data).

Experimental and control groups were compared, using Bonferroni $\alpha$-corrected independent sample t-tests, regarding age, body mass index (BMI) and videogame use. Resting HR, SBP, DBP, and other hemodynamic measures, and initial videogame score were analyzed using one-way ANOVAs [Group (FB+, FB-)]. Mean HR, SBP, and DBP during the initial presentation of the tasks were analyzed using one-way ANCOVAs [Group (FB+, FB-)], covarying baseline measures. A one-way ANOVA [Group (FB+, FB-)] was used to assess for differences in videogame performance at pre-training.

HR during the training trials was analyzed for differences using 2 x 5 [Group x Training Trials (A, B, C, D, E)] mixed factors ANOVAs.

A 2 x 2 [Group (FB+, FB-) x Phase (pre, post-training)] analysis of covariance 
(ANCOVA) for SBP, DBP, HR, and PEP, covarying respective baseline measures, and 2 × 2

[Group (FB+, FB-) x Phase (pre, post-training)] ANOVAs for the percent change of SV, $\mathrm{CO}$, and TPR were used to determine group cardiovascular response differences between the pre and posttraining of the videogame and mental arithmetic tasks. A 2 × 2 [Group (FB+, FB-) x Phase (pre, post-training)] mixed factors ANOVA was calculated to assess for any differences in videogame performance between the two groups. When the Group x Phase interaction was significant, simple main effects analyses were conducted and the main effects for that cardiovascular measure were not discussed.

Manuck (1994) observed a group of HR feedback trainees who evidenced small changes in MAP from pre- to post-training videogame presentations; a similar group was observed in the present sample. $\mathrm{FB}+$ participants $(\underline{\mathrm{N}}=5)$ showing higher, or equivalent mean blood pressure responses to the post-training videogame in contrast to the pre-training videogame (i.e., MAP reactivity to the post-training videogame subtracted from the MAP reactivity to the pre-training videogame was less than $3 \mathrm{~mm} \mathrm{Hg}$ ), were categorized as FB+_MAP+ participants. The remaining FB+ subjects $(\underline{N}=7)$, who demonstrated a decreased MAP response to the posttraining videogame compared to the pre-training session were categorized as FB+_MAPparticipants. The FB+_MAP+ and FB+_MAP-groups were compared using a 2 x 2 [Group (FB+_MAP+, FB+_MAP-) x Phase (Pre-, Post-training)] mixed factors ANOVA or ANCOVA for each cardiovascular measure.

Results

Cardiovascular Measures During the Pre-Training Baseline Periods

As shown in Table 2, no significant differences were found between the FB+ and FBgroups for any cardiovascular measure during the baseline period preceding either the videogame 
or mental arithmetic challenge.

Cardiovascular and Behavioral Responses to the Pre-Training Videogame Presentation

As shown in Table 2, no significant differences were found between the groups on initial cardiovascular reactivity to the videogame except that the $\mathrm{FB}+\operatorname{group}(\mathrm{M}=138.0 \mathrm{~mm} \mathrm{Hg})$ demonstrated a significantly higher SBP response than the FB- group $(\underline{\mathrm{M}}=128.7 \mathrm{~mm} \mathrm{Hg})$. There was no significant difference between the $\mathrm{FB}+\operatorname{group}(\underline{\mathrm{M}}=31350, \underline{\mathrm{SD}}=2583)$ and FB- group $(\underline{\mathrm{M}}$ $=30265, \underline{\mathrm{SD}}=2678$ ) on the videogame score obtained during the pre-training presentation of the videogame $(\underline{\mathrm{F}}(1,23)=1.06, \underline{\mathrm{p}}>0.05$; see Table 3$)$.

Cardiovascular Responses to the Pre-Training Mental Arithmetic Task

As shown in Table 2, no significant differences were found between the FB+ and FBgroups on cardiovascular response to the mental arithmetic challenge at pre-training. Cardiovascular and Behavioral Responses During the Training Trials

An analysis of the HR during training trials revealed a main effect for Group, $\underline{F}(1,27)=$ 21.07, $\underline{p}<0.001, \eta^{2}=0.44$. Mean HR for the FB+ group $(\underline{\mathrm{M}}=74.1 \mathrm{bpm}, \underline{\mathrm{SD}}=10.0)$ was significantly lower compared to the mean $\mathrm{HR}$ of the FB- group $(\underline{\mathrm{M}}=76.6 \mathrm{bpm}, \underline{\mathrm{SD}}=6.8)$. The main effect for Training Trials, $\underline{\mathrm{F}}(4,108)=0.70, \mathrm{p}>0.05$, and the Group $\mathrm{x}$ Training Trials interaction $\mathrm{F}(4,112)=2.13, \mathrm{p}>0.05$ were not significant. As shown in Figure 2, although the HR levels were different between the two groups across training trials, no systematic change in HR was observed over the training trials for either group.

As hypothesized, the videogame scores earned during the training sessions on the videogame (calculated without using HR bonus points for the feedback group) were not significantly different between the $\mathrm{FB}+$ and $\mathrm{FB}$ - groups, $\underline{\mathrm{F}}(1,23)=0.00$, $\mathrm{p}>0.05$. A significant main effect was found for Training Trials, $\underline{\mathrm{F}}(4,92)=4.15, \underline{\mathrm{p}}<0.01$, as the average score 
increased from the first trial game $(\underline{\mathrm{M}}=30,138$ points $)$ to the fifth trial game $(\underline{\mathrm{M}}=31,676$ points; $\mathrm{p}<0.01$ ), as shown in Figure 3. Mean comparisons also revealed that the videogame scores obtained during Trial 1 were significantly lower than Trial $4(\underline{p}<0.03)$, and Trial 2 scores were significantly lower than Trial $5(\mathrm{p}<0.01)$. The Group x Training Trial interaction was not significant $\underline{F}(4,92)=.91, \underline{p}>.05$.

Change in Cardiovascular and Behavioral Response from Pre- to Post-Training During the Videogame

Heart rate. As shown in Tables 4 and 5, the Group x Phase interaction was significant for change in HR response to the videogame. The simple effects analyses, as shown in Table 6, revealed that the $\mathrm{FB}+\operatorname{group}(\Delta \underline{\mathrm{M}}=-1.2 \mathrm{bpm})$ demonstrated a significantly smaller response during the post-training compared to the FB- group $(\Delta \underline{\mathrm{M}}=+7.0$ bpm; $\mathrm{p}<0.01$; see Figure 2$)$. No significant differences in HR response were observed at pre-training.

Systolic blood pressure. The Group x Phase interaction for SBP was also significant, as shown in Table 6. Although the FB+ and FB- group's SBP reaction to the post-training videogame was not significantly different, as stated previously, the FB+ group exhibited a greater SBP response to the pre-training videogame than the FB- group. The simple effects analyses also revealed that the SBP reaction to the videogame for the FB+ group significantly decreased from the pre-training $(\Delta \underline{\mathrm{M}}=17.6 \mathrm{~mm} \mathrm{Hg})$ to post-training $(\Delta \underline{\mathrm{M}}=2.9 \mathrm{~mm} \mathrm{Hg})$ videogame presentation, as shown in Figure 4. The SBP response of the FB- group, on the other hand, was not significantly different between pre-training $(\Delta \underline{\mathrm{M}}=8.5 \mathrm{~mm} \mathrm{Hg})$ and post-training $(\Delta \underline{\mathrm{M}}=5.3 \mathrm{~mm}$ $\mathrm{Hg}$ ) videogame presentations.

Diastolic blood pressure. The Group x Phase interaction and main effects for Group and Phase for the DBP reaction to the videogame were not significant, as shown in Table 7 and Figure 
Pre-ejection period. As shown in Figure 6, the PEP response to the videogame was similar between the FB+ and FB- groups during the pre-training and post-training presentations of the videogame. Table 8 shows that the interaction between Group and Phase was not significant for PEP. However, the main effects for Group and Phase were significant. The significant Group main effect revealed that the FB- group demonstrated a longer mean PEP during the videogame presentations $(\underline{\mathrm{M}}=106.6 \mathrm{msec})$ compared to the $\mathrm{FB}+$ group $(\underline{\mathrm{M}}=102.9 \mathrm{msec})$. The significant Phase main effect revealed that the mean PEP reaction to the videogame during the pre-training phase $(\underline{\mathrm{M}}=99.4 \mathrm{msec})$ was significantly shorter than the mean PEP during the posttraining phase $(\underline{\mathrm{M}}=109.3 \mathrm{msec})$.

Stroke volume (index). The Group x Phase interaction for the SV (index) response to the videogame was significant, as shown in Table 9. As plotted in Figure 7, although not significantly different during pre-training, the FB+ group's SV response to the post-training videogame ( $\Delta \underline{\mathrm{M}}=$ $0.3 \%)$ was significantly smaller than the SV response of the FB- group ( $\Delta \underline{\mathrm{M}}=-11.7 \%)$.

Cardiac index. The Group $\mathrm{x}$ Phase interaction for the CI response to the videogame task approached significance (i.e., $\mathrm{p}=0.10$ ), as shown in Table 10. Simple effects analyses revealed that the $\mathrm{FB}+$ group's $\mathrm{CI}$ reaction during the post-training videogame $(\Delta \underline{\mathrm{M}}=+0.8 \%)$ was somewhat smaller, albeit not significantly, than the FB- group's CI reaction $(\Delta \underline{\mathrm{M}}=-4.9 \% ; \mathrm{p}=$ 0.11, see Figure 8). CI decreased for FB- subjects from pre- $(\underline{\mathrm{M}}=+0.9)$ to post-training $(\underline{\mathrm{M}}=$ 4.9), a finding not observed for FB+ participants. The main effects for Group and Phase were not significant.

Total peripheral resistance. The Group $\mathrm{x}$ Phase interaction for the TPR response to the videogame task was also significant, as shown in Table 11. Simple effects analyses revealed that 
the FB+ and FB- groups demonstrated that although no difference was observed at pre-training, significantly different TPR reactions to the post-training videogame were observed. As shown in Figure 9, the FB+ group demonstrated a small change between the preceding baseline and the post-training videogame $(\Delta \underline{\mathrm{M}}=0.7 \%)$. However, the FB- group demonstrated a TPR percent change $(\Delta \underline{\mathrm{M}}=16.5 \%)$ that was almost twice as large as the change observed during the pretraining videogame.

Behavioral responses. As shown in Table 12, the main effect for Phase was significant for the scores obtained during the videogame. Participants obtained higher scores during the posttraining videogame $(\underline{\mathrm{M}}=33690$ pts $)$ compared to the scores obtained during the pre-training videogame $(\underline{M}=30786$ pts $)$. The Group x Phase interaction and the main effect for Group were not significant.

Changes in Cardiovascular Responses from Pre- to Post-Training During the Mental Arithmetic Task.

The mental arithmetic task analyses revealed no significant Group x Phase interactions for any cardiovascular measure. Therefore, only significant main effects are discussed for each cardiovascular measure.

Heart rate. As shown in Table 5, the main effect for Phase was significant for the HR response to the mental arithmetic task. The HR response to the mental arithmetic task was higher during the pre-training phase $(\underline{\mathrm{M}}=80.0 \mathrm{bpm})$ compared to the post-training phase $(\underline{\mathrm{M}}=78.0$ bpm). As shown in Figure 2, the HR response to the mental arithmetic task was similar for both the $\mathrm{FB}+$ and FB- groups during both the pre- and post-training presentations of the mental arithmetic task.

Systolic blood pressure. Table 6 shows that the main effect for Phase was also significant 
for SBP during the mental arithmetic task; however, the Group main effect was not significant. SBP was higher during the pre-training mental arithmetic task $(\underline{\mathrm{M}}=131.8 \mathrm{~mm} \mathrm{Hg})$ compared to the post-training mental arithmetic task $(\underline{\mathrm{M}}=126.7 \mathrm{~mm} \mathrm{Hg}$; see Figure 4).

Diastolic blood pressure. As shown in Table 7, the main effects for Group and Phase were not significant for DBP during the mental arithmetic task (see Figure 5).

Pre-ejection period. The ANCOVA of the PEP response to the mental arithmetic task, displayed in Table 8, shows a main effect for Phase. PEP during the pre-training mental arithmetic presentation $(\underline{\mathrm{M}}=106.5 \mathrm{msec})$ was shorter compared to the PEP during the posttraining presentation of the mental arithmetic task ( $\underline{\mathrm{M}}=111.3 \mathrm{msec}$; see Figure 6). The Group main effect was not significant.

Stroke volume index. The analyses for SV are displayed in Table 9. The ANCOVA for the SV response to the mental arithmetic task revealed a significant main effect for Phase. As shown in Figure 7, during the pre-training phase, participants demonstrated a decreased SV response to the mental arithmetic task ( $\underline{\mathrm{M}}=-13.4 \%)$, while during the post-training session the participants demonstrated a smaller reduction in SV $(\underline{\mathrm{M}}=-6.9 \%)$. The main effect for Group was not significant.

Cardiac index. As shown in Table 10, the ANCOVA for the CI response to the mental arithmetic task revealed that the Group and Phase main effects were not significant. However, the Phase main effect approached significance $(\mathrm{p}=0.07)$. The percentage change of CI during the pre-training mental arithmetic task was slightly larger $(\underline{M}=-4.0 \%)$ than the change observed during the post-training mental arithmetic task $(\underline{\mathrm{M}}=-0.9 \%)$, as shown in Figure 8 .

Total peripheral resistance. The ANCOVA for the TPR response to the mental arithmetic task, shown in Table 11, revealed a significant main effect for Phase, but not for Group. During 
pre-training, the TPR response to the mental arithmetic task was larger $(\underline{M}=17.5 \%)$ than the post-training response $(\underline{\mathrm{M}}=6.5 \%)$. As shown in Figure 9 and Table 11, during pre-training and post-training the FB+ and FB- groups showed similar TPR changes to the mental arithmetic task. Cardiovascular Changes Associated with FB+_MAP+ and FB+_MAP-Subjects from Pre-training to Post-training Videogame Presentations

Heart rate. As shown in Table 14, the ANCOVA for the HR reaction to the videogame revealed a significant main effect for Phase, while the main effect for Group and the Group x Phase interaction were not significant. As shown in Figures 10 and 11, FB+_MAP+ and FB+_MAP-groups demonstrated similar attenuated HR responses to the post-training videogame $(\mathrm{FB}+\mathrm{MAP}+\Delta \underline{\mathrm{M}}=0.3 ; \mathrm{FB}+$ _MAP- $\Delta \underline{\mathrm{M}}=0.5)$ compared to the pre-training presentation. $(\mathrm{FB}+\mathrm{MAP}+\Delta \underline{\mathrm{M}}=8.7 ; \mathrm{FB}+\mathrm{MAP}-\Delta \underline{\mathrm{M}}=10.9)$.

Mean arterial pressure. The ANCOVA for the MAP reaction to the videogame, shown in Table 15, revealed a significant Group x Phase interaction. Simple effects analyses revealed that the FB+_MAP and FB+_MAP-groups did not exhibit significantly different responses to the preor post-training videogame presentations. However, simple effects analyses revealed that the $\mathrm{FB}+$ _MAP-group demonstrated a significantly smaller MAP reaction $(\Delta \underline{\mathrm{M}}=-2.5 \mathrm{~mm} \mathrm{Hg})$ to the post-training videogame compared to the pre-training videogame $(\Delta \underline{M}=12.4 \mathrm{~mm} \mathrm{Hg}$; see Figure 11). As shown in Figure 10, the FB+_MAP+ group demonstrated a smaller MAP response $(\Delta \underline{\mathrm{M}}=2.0)$ to the pre-training videogame compared to the post-training videogame response $(\Delta \underline{\mathrm{M}}=5.5)$; however, this difference was not significant.

Systolic blood pressure. As shown in Table 16, the ANCOVA for SBP revealed a significant main effect for Phase. The average SBP response to the pre-training videogame $(\Delta \underline{\mathrm{M}}$ $=17.7 \mathrm{~mm} \mathrm{Hg})$ was significantly greater than the SBP post-training videogame response $(\Delta \underline{\mathrm{M}}=$ 
$2.5 \mathrm{~mm} \mathrm{Hg}$ ). The Group x Phase interaction approached significance. Simple effect analyses revealed that the $\mathrm{FB}+\_\mathrm{MAP}+$ and $\mathrm{FB}+\_\mathrm{MAP}$ - groups did not demonstrate significantly different SBP responses to the pre-training or post-training videogame presentations (see Figures 10 and 11). However, simple effect analyses revealed that the FB+_MAP- group demonstrated a significantly smaller response to the post-training videogame $(\Delta \underline{\mathrm{M}}=-0.0 \mathrm{~mm} \mathrm{Hg})$ compared to the pre-training videogame $(\Delta \underline{\mathrm{M}}=21.3 \mathrm{~mm} \mathrm{Hg})$. The Group main effect was not significant.

Diastolic blood pressure. As shown in Table 17, the ANCOVA for the DBP reaction to the videogame revealed that the Group x Phase interaction was significant. During the posttraining presentation of the videogame, the $\mathrm{FB}+$ _MAP+ group demonstrated a larger DBP response $(\Delta \underline{\mathrm{M}}=+8.3 \mathrm{~mm} \mathrm{Hg}$ ), while those in the $\mathrm{FB}+$ _MAP-group demonstrated a DBP response that was lower than the preceding baseline $(\Delta \underline{\mathrm{M}}=-3.7 \mathrm{~mm} \mathrm{Hg})$; this difference between the groups approached significance $(\mathrm{p}=0.07$; see Figures 10 and 11). Simple effect analyses also revealed that the FB+_MAP-group's DBP response to the pre-training videogame $(\Delta \underline{\mathrm{M}}=+8.0)$ was somewhat higher than the DBP response during the post-training videogame $(\Delta \underline{\mathrm{M}}=-3.7)$; this difference approached significance $(\mathrm{p}=0.07$; see Figure 11$)$. The main effects for Group and Phase were not significant.

Pre-ejection period. The ANCOVA for the PEP response to the videogame, shown in Table 18, revealed a significant main effect for Phase. Both groups demonstrated similar PEP responses to the pre-training $(\mathrm{FB}+\mathrm{MAP}+\Delta \underline{\mathrm{M}}=-13.1, \mathrm{FB}+\mathrm{MAP}-\Delta \underline{\mathrm{M}}=-12.6)$ and posttraining $\left(\mathrm{FB}+\_\mathrm{MAP}+\Delta \underline{\mathrm{M}}=-5.1, \mathrm{FB}+\mathrm{MAP}-\Delta \underline{\mathrm{M}}=-2.3\right)$ presentations of the videogame, as shown in Figures 10 and 11. The main effect for Group and the Group x Phase interaction were not significant.

Stroke volume. As shown in Table 19, the ANCOVA for the SV response to the 
videogame revealed a significant main effect for Phase. The SV response for all participants increased from pre-training $(\underline{\mathrm{M}}=-12.7)$ to post-training $(\underline{\mathrm{M}}=0.3 \%)$ as shown in Figure 10. The Group main effect approached significance. The FB+_MAP-group demonstrated a greater SV decrease $(\underline{\mathrm{M}}=-9.7 \%)$ to both pre- and post-training videogame than the FB+_MAP+ group $(\underline{\mathrm{M}}=$ $-1.3 \%$ ), which demonstrated a reduced SV responding during pre-training, but an increased SV response to the videogame during post-training. The Group x Phase interaction, however, was not significant.

Cardiac index. The ANCOVA for the CI response to the videogame revealed no significant main effects for Group and Phase, nor Group x Phase interaction, as shown in Table 20.

Total peripheral resistance. The ANCOVA for TPR revealed that the main effect for Phase was significant, as shown in Table 21. The FB+_MAP+ and FB+_MAP-groups demonstrated reduced TPR reactions during the post-training videogame ( $\mathrm{FB}+\mathrm{MAP}+\Delta \underline{\mathrm{M}}=0.7$ , $\mathrm{FB}+\mathrm{MAP}-\Delta \underline{\mathrm{M}}=0.6)$ compared to the pre-training videogame presentation $(\mathrm{FB}+\mathrm{MAP}+\Delta \underline{\mathrm{M}}$ $\left.=7.3, F B+\_M A P-\Delta \underline{M}=20.1\right)$, as shown in Figures 10 and 11 . The Group main effect and the Group x Phase interaction were not significant. 


\section{Discussion}

The results of this study replicated the previous findings that individuals can learn to use HR feedback to reduce their HR reactivity to an environmental challenge (e.g., Ainslie \& Engel, 1974; Larkin et al., 1989; Larkin et al., 1990; Larkin, Zayfert, Veltum, \& Abel, 1992). Those receiving feedback training demonstrated lower HR and SBP responses to the post-training videogame compared to their counterparts who did not receive this training. In addition to replicating previous results, this study used impedance cardiography to extend previous findings to reveal the underlying hemodynamic changes that accompanied the observed HR reductions. SV, CI, and TPR responses were also lower during the post-training session compared to the pretraining videogame presentations. The reduced cardiovascular responses did not affect game performance. There was no evidence that the HR reduction skills during training on the videogame generalized to HR reductions during the mental arithmetic challenge. The present study was also designed to examine the hemodynamic changes that occurred in a group of individuals, similar to those described by Manuck (1994), who demonstrated small changes in MAP responses to the videogame from pre-training to post-training. Individuals in the present study who demonstrated small MAP response changes showed similar BP response patterns as those described by Manuck's. These individuals also demonstrated trends towards increased SV and CI responses during the post-training videogame. The following sections discuss the observed changes in HR, BP, PEP, SV, CI, and TPR responses to the videogame and mental arithmetic challenge, and provide directions for future studies.

\section{$\underline{\text { Heart Rate Responses to the Videogame }}$}

The FB+ and FB- groups demonstrated similar increased HR responses to the pre-training presentation of the videogame, thus differences between the groups following the pre-training 
phase could be attributed to the feedback training. HRs of the FB+ group were significantly lower than the HRs of the FB- group throughout the training trials. During the first feedback training trial, the $\mathrm{FB}+$ group demonstrated a marked decrease in $\mathrm{HR}$ responding to the videogame compared to the pre-training videogame presentation. Following the first training trial (i.e., Trials 2 - 5), the FB+ group demonstrated additional, but small, HR response reductions; however, these changes were not statistically significant. Therefore, the FB+ group appeared to learn the necessary skills to reduce HR during the initial training trial. Previous studies employing the same videogame task with multiple training periods (Larkin et al., 1989; Larkin et al., 1990; Larkin, Zayfert, Veltum, \& Abel, 1992) also reported that initial HR response reductions occurred during the first training trial accompanied by relatively stable HRs during subsequent training trials. In other words, individuals quickly learned the skills necessary to reduce their HR responses to an environmental challenge when provided with accurate HR feedback.

During post-training, the FB+ group demonstrated a $1.2 \mathrm{bpm}$ HR decrease from baseline to the videogame presentation, in contrast to the FB- group, which demonstrated a $7.0 \mathrm{bpm}$ increase. This significant difference between the FB+ and FB- groups for HR responses to the post-training videogame suggested that those in the FB+ group successfully applied the skills learned during the training sessions to decrease their HR responses to an environmental challenge when no HR feedback was provided. Previous studies using a similar protocol (Larkin et al., 1989; Larkin et al., 1990; Larkin, Zayfert, Veltum, \& Abel, 1992), have found similar HR response reductions from the preceding baseline to the post-training videogame.

The results from this study corroborate previous work demonstrating that when HR feedback training is provided in the presence of an environmental stressor, individuals can effectively learn to reduce their HR and apply those skills when no HR feedback is presented. 


\section{Blood Pressure Responses to the Videogame}

In the present study, participants in the FB+ and FB- groups demonstrated comparable baseline SBP and DBP levels. During the pre-training presentation of the videogame, however, the FB+ group demonstrated a significantly greater SBP response than those in the FB- group. Following HR feedback training, when the pre-training SBP response to the videogame was compared to the post-training SBP videogame response, the FB+ group demonstrated a greater reduction in SBP than the FB- group, which demonstrated no significant reduction in SBP. Therefore, the SBP response was significantly attenuated during training for the FB+ group, but this attenuation was not observed for the FB- group.

Because the $\mathrm{FB}+$ group demonstrated an exaggerated SBP response to the pre-training videogame compared to the FB- group, the impact of HR training is unclear. Although the observed SBP response reduction from pre- to post-training for the FB+ group may be due to HR feedback training, the SBP response reduction may also have occurred as a result of habituation to the task. Because the FB- group, in contrast to the FB+ group exhibited lesser SBP responding to begin with, less habituation was expected for the FB- group in comparison to their more reactive $\mathrm{FB}+$ counterparts.

Previous studies have found mixed results regarding changes in SBP responses associated with HR feedback training. Most researchers have found no significant differences between preand post-training measures of SBP response (Larkin et al., 1990; Perski \& Engle, 1980). However, Goldstein (1977) reported a reduced SBP response during a post-training compared to a pre-training presentation of a physical stressor. Because groups in previous studies had comparable pre-treatment SBP responses, it is difficult to compare the present results with this literature. On the one hand, the current results appear to be more congruent with the findings 
reported by Goldstein. On the other hand, it is more likely that the observed reductions in SBP response that occurred with HR feedback training are due to the SBP response differences that were detected at pre-treatment. After all, analyses of simple effects revealed no group differences in SBP response to the videogame at post-training.

The DBP response to the videogame did not significantly change for either the FB+ or FB- groups between the pre-training and post-training phases. However, it may be interesting to notice in Figure 5 that although both the FB+ and FB- groups demonstrated an increased DBP response to the pre-training videogame, during the post-training videogame presentation the $\mathrm{FB}+$ group showed a smaller DBP level compared to the preceding baseline, while the FB- groups continued to demonstrate an increased DBP response to the videogame. Differences in DBP response at post-training, however, were not significant.

Previous studies that have measured DBP responses to tasks have also reported nonsignificant DBP changes from pre- to post-training stressors (Larkin et al., 1990; Larkin et al., 1992). However, Larkin et al. (1992) reported decreased DBP responding during feedback training for the FB+ compared to the FB- group, which showed increased DBP responding. Although the DBP readings obtained during the training phase in this study were determined to be invalid, the trend of the data from pre- to post-training suggested that the FB+ group was demonstrating a smaller, although not significant, response to the videogame after training, while the FB- group was demonstrating increased responses. In the absence of significant findings for changes in DBP responses from pre- to post-training it is not possible to draw conclusions regarding the effect of $\mathrm{HR}$ feedback training on the DBP response to the videogame.

PEP, SV, CI, and TPR responses to the Videogame

The present study represents the first attempt to examine the effects of HR feedback on 
impedance cardiography-derived measures of hemodynamic functioning and systolic time intervals. Although HR was significantly reduced for FB+ participants, PEP response to the videogame was not differentially altered by HR feedback training. Rather, both the Group and Phase main effects for the PEP response to the videogame were significant. The Group main effect revealed that the $\mathrm{FB}+$ group demonstrated a significantly shorter PEP response than the FB- group across both pre- and post-training periods. The Phase main effect revealed that the PEP response to the videogame for both groups was significantly longer during the post-training compared to the pre-training phase. Changes in PEP are inversely related to changes in sympathetic arousal, which is positively correlated with increased HR responding. A longer PEP response is related to decreased sympathetic activity, whereas a shorter PEP response is suggestive of increased sympathetic arousal. If HR decreases while sympathetic activation is maintained, then it may be inferred that the decreased HR response is related to increased vagal activation. In the present study, exposure to the pre-training videogame for both FB+ and FBgroups was associated with a shortened PEP response, suggesting that increased sympathetic activation occurred during videogame play. During post-training, however, the PEP response to the videogame was comparable for both $\mathrm{FB}+$ and $\mathrm{FB}$ - groups, even though the $\mathrm{FB}+$ groups exhibited significantly lower HR responses. These findings seem to suggest that the observed reduction in $\mathrm{HR}$ response in the $\mathrm{FB}+$ group was mediated by something other than the sympathetic nervous system, namely vagal activation. This assumption that vagal activation may be responsible for the observed reductions in $\mathrm{HR}$ in the $\mathrm{FB}+$ group will need to be examined in future studies employing better methods for assessing parasympathetic nervous system effects.

The FB+ and FB- groups demonstrated similar SV reductions during the pre-training videogame presentation. However, during the post-training videogame presentation, the FB+ 
group demonstrated a significantly smaller SV response compared to the FB- group. The FBgroup demonstrated an SV response to the post-training videogame that was similar to the SV response observed during the pre-training videogame presentation. Therefore, on average, the amount of blood ejected from the heart during each contraction was equivalent during the posttraining baseline and the videogame presentation for the FB+ group, while the FB- group demonstrated a smaller amount of ejected blood during the post-training videogame compared to the preceding baseline. The changes in SV reflect the cardiovascular system's mechanism for maintaining a consistent blood supply throughout the organism. As HR increases the quantity of blood ejected from the HR decreases, whereas when HR decreases SV should increase. Without the compensatory increases and decreases of SV as HR changed, the blood supply throughout the organism fluctuate more radically.

The analyses for CI revealed that the FB+ and FB- groups demonstrated small but equivalent $\mathrm{CI}$ reactions to the videogame during the pre-training period. However, the FB- group demonstrated a substantial decrease in CI during the post-training period while the FB+ group continued to demonstrate a only a small change in CI. Although this finding only approached significance, it appears that the HR increase during the post-training videogame presentation among FB- participants was accompanied by an overcompensation of SV resulting in a net reduction in cardiac output. The lack of change in HR in response to the post-training videogame among $\mathrm{FB}+$ participants was accompanied by relatively minor changes in SV and CI.

The increased TPR response was also equivalent for the FB+ and FB- groups during the pre-training presentation of the videogame. Therefore, the resistance to blood flow throughout the vasculature increased equivalently for both groups during the pre-training videogame (i.e., both groups evidenced vasoconstriction at pre-training). However, during the post-training 
presentation of the videogame, the FB+ group demonstrated no change in TPR from baseline. In contrast, the FB- group demonstrated a TPR response that was higher than the TPR response observed during the pre-training videogame presentation. These differences during the posttraining phase resulted in a significant Group $x$ Phase interaction for TPR. The total resistance to blood flow throughout the vasculature was relatively unchanged from the post-training baseline to videogame presentation for the FB+ groups; however, the FB- group showed an increase in blood flow resistance from baseline to videogame presentation during the post-training period.

The overall pattern of hemodynamic responding of participants to the pre-training presentation of the videogame suggested that the observed BP increases were primarily associated with a vascular, rather than a cardiac, response (i.e., blood flow resistance was increased, resulting in higher SBP and DBP reactions to the videogame). Individuals demonstrated increased TPR response with only small changes in $\mathrm{CO}$, a hemodynamic response pattern that characterizes the videogame task as a "vascular response" task. Traditionally, vascular responding is associated with passive coping tasks (e.g., inescapable shock, cold pressor); however, the videogame is an active coping task (i.e., the participant has some instrumental control over the task), which is usually associated with cardiac responding (i.e., increased CI and decreased TPR). Without impedance cardiography, previous researchers could only speculate about the hemodynamic response pattern of participants to the videogame task; because the videogame was thought to be an active coping task, it was hypothesized that participants would demonstrate a cardiac response pattern. However, the relatively stable response of CI and the increased TPR response observed during the pre-training videogame for both groups provide evidence that the videogame actually elicits a vascular response pattern.

In contrast to Manuck's (1994) suggestion that individuals using HR feedback might shift 
from a cardiac pattern of responding to a vascular pattern of responding, the individuals in this study demonstrated an initial vascular response to the videogame that was significantly attenuated when participants actively reduced their HR following feedback training. Reducing HR responses to the videogame resulted in a benefit for the entire cardiovascular system; SBP, SV, and TPR responses were all significantly reduced for the $\mathrm{FB}+$ group from pre-training to post-training compared to the FB-group. Although it was hypothesized that active attempts to reduce HR may result in increased responses among other hemodynamic parameters such as TPR, the results of this study provide evidence that actively reducing HR with HR feedback training reduces responding throughout the entire cardiovascular system.

\section{Behavioral Responses During the Videogame}

The FB+ and FB- groups did not demonstrate significant differences in performance levels on the videogame during the pre-training or post-training phases of the study, which is consistent with previous findings (Larkin et al., 1990, 1992). There was also no significant difference in performance between groups during the training trials. In previous research, Larkin et al. (1989) discovered that those in the FB+ group obtained lower videogame scores than the FB- group during the training phase. However, the findings from this study corroborate the later findings of Larkin et. al. (1990), who found that those in the FB+ group did not perform significantly differently than those in a control group. Subjects in the FB+ group earned comparable scores to those in the FB- group during training and post-training videogames, despite their additional focus on reducing HR during the videogame trials during training. Therefore, actively reducing HR during an environmental stressor does not appear to interfere with performance during the stressful task. 


\section{Cardiovascular responses to the Mental Arithmetic Challenge}

The pre-training mental arithmetic task elicited an equivalent HR increase in both the FB+ and FB-groups. In sum, findings pertaining to the mental arithmetic task did not parallel findings observed for the videogame task. The only significant findings for any measure of cardiovascular reactivity to the mental arithmetic task were reduced $\mathrm{HR}, \mathrm{SBP}$, and TPR responses and increased PEP and SV responses during the post-training mental arithmetic presentation compared to the pre-training mental arithmetic task for all participants. The FB+ group failed to demonstrate a significantly attenuated cardiovascular response compared to the FB-group during the posttraining mental arithmetic task. The overall reductions in SBP and TPR, and the increased SV responses during the post-training mental arithmetic challenge suggest that the responses to the mental arithmetic task habituated over time without additional contributions related to active HR reduction. The increased PEP responses suggest that both groups demonstrated less sympathetic arousal during the post-training mental arithmetic task presentation. Apparently, the $\mathrm{FB}+$ group was unable to increase vagal responding during the post-training mental arithmetic to reduce HR responding as demonstrated during the post-training presentation of the videogame.

One interpretation of these results is that the skills to reduce HR responding to the videogame stressor, demonstrated by the $\mathrm{FB}+$ group during post-training, failed to generalize to the mental arithmetic task. These findings contradict the results reported by Larkin et al. (1992) and Sharpley (1994), who found that HR reductions generalized from the training task to other tasks. In the present study, as in Larkin et al.'s study, five HR feedback-training trials were used to train $\mathrm{FB}+$ participants to reduce $\mathrm{HR}$. In both studies, participants in the $\mathrm{FB}+$ groups were instructed to use the skills that they had learned during the training phase to reduce their HR response to the mental arithmetic challenge. However, the data analytic strategy was slightly 
different between the two studies. Larkin et al. found significant differences between FB+ and FB- groups when the difference of the change scores from pre-training to post-training was compared between groups. Using an identical analytic strategy in this study, however, generalization of the HR reduction to the mental arithmetic task was still not observed $(\underline{F}(1,22)$ $=0.12, \underline{p}=0.74)$.

The differences between the studies may be attributed in part to the use of different reinforcement contingencies for performance on the task between Larkin et al.'s (1992) study and the present study. Because they were paid for each correct subtraction, participants in Larkin et al.'s study may have demonstrated greater effort and possibly greater cardiovascular reactivity during the post-training mental arithmetic challenge compared to the participants in the present study. It is possible that HR reactions of all participants habituated in the present study due to the lack of reinforcement directly tied to mental arithmetic performance. Another noteworthy difference is that Larkin et al. found the largest differences between the HR reaction to the mental arithmetic task of the FB+ and FB-groups during a follow-up session 1-week later. Because the present study did not include a follow-up session, it is unknown whether the participants from this study would have demonstrated lowered HR responses to the mental arithmetic at that time.

The current study, as well as previous studies (Larkin et al., 1992; Sharpley, 1994), trained participants to lower their HR using tasks with different stimulus and response features than the task used to assess the generalizability of the HR reduction skills. For example, in the current study, participants were trained during the videogame task, requiring attention to visual cues (i.e., the videogame) and a motor response (i.e., movement of the joystick). In contrast, the mental arithmetic task, which was used to assess the generalization of the HR reduction skills, required participants to attend to auditory stimuli (i.e., the presentation of the number) and 
respond verbally (i.e., state each subtraction). The incongruence between stimulus and response features of the videogame and mental arithmetic tasks may have contributed to the failure of the participants to generalize the skills learned during the videogame. If both tasks had used similar stimulus and response features, the participants may have successfully generalized their HR reduction skills to the mental arithmetic task.

Nonetheless, the results from this study failed to support the findings that HR reduction taught during one task using HR feedback generalizes to other tasks that were not employed during training. However, future studies should attempt to examine the role of contingencies employed during tasks to determine whether discrepancies among studies can be accounted for by modifying specific reward contingencies. These studies should also match the stimulus and response features of the training and generalization tasks, to increase the likelihood that the learned skills will generalize from one task to another.

In summary, the cardiovascular responses to the mental arithmetic challenge did not differ significantly between the FB+ and FB- groups. In the absence of a significant smaller HR response in the $\mathrm{FB}+$ group compared to the $\mathrm{FB}$ - group during the post-training mental arithmetic task, it is not surprising that the other cardiovascular measures were also not significantly different. The HR reduction skills that were demonstrated during the videogame task, failed to generalize to the mental arithmetic challenge. Given that the HR response was not significantly different between the groups, BP, PEP, SV, CI, and TPR responses demonstrated significant habituation to the mental arithmetic task, but no additional effects due to increased HR reduction by the FB+ group.

$\underline{\mathrm{FB}+\_\mathrm{MAP}+\text { and FB+_MAP-Cardiovascular Responses to the Videogame }}$

The small sample sizes of the FB+_MAP+ and FB+_MAP - groups limited statistical 
power available to detect differences between these groups. Therefore, although most analyses did not reveal significant differences, there were interesting differences between the groups' cardiovascular response patterns to the videogame. Although HR responses were not significantly different between groups, there were significant BP differences. Although the hemodynamic differences between the groups were not significant, it is useful to discuss these results because they are helpful for interpreting the BP effects. HR responding was not expected to be different between FB+_MAP+ and FB+_MAP-groups because both groups were using skills learned during HR feedback training to reduce HR responses to the videogame. Therefore, it was not surprising that no significant group difference for HR responding to the videogame emerged. The FB+ and FB- groups both demonstrated lower HR responding during the posttraining videogame compared to the pre-training videogame.

Because groups were dichotomized based upon changing MAP response, it is not surprising that the $\mathrm{FB}+$ _MAP+ group demonstrated significantly increased MAP responding to the post-training videogame compared to the $\mathrm{FB}+$ _MAP-group. The differences in MAP responding were accompanied by both differences in SBP and DBP reactions to the post-training videogame. Although $\mathrm{FB}+$ _MAP+ and FB+_MAP-groups demonstrated equivalent SBP responding during the pre-training videogame, the FB+_MAP-group demonstrated almost no changes in SBP responding to the post-training videogame $(\underline{\mathrm{M}}=0.0 \mathrm{~mm} \mathrm{Hg})$, while the $\mathrm{FB}+\mathrm{MAP}+$ group continued to show increased SBP responding $(\underline{\mathrm{M}}=6.0)$ to the post-training videogame. Likewise, analysis of DBP revealed that the FB+_MAP+ group demonstrated a significantly increased DBP response to the post-training videogame compared to the FB+_MAPgroup. The reduced SBP and DBP responses of the FB+_MAP-group accounted for the group's reduced MAP responses to the post-training videogame. Similarly, the increased DBP responses 
and to a lesser extent the, smaller, but still increased SBP response to the post-training videogame for $\mathrm{FB}+\_\mathrm{MAP}+$ participants contributed to their designation as persons who exhibited no change or increases in MAP with HR feedback training.

The FB+_MAP+ and FB+_MAP-groups demonstrated longer PEP responses to the posttraining videogame compared to the PEP responses to the pre-training videogame; no group differences were evident for PEP either at pre- or post-training. Both groups demonstrated equivalent, but decreased sympathetic responding to the post-training videogame.

No significant differences were found for the SV response to the videogame, however, it is interesting to observe that the SV responses to the pre-training videogame were similar for the $\mathrm{FB}+$ _MAP+ and FB+_MAP-groups. The average SV response to the videogame decreased from pre-training to post-training; however, slightly different patterns of SV responding for the $\mathrm{FB}+\_\mathrm{MAP}+$ and $\mathrm{FB}+$ _MAP-groups to the post-training videogame were observed. The $\mathrm{FB}+$ _MAP-group demonstrated an attenuated SV response at post-training, while the FB+_MAP+ group actually demonstrated an increased SV response to the post-training videogame. Therefore, the FB+_MAP-group demonstrated a smaller change, but still a decrease, in the amount of blood ejected from the preceding baseline SV at post-training. The FB+_MAP+ group, in contrast, demonstrated greater amounts of blood ejected from the heart during the posttraining videogame compared to the preceding baseline.

Although no significant differences were found for the CI response to the videogame, the FB+_MAP+ and FB+_MAP-groups demonstrated somewhat different CI response patterns to the post-training videogame. During the pre-training videogame presentation, the FB+_MAP+ and FB+_MAP-groups demonstrated reduced CI responding. The FB+_MAP-group continued to demonstrate a small reduction in CI responding during the post-training videogame; however, 
the $\mathrm{FB}+\mathrm{MAP}+$ demonstrated an increased $\mathrm{CI}$ response to the post-training videogame.

Therefore, the about of blood ejected from the heart per minute decreased in response to the posttraining videogame for the FB+_MAP-group, but increased for the FB+_MAP+ group.

The TPR response to the videogame was also similar for the FB+_MAP+ and FB+_MAPgroups during pre-training and post-training. The average TPR response decreased from pretraining to post-training presentations of the videogame for all participants. Therefore, the resistance to blood flow throughout the vasculature was reduced from pre-training to posttraining videogame presentations.

In summary, the FB+_MAP+ group's SBP and DBP pattern of responding to the pretraining compared to the post-training videogame presentations, is similar to the pattern of responding observed by Manuck (1994) in a comparable group of participants. In the present study and Manuck's study, a set of participants who successfully reduced HR following HR feedback training demonstrated somewhat reduced SBP responding, but increased DBP responding to the videogame task. Manuck hypothesized that these subjects initially exhibited a cardiac response to the videogame, which shifted to a vascular response with HR feedback training. However, as previously discussed, the impedance cardiography measures employed in this study revealed that the participants in this study demonstrated an initial vascular response to the pre-training videogame. Contrary to Manuck's (1994) hypothesis, the impedance cardiography measures used in this study revealed that FB+_MAP+ participants demonstrated a hemodynamic response pattern that is more consistent with a cardiac response pattern during post-training than a vascular response patterns. SV and CI responses increased from pre- to posttraining videogame for $\mathrm{FB}+$ _MAP+ participants, while TPR responding decreased from pre- to post-training for all subjects. Therefore, during the pre-training videogame, the resistance to 
blood flow was increased for all participants, while the amount of blood ejected by the heart (i.e., CI) was decreased. However, for the FB+_MAP+ group following training, cardiac output increased as resistance to blood flow (i.e., TPR) decreased in response to stress. The increased quantity of blood placed additional pressure on the arterial walls, resulting in the increased MAP, particularly DBP, during the post-training videogame. In contrast, the FB+_MAP-group did not demonstrate this post-training increase in cardiac output responsivity.

\section{Limitations and Future Directions}

The results from this study provide evidence that HR feedback training is an effective method for reducing not only the exaggerated HR response to an environmental stressor, but the entire hemodynamic response to that stressor. However, these findings also suggest that the HR reduction skills learned during feedback training to one stressor, may not generalize to other stressors. Likewise, the comparisons of the $\mathrm{FB}+$ _MAP+ and FB+_MAP- group suggest that a significant proportion of individuals may not experience decreased cardiovascular responding when their HR response is decreased. Instead, some individuals may simply shift their hemodynamic response patterns from a vascular response to a cardiac response. Therefore, the potential benefit of HR feedback training for these individuals may be questionable.

It may be interesting to consider that participants in the present study, as well as previous studies (e.g., Larkin et al., 1989, 1990), were presented with a fixed number of training trials to learn how to effectively reduce their HR. When participants' decreased their HR at least $1 \mathrm{bpm}$ below the established criterion, they received feedback that they were successfully reducing their HR. An alternative training method could use a mastery model to teach HR reduction skills. Participants would engage in training sessions until their HR responses to the videogame were 
reliably decreased below an established criterion (e.g., 5 bpm below their HR responses to the pre-training videogame). This alternative training method may result in more robust findings regarding the effectiveness of $\mathrm{HR}$ feedback training. Participants who demonstrated smaller HR reductions (e.g., 3 bpm reductions) may be taught to increase their HR reductions. Likewise, individuals who failed to learn the HR reduction techniques during the 5 training trials, may have learned to reduce their HR reactions to the videogame using this alternative strategy.

Generalizability of the HR reduction skills may also be increased using this alternative training model. Future studies should explore the use of a mastery model for training participants to reduce their HR to stressful stimuli.

There are several important limitations of this study. First, a primarily Caucasian, healthy male college student sample was used. It is unknown whether females, other ethnic groups, or clinical samples (e.g., hypertensives) would demonstrate the same effects or presumed benefits of HR feedback training. Secondly, the sample sizes of the FB+_MAP+ and FB+_MAP-groups were small. Comparisons between these groups were not statistically significant, except for differences in BP. These findings could be interpreted with more confidence with a larger sample. The data from this study suggested that those who decreased their HR responses to a stressor following HR feedback may have done so through vagal activation. Future studies should measure vagal activity during active HR reduction to determine the role of vagal activation during training in HR reduction. Finally, the issue of generalizability must still be explored. Perhaps modifications to the present protocol or the training of individuals using multiple stressors would increase the generalizability of HR feedback training to other stressors.

Despite its limitations, this study adds to the body of literature suggesting that HR feedback training can be a useful method for many individuals to reduce not only HR responses, 
but BP, blood flow, and peripheral resistance responses to stressors. Future studies should be encouraged to apply the methodology and results from this study and its predecessors to test the effectiveness of HR feedback training on individuals at risk of developing cardiovascular disease. As additional information about the effectiveness of HR feedback training is learned, the use of HR feedback training may become a more reliable method of helping individuals to reduce their cardiovascular responses to stress, and thus help to reduce the strain placed on the cardiovascular system and help to prevent the development of cardiovascular disease. 


\section{References}

Ahles, T. A., Blanchard, E. B., \& Leventhal, H. (1983). Cognitive control of pain: Attenuation to the sensory aspects of the cold pressor stimulus. Cognitive Therapy and Research, 7, 159-178.

Ainslie, G. W., \& Engel, B. T. (1974). Alternation of classically conditioned heart rate by operant reinforcement in monkeys. Journal of Comparative and Physiological Psychology, 87, $373-382$.

Allen, M. T., Stoney, C. M., Owens, J. F., \& Matthews, K. A. (1993). Hemodynamic adjustments to laboratory stress: The influence of gender and personality. Psychosomatic Medicine, 55, 505-517.

Appels, A., \& Mulder, P. (1984). Imminent myocardial infarction: A psychological study. Journal of Human Stress, 10, 129-134.

Armstrong, H. R., \& Rafferty, J. A. (1950). Cold pressor test follow-up study for seven years on 166 officers. American Heart Journal, 39, 484-490.

Barnett, P. H. , Hines, E. A., Schirger, A., \& Gage, R. P. (1963). Blood pressure and vascular reactivity to the cold pressor test. Journal of the American Medical Association, 183, 845-848.

Barnett, P. A., Spence, J. D., Manuck, S. B., \& Jennings, J. R. (1997). Psychological stress and the progression of carotid artery disease. Journal of Hypertension, 7, 49-55.

Bennett, D. H., Holmes, D. S., \& Frost, R. O. (1978). Effects of instructions, biofeedback, reward, and cognitive mediation on the control of heart rate and the application of that control in a stressful situation. Journal of Research in Personality, 12, 416-430.

Bentham, J. A., \& Glaros, A. G. (1982). Self control of stress-induced cardiovascular 
change using transit time feedback. Psychophysiology, 19, 502-505.

Blackburn, H., \& Jacobs, D. (1984). Sources of the diet-heart controversy: Confusion over population vs. individual correlations. Circulation, 70, 775-780.

Blanchard, E. B., \& Young, L. D. (1972). Self-control of cardiac function: A promise as yet unfulfilled. Psychological Bulletin, 79, 145-163.

Bouchard, M. A., \& Labelle, J. (1982). Voluntary heart rate deceleration: A critical evaluation. Biofeedback and Self-Regulation, 7, 121-137.

Carroll, D., \& Evans, L. (1981). Effects of heart rate biofeedback and false biofeedback on reactions to stressful stimulation. Perceptual and Motor Skills, 53, 387-393.

Corse, C. D., Manuck, S. B., Cantwell, J. D., Giordani, B., \& Matthews, K. A. (1982). Coronary-prone behavior pattern and cardiovascular response in persons with and without coronary heart disease. Psychosomatic Medicine, 44, 449-459.

Dembroski, T. M., \& Czajkowski, S. M. (1989). Historical and current developments in coronary-prone behavior. In A. W. Siegman \& T. M. Dembroski (Eds.), In search of coronaryprone behavior: Beyond Type A. Hillsdale, NJ: Lawrence Erlbaum Associates.

Dembroski, T. M., MacDougall, J. M., \& Lushene, R. (1979). Interpersonal interaction and cardiovascular response in Type A participants and coronary patients. Journal of Human Stress, 5, 28-36.

Eich, R. H., \& Jacobsen, E. C. (1967). Vascular reactivity in medical students followed for 10 years. Journal of Chronic Disease, 20, 583-592.

Engel, B. T., \& Chism, R. (1967). Operant conditioning of heart rate speeding, Psychophysiology, 3 , 419-426.

Engel, B. T., \& Hansen, S. P. (1966). Operant conditioning of heart rate slowing. 
Psychophsiology, 3, 176-188.

Engel, B. T., \& Gottlieb, S. H. (1970). Differential operant conditioning of heart rate in the restrained monkey. Journal of Comparative and Physiological Psychology, 73, 217-225.

Ewart, C. K., Burnett, K. F., \& Taylor, C. B. (1983). Communication behaviors that affect blood pressure: An A-B-A-B analysis of marital interaction. Behavior Modification, 7. 331-344.

Girdler, S. S., Turner, J. R., Sherwood, A., \& Light, K. C. (1990). Gender differences in blood pressure control during a variety of behavioral stressors. Psychosomatic Medicine, 52, $571-591$.

Goldstein, D. S., Ross, R. S., \& Brady, J. V. (1977). Biofeedback heart rate training during exercise. Biofeedback and Self-Regulation, 2, 107-125.

Goldstein, D. S., Cannon, R. O., Zimlichman, R., \& Keiser, H. R. 1986 Clinical evaluation of impedance cardiography. Clinical Physiology, 6, 235-251

Goleman, D. J. \& Schwartz, G. E. (1976). Meditation as an intervention in stress reactivity. Journal of Consulting and Clinical Psychology, 44, 456-466.

Green, K. D., Webster, J., Beiman, I., Rosmarin, D., \& Holliday, P. (1981). Progressive and self-induced relaxation training: Their relative effects on participantive and autonomic arousal to fearful stimuli. Journal of Clinical Psychology, 37, 309-315.

Grimm, L., \& Kanfer, F. H. (1976). Tolerance of aversive stimulation. Behavior Therapy, 7, 593-601.

Harlan, W. R. Jr., Osborne, R. K., \& Graybiel, A. (1964). Prognostic value of the old pressor test and the basal blood pressure based on an eighteen-year follow-up study. American Journal of Cardiology, 13, 832-837. 
Hatch, J. P. (1980). The effects of operant reinforcement schedules on the modification of human heart rate. Psychophysiology, 17, 559-567.

Haudenschild, C. C., Prescott, M. F., \& Chobanian, A. V. (1980). Effects of hypertension and its reversal on aortic intima lesions of the rat. Hypertension, 2, 33-44.

Houston, B. K., \& Holmes, D. (1974). Effect of avoidant thinking and reappraisal for coping with threat involving temporary uncertainty. Journal of Personality and Social Psychology, 3, 382-388.

Jenkins, C. D. (1988). Epidemiology of cardiovascular diseases. Journal of Consulting and Clinical Psychology, 56, 324-332.

Jorgenson, R. S., Houston, B. K., \& Zurawski, R. M. (1981). Anxiety management training in the treatment of essential hypertension. Behavior Research and Therapy, 19, 467-474.

Kamarck, T. W., Jennings, J. R., Pogue-Geile, M., \& Manuck, S. B. (1994). A multidimensional measurement model for cardiovascular reactivity: Stability and cross-validation in two adult samples. Health Psychology, 13, 471-478.

Kaplan, J. R., Pettersson, K., Manuck, S. B., \& Olsson, G. (1991). The role of sympathoadrenal medullary activation in the initiation and progression of atherosclerosis, Circulation, 84 (Suppl. VI), 23-32.

Kaplan, G. A., Salonen, J. T., Cohen, R. D., Brand, R. J., Syme, S. L., \& Puska, P. (1988). Social connections and mortality from all causes and from cardiovascular disease: Prospective evidence from eastern Finland. American Journal of Epidemiology, 128, 370-380.

Kasprowicz, A. L., Manuck, S. B., Malkoff, S. B., \& Krantz, D. A. (1990). Individual differences in behaviorally evoked cardiovascular response: Temporal stability and hemodynamic patterning. Psychophysiology, 27, 605-619. 
Keys, A., Taylor, H. L., Blackburn, H. Y., Brozek, J., Anderson, J., \& Simonson, E. (1971). Mortality and coronary heart disease among men studied for 23 years. Archives of Internal Medicine, 128, 201-214.

Kirsch, I., \& Henry, D. (1979). Self-desensitization and meditation in the reduction of public speaking anxiety. Journal of Consulting and Clinical Psychology, 47, 536-541.

Krantz, D. S., Schaeffer, M. A., Davia, J. E., Dembroski, T. M., MacDougall, J. M., \& Schaffer, R. T. (1981). Extent of coronary atherosclerosis, Type A behavior, and cardiovascular response to social interaction. Psychophysiology, 18, 654-664.

Kubicek, W. G., Karnegis, J. N., Patterson, R. P., Witsoe, D. A., \& Attson, R. H. (1966). Development and evaluation of an impedance cardiac output system. Aerospace Medicine, 37. 1208-1212.

Larkin, K. T., Manuck, S. B. \& Kasprowicz, A. L. (1989). Heart rate feedback-assisted reduction in cardiovascular reactivity to a videogame challenge. The Psychological Record, 39, 365-371.

Larkin, K. T., Manuck, S. B., \& Kasprowicz, A. L. (1990). The effect of feedbackassisted reduction in heart rate reactivity on videogame performance. Biofeedback and SelfRegualtion, 15, 285-303.

Larkin, K. T., Zayfert, C., Veltum, L. G., \& Abel, J. L. (1992). Effects of feedback and contingent reinforcement in reducing heart rate response to stress. Journal of Psychophysiology, $\underline{6,119-130 .}$

Larkin, K. T., Zayfert, C., Abel, J. L., \& Veltum, L. G. (1992). Reducing heart rate reactivity to stress with feedback. Behavior Modification, 16, 118-131.

Lehrer, P. M. (1978). Psychophysiological effects of progressive relaxation in anxiety 
neurotic patients and of progressive relaxation and alpha feedback in non-patients. Journal of Consulting and Clinical Psychology, 46, 389-404.

Manuck, S. B. (1994). Cardiovascular reactivity in cardiovascular disease: "Once more unto the breach". International Journal of Behavioral Medicine, 1, 4-31.

Manuck, S. B., Kaplan, J. R., \& Clarkson, T. B. (1983). Behaviorally induced heart rate reactivity and atherosclerosis in cynomolgus monkeys. Psychosomatic Medicine, 45, 95-108.

Manuck, S. B., Kasprowicz, A. L., Monroe, S. B., Larkin, K. T., \& Kaplan, J. R. (1989). Psychophysiologic reactivity as a dimension of individual differences. In N. Schneiderman, S. B. Weiss, \& P. Kaufmann (Eds.), Handbook of methods and measurements in cardiovascular behavioral medicine (pp. 365-382). New York: Plenum.

Manuck, S. B., Levenson, R. W., Hinrichsen, J. J., \& Gryll, S. L. (1975). Role of feedback in voluntary control of heart rate. Perceptual and Motor Skills, 40, 747-752.

Manuck, S. B., Muldoon, M. F., Kaplan, J. R., Adams, M. R., \& Polefrone, J. M. (1989). Coronary artery atherosclerosis and cardiac response to stress in cynomolgus monkeys. In A. W. Siegman \& T. M. Dembroski (Eds.), In search of coronary-prone behavior: Beyond type A (pp. 207-227). Hillsdale, NJ: Lawrence Erlbaum Associates.

Menkes, M. S., Matthews, K. A., Krantz, D. S., Lundberg, U., Mead, L. A., Qaqish, B., Liang, K., Thomas, C. B., \& Pearson, T. A. (1989). Cardiovascular reactivity to the cold pressor test as a predictor of hypertension. Hypertension, 14, 524-530.

Miller, J. C., \& Horvath, S. M. (1978). Impedance cardiography. Psychophysiology, 22, 453-463.

Mohapatra, S. N. (1981). Non-invasive cardiovascular monitoring by electrical impedance technique. London: Pittman Medical Ltd. 
Obrist, P. A., Gaebelein, C. J., Teller, S. E., Langer, A. W., Grignolo, A., Light, K. C., \& McCubbin, J. A. (1978). The relationship among heart rate, carotid dp/dt and blood pressure in humans as a function of the type of stress. Psychophysiology, 15, 102-115.

Perski, A., \& Engel, B. T. (1980). The role of behavioral conditioning in the cardiovascular adjustment to exercise. Biofeedback and Self-Regulation, 5, 91-104.

Ross, R. (1981). Atherosclerosis: A problem of the biology of arterial wall cells and their interactions with blood components. Arteriosclerosis, 1, 293-311.

Rushmer, R. F. (1989). Structure and function of the cardiovascular system. In N. Schneiderman, S. M. Weiss, \& P. G. Kaufmann (Eds.), Handbook of research methods in cardiovascular behavioral medicine (pp. 1-22). New York: Plenum Press.

Sawada, Y., \& Steptoe, A. (1988). The effects of brief meditation training on cardiovascular stress responses. Journal of Psychophysiology, 2, 249-257.

Schwartz, J. L. (1987). Review and evaluation of smoking cessation methods: The United States and Canada, 1978-1985. U.S. Department of Health and Human Services. NIH Publication No. 87-2940.

Sharpley, C. F. (1989). Biofeedback training versus simple instructions to reduce heart rate reactivity to a psychological stressor. Journal of Behavioral Medicine, 12, 435-447.

Sherwood, A., Allen, M. T., Fahrenberg, J., Kelsey, R. M., Lovallo, W. R., \& Van Dooren, L. J. P. (1990). Methodological guidelines for impedance cardiography. Pscyhophysiology, 27, 1-23.

Sherwood, A., Dolan, C., \& Light, K. C. (1990). Hemodynamics of blood pressure responses during active and passive coping. Psychophysiology, 27, 656-668.

Sherwood, A., \& Turner, J. R. (1995). Hemodynamic responses during psychological 
stress: Implications for studying disease processes. International Journal of Behavioral Medicine, 2, 193-218.

Sime, W. E., Buell, J. C., \& Eliot, R. S. (1980). Cardiovascular responses to emotional stress (quiz interview) in post-myocardial infarction patients and matched controls. Journal of Human Stress, 6, 39-46.

Sirota, A. D., Schwartz, G. E., \& Shapiro, D. (1974). Voluntary control of human heart rate: Effect on reaction to aversive stimulation. Journal of Abnormal Psychology, 83, 261-267.

Smith, T. W., \& Frohm, K. (1985). What's so unhealthy about hostility? Construct validity and psychosocial correlates of the Cook and Medley hostility scale. Health Psychology, $\underline{4,503-520 .}$

Smith, T. W., \& Leon, A. (1992). Coronary heart disease. Champaign, IL: Research Press.

Thacker, E. A. (1940). A comparative study of normal and abnormal blood pressures among university students, including the cold pressor test. American Heart Journal, 20, 89 - 97.

Turner, J. R., Sherwood, A., \& Light, K. C. (1991). Generalization of cardiovascular response: Supportive evidence for the reactivity hypothesis. International Journal of Psychophysiology, 11, 207-212.

Tursky, B., \& Jamner, L. D. (1982). Measurement of cardiovascular functioning. In J. T. Cacioppo \& R. E. Petty (Eds.), Perspectives in cardiovascular psychophysiology, (19-92). New York: The Guilford Press.

Wood, D. L., Sheps, S. G., Eleback, L. R., \& Schirger, A. (1984). Cold pressor test as a predictor of hypertension. Hypertension, 6, 301-306. 


\section{Appendix A}

\section{Demographics Questionnaire}

1. Age

2. Height (in)

3. Weight (lbs)

4. Race: White Black Asian Hispanic American Indian Other

5. Years of college completed

6. Do you have any chronic medical conditions Yes No (e.g. hypertension, heart disease, diabetes, asthma, etc...)?

If yes, explain:

7. Do you have a history of hypertension, coronary heart disease Yes No or strokes in your family?

What(Who):

8. Are you taking any medications on a regular basis?

Yes No

If yes, explain:

9. Do you currently use tobacco?

Yes No

(e.g. smoke cigarettes, cigars or chew tobacco)

What?

How frequently? (i.e. how many days per month)

How much per episode? (e.g. packs per day)

Last time? (hours ago)

10. Do you drink alcohol?

Yes No

What?

How frequently? (i.e. how many days per month)

How much per episode? (e.g. cans, glasses, shots)

Last time? (days ago)

11. Do you use any recreational or street drugs?

(e.g. marijuana, crack, cocaine, heroin)

What?

How frequently? (i.e. how many days per month)

How much per episode?

Last time? (days ago) 
12. In the past 24-hours have you taken any of the following substances:

Amphetamines...................................... Yes No

Diet pills......................................... Yes No

Cold or allergy medication............................. Yes No

Asthma medication.................................. Yes No

Beta-Blockers (e.g. Inderal, Tenormin)................... Yes No

Psychoactive (e.g. Xanax, Haldol, Lithium)................ Yes No

Heart medication (nitroglycerin, Coumadin)............... Yes No

13. In the past 24 hours, have you taken any over-the-counter...... Yes No medications?

14. In the past three hours have you consumed:

Alcohol (e.g. beer, wine, liquor, cough medication)........ Yes No

Caffeine-Containing products (soda, coffee, No-doz)....... Yes No

If yes, explain:

15. In the past three hours have you used any tobacco products? Yes No

If yes, explain:

16. In the past hour, have you exercised:.......................... Yes No

If yes, explain: 


\section{Appendix B}

Videogame Use Questionnaire

1. Do you own a computer? $\quad$ Yes No

Do you play games on your computer? Yes No

2. Do you own a game system? Yes No

(e.g. Nintendo, Playstation, Atari)

3. Do you go to arcades to play games Yes No

4. How often do you play videogames?

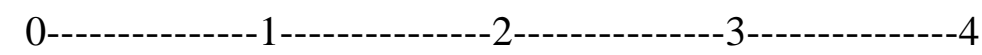

Never < 1x month Several x/month > 3x/week Every day

5. Do you enjoy playing videogames?

0-----------------1-----------------2-----------------3-----------------4

Not at all A little Some Quite a bit Very much

6. How would you rate your ability to play computer games?

$\begin{array}{llll}\text { Poor } & \text { Fair } & \text { Good } & \text { Very Good Excellent }\end{array}$




\section{Appendix C}

\section{$\underline{\text { Consent Form }}$}

Using Impedance Cardiography to Examine Blood Pressure and Heart Rate Changes during a Videogame Task

Introduction: I, have been asked to participate in this research study,

which has been explained to me by . This study is being conducted by Jeffrey Goodie and Dr. Kevin Larkin at West Virginia University for partial fulfillment of the requirements for Jeffrey Goodie's master's thesis.

Purpose of the Study: I understand that the purpose of this research project is to examine how changes in heart rate affect blood pressure and other cardiovascular measures during a videogame task.

Description of Procedures: I understand that I am being requested to participate in a 2.5 hour session. I further understand that my participation in this study will involve the measurement of my heart rate using a finger heart rate monitor and blood pressure using a blood pressure cuff wrapped around my arm. I also understand that additional information about my cardiovascular functioning will be obtained using a blood flow monitoring device, which involves placing two strips of electrode tape around my neck and two strips around my abdomen. Three spot electrodes will also be attached to my torso to measure heart rate. During the session, I will be asked to sit quietly for a baseline period. I will then be asked to play a series of videogames and calculate mental arithmetic problems. During some videogame sessions and mental arithmetic problems, I may be instructed to try to increase or decrease my HR. After these challenges, I will again be asked to sit quietly and finally will be asked to play another series of videogames and calculate mental arithmetic problems. I will also be asked to complete a set of 6 questionnaires. I understand that I can review these questionnaires before signing this consent agreement and that I do not have to answer all questions. Approximately 60 male subjects will be entered in this study.

Risks and Discomforts: My participation in this study is not expected to produce a risk to my health or well-being. I understand that some discomfort and irritation may arise during the placement and removal of the strip and spot electrodes. I may also experience some discomfort in my arm during the repeated blood pressure measures. However, the procedures involved in this study may have risks that are unforeseeable. In the unlikely event that I incur an injury as a result of my participation in this research, I understand that voluntary compensation or costs for medical treatment will not be provided by West Virginia University for research-related injuries. I am aware that the experimental procedures will be terminated if at any time during the laboratory sessions, my blood pressure is found to be above $200 \mathrm{mmHg}$ (systolic) and/ $120 \mathrm{mmHg}$ (diastolic). In the event of such termination of the experiment, I understand that I will receive a proportion (reflecting the extent of my participation) of the class credit and lottery entries described below. 
Compensatory Considerations: I understand that I will receive extra credit points toward my psychology course grade in return for my participation. I also understand that other methods of obtaining extra credit are available in my class. Based on my performance during the videogame I will earn entries into a lottery. When the study is completed, all of the entries will be collected and three names will randomly be drawn for a $\$ 50$ first prize, $\$ 30$ second prize, and a $\$ 10$ third prize. I am also aware that the individual who obtains the highest score during the entire study will be awarded \$20. However, I also understand that my participation in this study does not guarantee that I will be awarded a cash prize.

Benefits: My participation in this study may lead to an increased understanding of how changing heart rate effects blood pressure and other cardiovascular measures.

Contact Persons: For more information about this research and about research-related risks or injury, I should contact Jeffrey Goodie at 293-2001 ext. 859 or Dr. Kevin T. Larkin at 293-2001 ext. 668. For information regarding my rights as a research subject, I may contact the Executive Secretary of the Institutional Review Board for the Protection of Human Subjects at 293-7073.

Confidentiality: I understand that any information about me obtained as a result of my participation in this research will be kept as confidential as legally possible. I understand that my research records, just like hospital records, may be subpoenaed by court order or may be inspected by federal regulatory agencies. If any publications result from this research, neither my name nor any information from which I might be identified, will be published without my consent.

Voluntary Consent: Participation in this study is voluntary. I understand that I am free to withdraw my consent to participate in this study at any time and this will have no effect on my course grade. I have been given the opportunity to ask questions about the research, and I have received answers concerning areas I did not understand. In the event new information becomes available that may affect my willingness to continue to participate in this study, this information will be given to me so I may make an informed decision about my participation. Upon signing this form, I will receive a copy.

I willingly consent to participate in this study.

Signature of Subject or Subject's Representative

Signature of Investigator or Investigator's Representative
Date

Date 
Table 1.

Demographic Information for Participants in the FB+ and FB- Groups

\begin{tabular}{|c|c|c|c|c|c|c|}
\hline \multirow[b]{2}{*}{ Question } & \multicolumn{2}{|c|}{$\mathrm{FB}+$} & \multicolumn{2}{|c|}{ FB- } & \multirow{2}{*}{$\begin{array}{c}\underline{\mathrm{t}} \\
\text { (Phi) }\end{array}$} & \multirow[b]{2}{*}{$\mathrm{p}$} \\
\hline & $\underline{\mathrm{M}}$ & $\underline{\mathrm{SD}}$ & $\underline{\mathrm{M}}$ & $\underline{\mathrm{SD}}$ & & \\
\hline Age (years) & 23.9 & 5.7 & 21.1 & 2.8 & 1.6 & 0.12 \\
\hline Body Mass Index & 27.5 & 5.4 & 25.3 & 2.2 & $1.4^{\mathrm{a}}$ & 0.19 \\
\hline Years of Education & 14.6 & 1.8 & 14.2 & 1.6 & 0.6 & 0.54 \\
\hline Race (\% Caucasian) & $(100 \%)$ & & $(85 \%)$ & & $(0.28)$ & 0.16 \\
\hline $\begin{array}{l}\text { Family History of } \\
\text { Cardiovascular Problems } \\
\text { (\% with history) }\end{array}$ & $(25 \%)$ & & $(31 \%)$ & & $(-0.06)$ & 0.75 \\
\hline $\begin{array}{l}\text { Alcohol frequency } \\
\text { (drinks/month) }\end{array}$ & 33.7 & 53.3 & 60.3 & 99.3 & -0.8 & 0.41 \\
\hline $\begin{array}{l}\text { Drug frequency } \\
\text { (joints/month) }\end{array}$ & 2.0 & 5.0 & 0.6 & 1.4 & 1.0 & 0.33 \\
\hline $\begin{array}{l}\text { Tobacco Frequency } \\
\text { (packs/month) }\end{array}$ & 0.4 & 1.1 & 3.9 & 8.9 & -1.4 & 0.19 \\
\hline Videogame ability & 1.8 & 0.6 & 2.6 & 0.8 & $-2.7 *$ & 0.01 \\
\hline Videogame frequency & 2.4 & 0.7 & 1.9 & 1.0 & 1.5 & 0.15 \\
\hline
\end{tabular}


Table 2.

$\underline{\text { Summary of Analyses of Variance Results Comparing FB+ }(\mathrm{N}=12) \text { and FB- }(\mathrm{N}=13) \text { During Pre-Training Baseline and Task Periods }}$

\begin{tabular}{|c|c|c|c|c|c|c|c|c|c|c|c|c|}
\hline \multirow[b]{3}{*}{ Parameter } & \multicolumn{6}{|c|}{ Videogame } & \multicolumn{6}{|c|}{ Mental Arithmetic } \\
\hline & \multicolumn{2}{|c|}{$\mathrm{FB}+$} & \multicolumn{2}{|c|}{ FB- } & \multirow[b]{2}{*}{$\underline{F}$} & \multirow[b]{2}{*}{$\mathrm{p}$} & \multicolumn{2}{|c|}{$\mathrm{FB}+$} & \multicolumn{2}{|c|}{ FB- } & \multirow[b]{2}{*}{$\underline{F}$} & \multirow[b]{2}{*}{$\mathrm{p}$} \\
\hline & $\underline{\mathrm{M}}$ & $\underline{\mathrm{SD}}$ & $\underline{\mathrm{M}}$ & $\underline{\mathrm{SD}}$ & & & $\underline{\mathrm{M}}$ & $\underline{\mathrm{SD}}$ & $\underline{\mathrm{M}}$ & $\underline{\mathrm{SD}}$ & & \\
\hline HR Baseline & 73.1 & 11.4 & 67.0 & 6.9 & 1.8 & 0.19 & 73.5 & 10.7 & 70.2 & 7.2 & 0.9 & 0.36 \\
\hline Task & 81.0 & 5.5 & 79.8 & 5.8 & 0.3 & 0.59 & 80.6 & 5.2 & 79.4 & 5.0 & 0.7 & 0.60 \\
\hline SBP Baseline & 120.4 & 8.0 & 120.2 & 8.7 & 0.0 & 0.95 & 120.3 & 6.9 & 121.1 & 7.2 & 0.1 & 0.77 \\
\hline Task & 138.0 & 10.4 & 128.7 & 10.5 & $4.9^{*}$ & 0.04 & 133.2 & 6.6 & 130.6 & 6.5 & 1.00 & 0.34 \\
\hline DBP Baseline & 73.9 & 11.4 & 69.9 & 10.1 & 0.9 & 0.36 & 74.4 & 8.7 & 70.0 & 10.8 & 1.3 & 0.27 \\
\hline Task & 75.6 & 9.7 & 76.8 & 9.4 & 0.1 & 0.76 & 82.0 & 6.6 & 81.0 & 6.5 & 0.1 & 0.72 \\
\hline PEP Baseline & 109.0 & 13.5 & 111.5 & 14.4 & 0.2 & 0.66 & 106.3 & 11.4 & 110.4 & 14.4 & 0.6 & 0.44 \\
\hline Task & 97.2 & 5.5 & 101.4 & 5.4 & 3.5 & 0.08 & 106.1 & 5.5 & 106.9 & 5.4 & 0.2 & 0.70 \\
\hline SV \% Change & -12.5 & 11.8 & -11.7 & 10.5 & 0.0 & 0.82 & -12.4 & 11.4 & -14.3 & 10.8 & 0.2 & 0.68 \\
\hline CI \% Change & -1.1 & 12.5 & 0.9 & 10.1 & 0.7 & 0.67 & -2.5 & 9.7 & -5.46 & 8.3 & 0.7 & 0.42 \\
\hline TPR \% Change & 14.7 & 22.2 & 8.3 & 14.4 & 0.8 & 0.39 & 16.4 & 19.4 & 18.6 & 12.3 & 0.1 & 0.73 \\
\hline
\end{tabular}


Table 3.

Videogame Scores During Pre-Training, Training, and Post-Training Phases

\begin{tabular}{|c|c|c|c|c|c|c|}
\hline \multirow[b]{2}{*}{ Phase } & \multicolumn{2}{|c|}{$\mathrm{FB}+$} & \multicolumn{2}{|c|}{ FB+ with Bonus } & \multicolumn{2}{|c|}{ FB- } \\
\hline & $\underline{\mathrm{M}}$ & $\underline{\mathrm{SD}}$ & $\underline{\mathrm{M}}$ & $\underline{\mathrm{SD}}$ & $\underline{\mathrm{M}}$ & $\underline{\mathrm{SD}}$ \\
\hline Pre-Training & 31350 & 2583 & & & 30265 & 2678 \\
\hline \multicolumn{7}{|l|}{ Training } \\
\hline Trial A & 29925 & 2706 & 30911 & 3015 & 30335 & 2000 \\
\hline Trial B & 31206 & 1523 & 31492 & 2282 & 30426 & 2157 \\
\hline Trial C & 31278 & 1665 & 30786 & 1846 & 31010 & 2885 \\
\hline Trial D & 30994 & 1894 & 30686 & 2696 & 31536 & 1942 \\
\hline Trial E & 31581 & 1670 & 30908 & 2088 & 31764 & 1415 \\
\hline Post-Training & 33454 & 1881 & & & 33908 & 2516 \\
\hline
\end{tabular}


Table 4.

Adjusted Mean and Standard Error of FB+ $(\mathrm{N}=12)$ and FB- $(\mathrm{N}=13)$ Groups During Post-

Training Baselines and Tasks

\begin{tabular}{|c|c|c|c|c|c|c|c|c|c|}
\hline \multirow{3}{*}{\multicolumn{2}{|c|}{ Parameter }} & \multicolumn{4}{|c|}{ Videogame } & \multicolumn{4}{|c|}{ Mental Arithmetic } \\
\hline & & \multicolumn{2}{|c|}{$\mathrm{FB}+$} & \multicolumn{2}{|c|}{ FB- } & \multicolumn{2}{|c|}{$\mathrm{FB}+$} & \multicolumn{2}{|c|}{ FB- } \\
\hline & & $\underline{\mathrm{M}}$ & $\underline{\mathrm{SD}}$ & $\underline{M}$ & $\underline{\mathrm{SD}}$ & $\underline{\mathrm{M}}$ & $\underline{\mathrm{SD}}$ & $\underline{\mathrm{M}}$ & $\underline{\mathrm{SD}}$ \\
\hline \multirow[t]{2}{*}{ HR } & Baseline & 74.0 & 10.0 & 70.7 & 6.5 & 75.2 & 10.7 & 71.5 & 6.9 \\
\hline & Task & 72.6 & 4.5 & 77.8 & 4.5 & 78.5 & 4.8 & 77.6 & 4.8 \\
\hline \multirow[t]{2}{*}{ SBP } & Baseline & 118.6 & 5.2 & 120.2 & 7.6 & 122.0 & 6.9 & 122.4 & 7.6 \\
\hline & Task & 121.7 & 9.1 & 125.2 & 9.1 & 126.9 & 4.8 & 126.6 & 4.5 \\
\hline \multirow[t]{2}{*}{ DBP } & Baseline & 77.3 & 7.6 & 72.0 & 10.7 & 77.7 & 10.7 & 74.9 & 10.4 \\
\hline & Task & 74.9 & 9.7 & 80.5 & 9.7 & 83.0 & 9.0 & 78.0 & 8.7 \\
\hline \multirow[t]{2}{*}{ PEP } & Baseline & 110.0 & 12.8 & 112.6 & 12.5 & 107.8 & 12.5 & 111.7 & 13.5 \\
\hline & Task & 108.6 & 3.4 & 109.9 & 3.4 & 111.8 & 3.8 & 110.9 & 3.8 \\
\hline \multicolumn{2}{|c|}{ SV \% Change } & 0.3 & 10.0 & -11.7 & 7.3 & -4.5 & 10.0 & -9.2 & 7.3 \\
\hline \multicolumn{2}{|c|}{ CI \% Change } & 0.8 & 10.0 & -4.9 & 6.9 & 1.8 & 7.6 & -3.3 & 6.6 \\
\hline TPR & $\%$ Change & 0.6 & 10.7 & 16.5 & 21.1 & 4.8 & 11.1 & 8.1 & 16.3 \\
\hline
\end{tabular}


Table 5.

$\underline{\text { Repeated Measures Analysis of Covariance for HR during the Videogame and Mental Arithmetic }}$

\begin{tabular}{|c|c|c|c|c|c|c|}
\hline Source & $\mathrm{SS}$ & $\underline{\mathrm{df}}$ & MS & $\underline{F}$ & $\underline{p}$ & $\eta^{2}$ \\
\hline Videogame & \multicolumn{5}{|c|}{ Between subjects } & \\
\hline Group & 57.18 & 1 & 57.18 & 1.49 & 0.20 & 0.06 \\
\hline \multirow[t]{2}{*}{ Error } & 843.94 & 22 & 38.36 & & & \\
\hline & \multicolumn{5}{|c|}{ Within subjects } & \\
\hline Phase & 259.25 & 1 & 259.25 & $38.62 *$ & 0.001 & 0.64 \\
\hline Group x Phase & 150.38 & 1 & 150.38 & $22.40 *$ & 0.001 & 0.51 \\
\hline Error & 147.67 & 22 & 6.71 & & & \\
\hline
\end{tabular}

Simple effects

$\begin{array}{lllllll}\text { Group at Pre-Training } & 8.65 & 1 & 8.65 & 0.29 & 0.60 & 0.01\end{array}$

Error $\quad 665.00 \quad 22 \quad 30.23$

$\begin{array}{lllllll}\text { Group at Post-Training } & 1674.5 & 1 & 1674.5 & 85.8^{*} & 0.001 & 0.79\end{array}$

$\begin{array}{lll}\text { Error } \quad 429.4 & 22 & 19.5\end{array}$

$\begin{array}{lllllll}\text { Phase for } \mathrm{FB}+ & 416.6 & 1 & 416.6 & 47.7 * & 0.001 & 0.83\end{array}$

$\begin{array}{llll}\text { Error } & 87.9 & 10 & 8.7\end{array}$

$\begin{array}{lllllll}\text { Phase for FB- } & 9.08 & 1 & 9.08 & 1.65 & 0.23 & 0.13\end{array}$

Error $\quad 60.45 \quad 11 \quad 5.5$

\begin{tabular}{lcccccc} 
Mental Arithmetic & \multicolumn{7}{c}{ Between subjects } \\
Group & 10.11 & 1 & 10.11 & 0.23 & 0.63 & 0.01 \\
Error & 955.03 & 22 & 43.41 \\
\cline { 2 - 6 } & \multicolumn{7}{c}{ Within subjects } \\
Phase & 56.74 & 1 & 56.74 & $15.22 *$ & 0.001 & 0.41 \\
Group x Phase & 0.00 & 1 & 0.00 & 0.00 & 1.00 & 0.00 \\
Error & 82.00 & 22 & 3.73 & & & \\
$* \mathrm{p}<0.001$ & & & & &
\end{tabular}


Table 6.

Repeated Measures Analysis of Covariance for SBP during the Videogame and Mental Arithmetic

\begin{tabular}{|c|c|c|c|c|c|c|}
\hline Source & $\mathrm{SS}$ & $\underline{\mathrm{df}}$ & MS & $\underline{F}$ & $\mathrm{p}$ & $\eta^{2}$ \\
\hline Videogame & \multicolumn{6}{|c|}{ Between subjects } \\
\hline Group & 114.47 & 1 & 114.47 & 0.95 & 0.34 & 0.04 \\
\hline \multirow[t]{2}{*}{ Error } & 2656.23 & 22 & 120.74 & & & \\
\hline & \multicolumn{6}{|c|}{ Within subjects } \\
\hline Phase & 1134.33 & 1 & 1134.33 & $17.01 * *$ & 0.001 & 0.44 \\
\hline Group x Phase & 579.53 & 1 & 579.53 & $8.69 *$ & 0.007 & 0.28 \\
\hline \multirow[t]{2}{*}{ Error } & 1467.41 & 22 & 66.70 & & & \\
\hline & \multicolumn{6}{|c|}{ Simple effects } \\
\hline Group at Pre-Training & 541.50 & 1 & 541.20 & 4.86 & 0.04 & 0.18 \\
\hline Error & 2450.98 & 22 & 111.41 & & & \\
\hline Group at Post-Training & 76.02 & 1 & 76.02 & 0.92 & 0.35 & 0.04 \\
\hline Error & 1822.60 & 22 & 82.85 & & & \\
\hline Phase for FB+ & 1338.23 & 1 & 1338.23 & $14.68 *$ & 0.003 & 0.60 \\
\hline Error & 911.89 & 10 & 91.19 & & & \\
\hline Phase for FB- & 49.83 & 1 & 49.83 & 1.05 & 0.33 & 0.09 \\
\hline Error & 523.30 & 11 & 47.57 & & & \\
\hline Mental Arithmetic & & & Betwe & n subjects & & \\
\hline Group & 25.85 & 1 & 25.85 & 0.65 & 0.43 & 0.03 \\
\hline \multirow[t]{2}{*}{ Error } & 877.00 & 22 & 39.86 & & & \\
\hline & \multicolumn{6}{|c|}{ Within subjects } \\
\hline Phase & 389.27 & 1 & 389.27 & $14.65 * *$ & 0.001 & 0.40 \\
\hline Group x Phase & 12.75 & 1 & 12.75 & 0.48 & 0.50 & 0.02 \\
\hline Error & 584.75 & 22 & 26.58 & & & \\
\hline
\end{tabular}

${ }^{*} \mathrm{p}<.01 . * * \mathrm{p}<0.001$. 
Table 7 .

Repeated Measures Analysis of Covariance for DBP during the Videogame and Mental $\underline{\text { Arithmetic }}$

\begin{tabular}{|c|c|c|c|c|c|c|}
\hline Source & SS & $\underline{\mathrm{df}}$ & MS & $\underline{F}$ & $\mathrm{p}$ & $\eta^{2}$ \\
\hline Videogame & \multicolumn{6}{|c|}{ Between subjects } \\
\hline Group & 155.21 & 1 & 155.21 & 2.34 & 0.14 & 0.10 \\
\hline \multirow[t]{2}{*}{ Error } & 1456.40 & 22 & 66.20 & & & \\
\hline & \multicolumn{6}{|c|}{ Within subjects } \\
\hline Phase & 14.17 & 1 & 14.17 & 0.14 & 0.71 & 0.01 \\
\hline Group x Phase & 24.51 & 1 & 24.51 & 0.24 & 0.63 & 0.01 \\
\hline Error & 2284.42 & 22 & 103.84 & & & \\
\hline \multicolumn{3}{|l|}{ Mental Arithmetic } & \multicolumn{3}{|c|}{ Between subjects } & \\
\hline Group & 100.51 & 1 & 100.51 & 1.03 & 0.32 & 0.05 \\
\hline \multirow[t]{2}{*}{ Error } & 2139.08 & 22 & 97.23 & & & \\
\hline & \multicolumn{6}{|c|}{ Within subjects } \\
\hline Phase & 53.97 & 1 & 53.67 & 2.34 & 0.14 & 0.10 \\
\hline Group x Phase & 29.65 & 1 & 29.65 & 1.29 & 0.27 & 0.06 \\
\hline Error & 505.10 & 22 & 22.96 & & & \\
\hline
\end{tabular}


Table 8 .

Repeated Measures Analysis of Covariance for PEP during the Videogame and Mental Arithmetic

\begin{tabular}{|c|c|c|c|c|c|c|}
\hline Source & SS & $\underline{\mathrm{df}}$ & MS & $\underline{F}$ & $\mathrm{p}$ & $\eta^{2}$ \\
\hline Videogame & \multicolumn{6}{|c|}{ Between subjects } \\
\hline Group & 149.60 & 1 & 149.60 & $5.77 *$ & 0.03 & 0.21 \\
\hline \multirow[t]{2}{*}{ Error } & 570.55 & 22 & 255.93 & & & \\
\hline & \multicolumn{6}{|c|}{ Within subjects } \\
\hline Phase & 1014.49 & 1 & 1014.49 & $60.05^{* *}$ & 0.001 & 0.73 \\
\hline Group x Phase & 3.23 & 1 & 3.23 & 0.19 & 0.67 & 0.01 \\
\hline Error & 371.68 & 22 & 16.89 & & & \\
\hline \multicolumn{3}{|l|}{ Mental Arithmetic } & \multicolumn{3}{|c|}{ Between subjects } & \\
\hline Group & 0.13 & 1 & 0.13 & 0.00 & 0.95 & 0.00 \\
\hline \multirow[t]{2}{*}{ Error } & 639.58 & 22 & 29.07 & & & \\
\hline & \multicolumn{6}{|c|}{ Within subjects } \\
\hline Phase & 204.37 & 1 & 204.37 & $14.01 * *$ & 0.001 & 0.39 \\
\hline Group x Phase & 6.38 & 1 & 6.38 & 0.44 & 0.51 & 0.02 \\
\hline Error & 320.91 & 22 & 14.59 & & & \\
\hline
\end{tabular}

$* \mathrm{p}<0.05 . * * \mathrm{p}<0.001$. 
Table 9.

$\underline{\text { Repeated Measures Analysis of Variance for SV during the Videogame and Mental Arithmetic }}$

\begin{tabular}{|c|c|c|c|c|c|c|}
\hline Source & $\mathrm{SS}$ & $\underline{\mathrm{df}}$ & MS & $\underline{F}$ & $\mathrm{p}$ & $\eta^{2}$ \\
\hline Videogame & \multicolumn{6}{|c|}{ Between subjects } \\
\hline Group & 390.63 & 1 & 390.63 & 2.77 & 0.11 & 0.11 \\
\hline \multirow[t]{2}{*}{ Error } & 3244.93 & 23 & 141.08 & & & \\
\hline & \multicolumn{6}{|c|}{ Within subjects } \\
\hline Phase & 511.20 & 1 & 511.20 & $8.73 *$ & 0.01 & 0.28 \\
\hline Group x Phase & 515.21 & 1 & 515.21 & $8.80 *$ & 0.01 & 0.28 \\
\hline \multirow[t]{2}{*}{ Error } & 1346.14 & 23 & 58.53 & & & \\
\hline & \multicolumn{6}{|c|}{ Simple effects } \\
\hline Group at Pre-Training & 4.30 & 1 & 4.30 & 0.04 & 0.85 & 0.00 \\
\hline Error & 2789.79 & 23 & 121.30 & & & \\
\hline Group at Post-Training & 901.54 & 1 & 901.54 & $11.51 *$ & 0.003 & 0.33 \\
\hline Error & 1801.29 & 23 & 78.32 & & & \\
\hline Phase for $\mathrm{FB}+$ & 986.93 & 1 & 986.93 & $10.87 *$ & 0.007 & 0.50 \\
\hline Error & 998.89 & 11 & 90.81 & & & \\
\hline Phase for FB- & 0.00 & 1 & 0.00 & 0.00 & 0.99 & 0.00 \\
\hline Error & 347.25 & 12 & 28.94 & & & \\
\hline Mental Arithmetic & \multicolumn{6}{|c|}{ Between subjects } \\
\hline Group & 136.35 & 1 & 136.35 & 0.83 & 0.37 & 0.04 \\
\hline \multirow[t]{2}{*}{ Error } & 3781.66 & 23 & 164.42 & & & \\
\hline & \multicolumn{6}{|c|}{ Within subjects } \\
\hline Phase & 522.81 & 1 & 522.81 & $13.84 * *$ & 0.001 & 0.38 \\
\hline Group x Phase & 24.14 & 1 & 24.14 & 0.64 & 0.43 & 0.03 \\
\hline Error & 868.65 & 23 & 37.77 & & & \\
\hline
\end{tabular}


Table 10.

Repeated Measures Analysis of Variance for CI during the Videogame and Mental Arithmetic

\begin{tabular}{|c|c|c|c|c|c|c|}
\hline Source & $\mathrm{SS}$ & $\underline{\mathrm{df}}$ & MS & $\underline{\mathrm{F}}$ & $\underline{p}$ & $\eta^{2}$ \\
\hline Videogame & \multicolumn{6}{|c|}{ Between subjects } \\
\hline Group & 44.32 & 1 & 44.32 & 0.32 & 0.58 & 0.01 \\
\hline \multirow[t]{2}{*}{ Error } & 3163.10 & 23 & 137.53 & & & \\
\hline & \multicolumn{6}{|c|}{ Within subjects } \\
\hline Phase & 48.20 & 1 & 48.20 & 0.76 & 0.39 & \\
\hline Group x Phase & 183.04 & 1 & 183.04 & 2.88 & 0.10 & \\
\hline \multirow[t]{2}{*}{ Error } & 1463.80 & 23 & 63.64 & & & \\
\hline & \multicolumn{6}{|c|}{ Simple effects } \\
\hline Group at Pre-Training & 23.61 & 1 & 23.61 & 0.19 & 0.67 & 0.01 \\
\hline Error & 2936.85 & 23 & 127.69 & & & \\
\hline Group at Post-Training & 203.75 & 1 & 203.75 & 2.77 & 0.11 & \\
\hline Error & 1690.05 & 23 & 73.48 & & & \\
\hline Phase for $\mathrm{FB}+$ & 20.86 & 1 & 20.86 & 0.27 & 0.62 & 0.50 \\
\hline Error & 859.20 & 11 & 78.11 & & & \\
\hline Phase for FB- & 218.28 & 1 & 218.28 & 4.33 & 0.06 & 0.27 \\
\hline Error & 604.60 & 12 & 50.38 & & & \\
\hline Mental Arithmetic & & & Betw & subject & & \\
\hline Group & 202.92 & 1 & 202.92 & 2.00 & 0.17 & 0.80 \\
\hline \multirow[t]{2}{*}{ Error } & 2328.13 & 23 & 101.22 & & & \\
\hline & \multicolumn{6}{|c|}{ Within subjects } \\
\hline Phase & 128.59 & 1 & 128.59 & 3.74 & 0.07 & 0.14 \\
\hline Group x Phase & 14.13 & 1 & 14.13 & 0.41 & 0.53 & 0.02 \\
\hline Error & 790.67 & 23 & 34.38 & & & \\
\hline
\end{tabular}


Table 11.

Repeated Measures Analysis of Variance for TPR during the Videogame and Mental Arithmetic

\begin{tabular}{|c|c|c|c|c|c|c|}
\hline Source & SS & $\underline{\mathrm{df}}$ & MS & $\underline{\mathrm{F}}$ & $\mathrm{p}$ & $\eta^{2}$ \\
\hline Videogame & \multicolumn{6}{|c|}{ Between subjects } \\
\hline Group & 273.09 & 1 & 273.09 & 0.75 & 0.39 & 0.03 \\
\hline \multirow[t]{2}{*}{ Error } & 8369.85 & 23 & 363.91 & & & \\
\hline & \multicolumn{6}{|c|}{ Within subjects } \\
\hline Phase & 108.19 & 1 & 108.19 & 0.38 & 0.54 & 0.02 \\
\hline Group x Phase & 1551.77 & 1 & 1551.77 & $5.47 *$ & 0.03 & 0.19 \\
\hline \multirow[t]{2}{*}{ Error } & 6528.56 & 23 & 283.56 & & & \\
\hline & \multicolumn{6}{|c|}{ Simple effects } \\
\hline Group at Pre-Training & 261.45 & 1 & 261.45 & 0.76 & 0.39 & 0.03 \\
\hline Error & 7902.68 & 23 & 343.60 & & & \\
\hline Group at Post-Training & 1563.41 & 1 & 1563.41 & $5.14 *$ & 0.03 & \\
\hline Error & 6995.73 & 23 & 304.16 & & & \\
\hline Phase for FB+ & 1192.03 & 1 & 1192.03 & $6.23 *$ & 0.03 & 0.36 \\
\hline Error & 2105.19 & 11 & 191.38 & & & \\
\hline Phase for FB- & 437.75 & 1 & 437.75 & 1.19 & 0.30 & 0.09 \\
\hline Error & 4423.37 & 12 & 368.61 & & & \\
\hline Mental Arithmetic & & & Between & ubjects & & \\
\hline Group & 96.19 & 1 & 96.19 & 0.26 & 0.61 & 0.01 \\
\hline \multirow[t]{2}{*}{ Error } & 8389.15 & 23 & 364.75 & & & \\
\hline & \multicolumn{6}{|c|}{ Within subjects } \\
\hline Phase & 1517.78 & 1 & 1517.78 & $15.25^{* *}$ & 0.001 & 0.40 \\
\hline Group x Phase & 4.12 & 1 & 4.12 & 0.04 & 0.84 & \\
\hline Error & 2288.61 & 23 & 99.50 & & & \\
\hline
\end{tabular}


Table 12 .

Repeated Measures Analysis of Variance of Performance Scores during the Videogame

\begin{tabular}{|c|c|c|c|c|c|c|}
\hline Source & SS & $\underline{\mathrm{df}}$ & MS & $\underline{F}$ & $\mathrm{p}$ & $\eta^{2}$ \\
\hline Videogame & \multicolumn{6}{|c|}{ Between subjects } \\
\hline Group & $1.2 \times 10^{6}$ & 1 & $1.2 \times 10^{6}$ & 0.19 & 0.67 & 0.01 \\
\hline \multirow[t]{2}{*}{ Error } & $1.5 \times 10^{8}$ & 23 & $6.4 \times 10^{6}$ & & & \\
\hline & \multicolumn{6}{|c|}{ Within subjects } \\
\hline Phase & $1.0 \times 10^{8}$ & 1 & $1.0 \times 10^{8}$ & 18.78 & 0.001 & 0.43 \\
\hline Group x Phase & $7.4 \times 10^{6}$ & 1 & $7.4 \times 10^{6}$ & 1.35 & 0.26 & 0.05 \\
\hline Error & $1.3 \times 10^{8}$ & 23 & $5.5 \times 10^{6}$ & & & \\
\hline
\end{tabular}


Table 13.

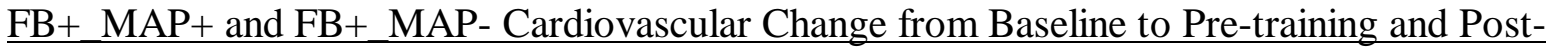
training Videogame Presentations.

\begin{tabular}{|c|c|c|c|c|c|c|c|c|}
\hline \multirow[b]{3}{*}{ Parameter } & \multicolumn{4}{|c|}{ Pre-Training } & \multicolumn{4}{|c|}{ Post-Training } \\
\hline & \multicolumn{2}{|c|}{$\mathrm{FB}+$ MAP+ } & \multicolumn{2}{|c|}{$\mathrm{FB}+$ _MAP- } & \multicolumn{2}{|c|}{$\mathrm{FB}+\_\mathrm{MAP}+$} & \multicolumn{2}{|c|}{$\mathrm{FB}+$ _MAP- } \\
\hline & $\Delta \underline{\mathrm{M}}$ & $\underline{\mathrm{SD}}$ & $\Delta \underline{\mathrm{M}}$ & $\underline{\mathrm{SD}}$ & $\Delta \underline{\mathrm{M}}$ & $\underline{\mathrm{SD}}$ & $\Delta \underline{\mathrm{M}}$ & $\underline{\mathrm{SD}}$ \\
\hline HR (bpm) & 8.7 & 5.5 & 10.9 & 4.8 & 0.3 & 2.2 & 0.5 & 3.1 \\
\hline MAP (mm Hg) & 2.0 & 9.1 & 12.4 & 8.6 & 5.5 & 8.1 & -2.5 & 4.6 \\
\hline $\mathrm{SBP}(\mathrm{mm} \mathrm{Hg})$ & 12.6 & 11.4 & 21.3 & 13.1 & 6.0 & 11.7 & -0.0 & 6.9 \\
\hline DBP (mm Hg) & 0.4 & 10.0 & 8.0 & 7.9 & 8.3 & 7.1 & -3.7 & 5.9 \\
\hline PEP (msec) & -13.1 & 10.0 & -12.6 & 5.0 & -5.1 & 5.7 & -2.3 & 1.8 \\
\hline SV \% Change & -8.6 & 9.3 & -15.6 & 12.9 & 6.0 & 12.5 & -3.8 & 5.6 \\
\hline CI \% Change & -0.2 & 9.6 & -1.7 & 14.8 & 6.3 & 13.3 & -3.2 & 4.2 \\
\hline TPR \% Change & 7.3 & 23.4 & 20.1 & 21.6 & 0.7 & 15.1 & 0.6 & 7.8 \\
\hline
\end{tabular}


Table 14.

Repeated Measures Analysis of Variance for HR Comparing the FB+ $\mathrm{MAP}+$ and $\mathrm{FB}+\mathrm{MAP}-$

Groups During the Videogame

\begin{tabular}{lcccccc}
\hline \multicolumn{1}{c}{ Source } & SS & $\underline{\mathrm{df}}$ & $\mathrm{MS}$ & $\underline{\mathrm{F}}$ & $\mathrm{p}$ & $\underline{\eta}^{2}$ \\
\hline Group & & \multicolumn{5}{c}{ Between subjects } \\
Error & 198.61 & 9 & 22.07 & & \\
& & 1 & 0.95 & 0.04 & 0.84 & 0.01 \\
& & & Within subjects & & \\
Phase & 417.68 & 1 & 417.68 & 43.71 & 0.00 & 0.83 \\
Group x Phase & 1.27 & 1 & 1.27 & 0.13 & 0.72 & 0.02 \\
Error & 86.00 & 9 & 9.56 & & & \\
\hline
\end{tabular}


Table 15 .

Repeated Measures Analysis of Variance for MAP Comparing the FB+ MAP+ and FB+ MAPGroups During the Videogame

\begin{tabular}{|c|c|c|c|c|c|c|}
\hline Source & $\mathrm{SS}$ & $\underline{\mathrm{df}}$ & MS & $\underline{F}$ & $\mathrm{p}$ & $\eta^{2}$ \\
\hline & \multicolumn{6}{|c|}{ Between subjects } \\
\hline Group & 0.01 & 1 & 0.01 & 0.00 & 0.99 & 0.00 \\
\hline \multirow[t]{2}{*}{ Error } & 802.91 & 9 & 89.21 & & & \\
\hline & \multicolumn{6}{|c|}{ Within subjects } \\
\hline Phase & 175.37 & 1 & 175.37 & 4.50 & 0.06 & 0.33 \\
\hline Group x Phase & 325.72 & 1 & 325.72 & 8.35 & 0.02 & 0.48 \\
\hline \multirow[t]{2}{*}{ Error } & 350.87 & 9 & 38.99 & & & \\
\hline & \multicolumn{6}{|c|}{ Simple effects } \\
\hline Group at Pre-Training & 85.05 & 1 & 85.05 & 1.03 & 0.34 & 0.10 \\
\hline Error & 743.12 & 9 & 82.57 & & & \\
\hline Group at Post-Training & 88.48 & 1 & 88.48 & 2.07 & 0.18 & 0.19 \\
\hline Error & 384.78 & 9 & 42.75 & & & \\
\hline Phase for FB+_MAP+ & 20.49 & 1 & 20.49 & 0.70 & 0.47 & 0.19 \\
\hline Error & 88.19 & 3 & 29.40 & & & \\
\hline Phase for $\mathrm{FB}+$ _MAP- & 370.33 & 1 & 370.33 & 7.45 & 0.04 & 0.60 \\
\hline Error & 248.38 & 5 & 49.68 & & & \\
\hline
\end{tabular}


Table 16.

Repeated Measures Analysis of Variance for SBP Comparing the FB+ MAP+ and FB+ MAP-

Groups During the Videogame

\begin{tabular}{|c|c|c|c|c|c|c|}
\hline Source & $\mathrm{SS}$ & $\underline{\mathrm{df}}$ & MS & $\underline{F}$ & $\mathrm{p}$ & $\eta^{2}$ \\
\hline & \multicolumn{6}{|c|}{ Between subjects } \\
\hline Group & 48.38 & 1 & 48.38 & 0.26 & 0.63 & .03 \\
\hline \multirow[t]{2}{*}{ Error } & 1702.12 & 9 & 189.12 & 5.93 & 0.04 & \\
\hline & \multicolumn{6}{|c|}{ Within subjects } \\
\hline Phase & 114.04 & 1 & 114.04 & 16.90 & 0.003 & 0.65 \\
\hline Group x Phase & 318.54 & 1 & 318.54 & 4.83 & 0.06 & 0.35 \\
\hline \multirow[t]{2}{*}{ Error } & 593.35 & 9 & 65.93 & & & \\
\hline & \multicolumn{6}{|c|}{ Simple effects } \\
\hline Group at Pre-Training & 247.97 & 1 & 247.97 & 1.47 & 0.26 & 0.14 \\
\hline Error & 1518.69 & 9 & 168.74 & & & \\
\hline Group at Post-Training & 52.58 & 1 & 52.58 & 0.57 & 0.47 & 0.06 \\
\hline Error & 837.83 & 9 & 93.09 & & & \\
\hline Phase for $\mathrm{FB}+$ MAP+ & 128.09 & 1 & 128.09 & 4.83 & 0.12 & 0.62 \\
\hline Error & 79.59 & 3 & 26.53 & & & \\
\hline Phase for $\mathrm{FB}+\_\mathrm{MAP}-$ & 1352.34 & 1 & 1352.34 & $13.21 *$ & 0.02 & 0.72 \\
\hline Error & 511.91 & 5 & 102.38 & & & \\
\hline
\end{tabular}


Table 17.

Repeated Measures Analysis of Variance for DBP Comparing the FB+ MAP+ and FB+ MAP-

Groups During the Videogame

\begin{tabular}{|c|c|c|c|c|c|c|}
\hline Source & SS & $\underline{\mathrm{df}}$ & MS & $\underline{F}$ & $\underline{\mathrm{P}}$ & $\eta^{2}$ \\
\hline & \multicolumn{6}{|c|}{ Between subjects } \\
\hline Group & 0.50 & 1 & 0.50 & 0.01 & 0.93 & 0.00 \\
\hline \multirow[t]{2}{*}{ Error } & 569.25 & 9 & 63.25 & & & \\
\hline & \multicolumn{6}{|c|}{ Within subjects } \\
\hline Phase & 18.62 & 1 & 18.62 & 0.33 & 0.58 & 0.04 \\
\hline Group x Phase & 365.67 & 1 & 365.67 & 6.40 & 0.03 & 0.42 \\
\hline \multirow[t]{2}{*}{ Error } & 514.46 & 9 & 57.16 & & & \\
\hline & \multicolumn{6}{|c|}{ Simple effects } \\
\hline Group at Pre-Training & 103.49 & 1 & 103.49 & 1.33 & 0.28 & 0.13 \\
\hline Error & 698.03 & 9 & 77.56 & & & \\
\hline Group at Post-Training & 180.60 & 1 & 180.60 & 4.21 & 0.07 & 0.32 \\
\hline Error & 386.38 & 9 & 42.93 & & & \\
\hline Phase for FB+_MAP+ & 126.86 & 1 & 126.86 & 2.76 & 0.20 & 0.10 \\
\hline Error & 137.74 & 3 & 45.91 & & & \\
\hline Phase for FB+_MAP- & 308.72 & 1 & 308.72 & 5.07 & 0.07 & 0.50 \\
\hline Error & 304.74 & 5 & 60.95 & & & \\
\hline
\end{tabular}


Table 18.

Repeated Measures Analysis of Variance for PEP Comparing the FB+ $\mathrm{MAP}+$ and $\mathrm{FB}+\mathrm{MAP}-$ Groups During the Videogame

\begin{tabular}{|c|c|c|c|c|c|c|}
\hline Source & SS & $\underline{\mathrm{df}}$ & MS & $\underline{F}$ & $\mathrm{p}$ & $\eta^{2}$ \\
\hline & \multicolumn{6}{|c|}{ Between subjects } \\
\hline Group & 0.66 & 1 & 0.66 & 0.03 & 0.86 & 0.00 \\
\hline \multirow[t]{2}{*}{ Error } & 184.89 & 9 & 20.54 & & & \\
\hline & \multicolumn{6}{|c|}{ Within subjects } \\
\hline Phase & 502.11 & 1 & 502.11 & $21.88^{*}$ & 0.001 & 0.71 \\
\hline Group x Phase & 11.65 & 1 & 11.65 & 0.51 & 0.49 & 0.05 \\
\hline Error & 206.53 & 9 & 22.95 & & & \\
\hline
\end{tabular}

$* \underline{p}<0.001$. 
Table 19.

$\underline{\text { Repeated Measures Analysis of Variance for SV Comparing the FB+ } \mathrm{MAP}+\text { and } \mathrm{FB}+\mathrm{MAP}-}$

Groups During the Videogame

\begin{tabular}{lcccccc}
\hline \multicolumn{1}{c}{ Source } & SS & $\underline{\mathrm{df}}$ & $\mathrm{MS}$ & $\underline{\mathrm{F}}$ & $\mathrm{p}$ & $\underline{\eta}^{2}$ \\
\hline Group & 433.40 & 1 & 433.40 & 3.69 & 0.08 & 0.27 \\
Error & 1174.78 & 10 & 117.48 & & & \\
\cline { 2 - 7 } & & & Wetween subjects & & \\
Phase & 989.20 & 1 & 989.20 & 9.98 & 0.01 & 0.50 \\
Group x Phase & 8.14 & 1 & 8.14 & 0.08 & 0.78 & 0.01 \\
Error & 990.75 & 10 & 99.08 & & & \\
\hline
\end{tabular}


Table 20 .

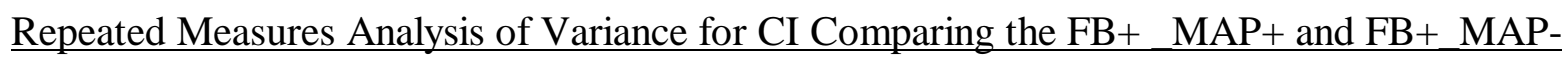
Groups During the Videogame

\begin{tabular}{|c|c|c|c|c|c|c|}
\hline Source & SS & $\underline{\mathrm{df}}$ & MS & $\underline{F}$ & $\mathrm{p}$ & $\eta^{2}$ \\
\hline & \multicolumn{6}{|c|}{ Between subjects } \\
\hline Group & 177.77 & 1 & 177.77 & 1.02 & 0.34 & 0.09 \\
\hline \multirow[t]{2}{*}{ Error } & 1735.82 & 10 & 173.58 & & & \\
\hline & \multicolumn{6}{|c|}{ Within subjects } \\
\hline Phase & 37.34 & 1 & 37.34 & 0.49 & 0.50 & 0.05 \\
\hline Group x Phase & 93.02 & 1 & 93.02 & 1.21 & 0.30 & 0.11 \\
\hline Error & 766.18 & 10 & 76.62 & & & \\
\hline
\end{tabular}


Table 21.

Repeated Measures Analysis of Variance for TPR Comparing the FB+ MAP+ and FB+ MAP-

Groups During the Videogame

\begin{tabular}{lcccccc}
\hline \multicolumn{1}{c}{ Source } & \multicolumn{1}{c}{ SS } & $\underline{\mathrm{df}}$ & $\mathrm{MS}$ & $\underline{\mathrm{F}}$ & $\mathrm{p}$ & $\underline{\eta}^{2}$ \\
\hline Group & 233.48 & 1 & 233.48 & 0.53 & 0.48 & 0.05 \\
Error & 4404.82 & 10 & 440.48 & & & \\
\cline { 2 - 7 } & & & Wetween subjects & & \\
Phase & 989.08 & 1 & 989.08 & 5.31 & 0.04 & 0.35 \\
Group x Phase & 242.11 & 1 & 242.11 & 1.30 & 0.28 & 0.12 \\
Error & 1863.08 & 10 & 186.31 & & & \\
\hline
\end{tabular}


Figure 1.

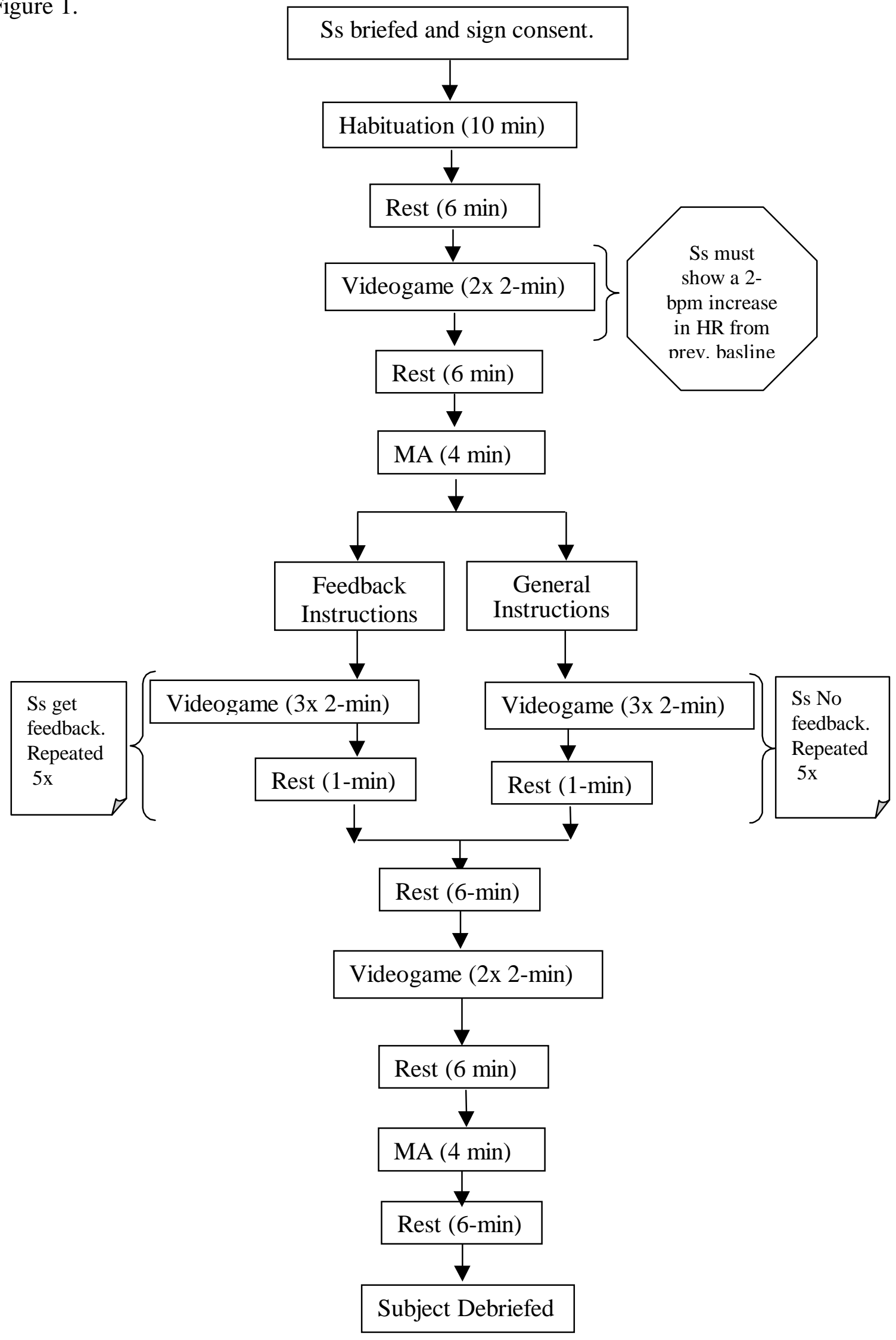


Figure 2.

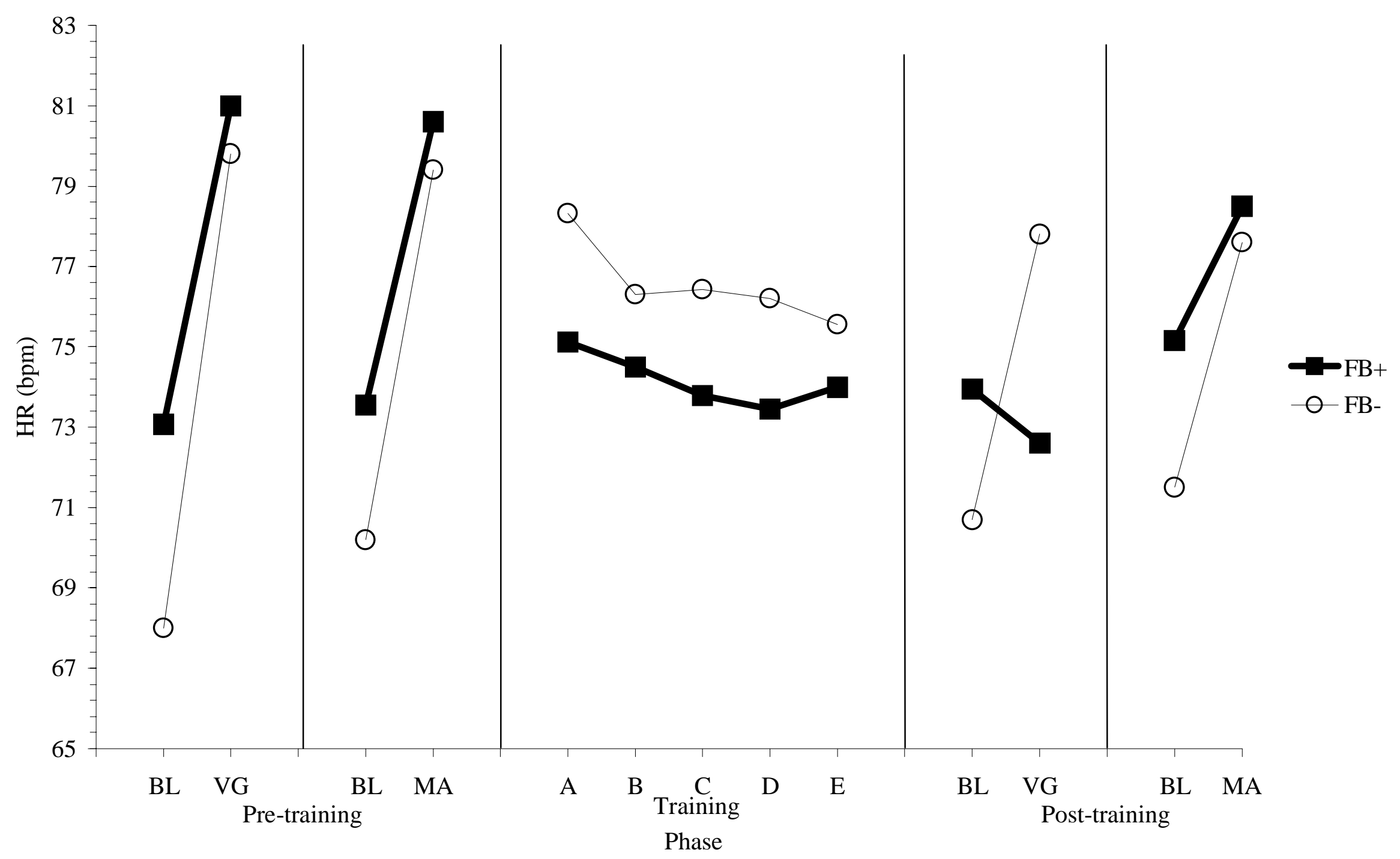


Figure 3.

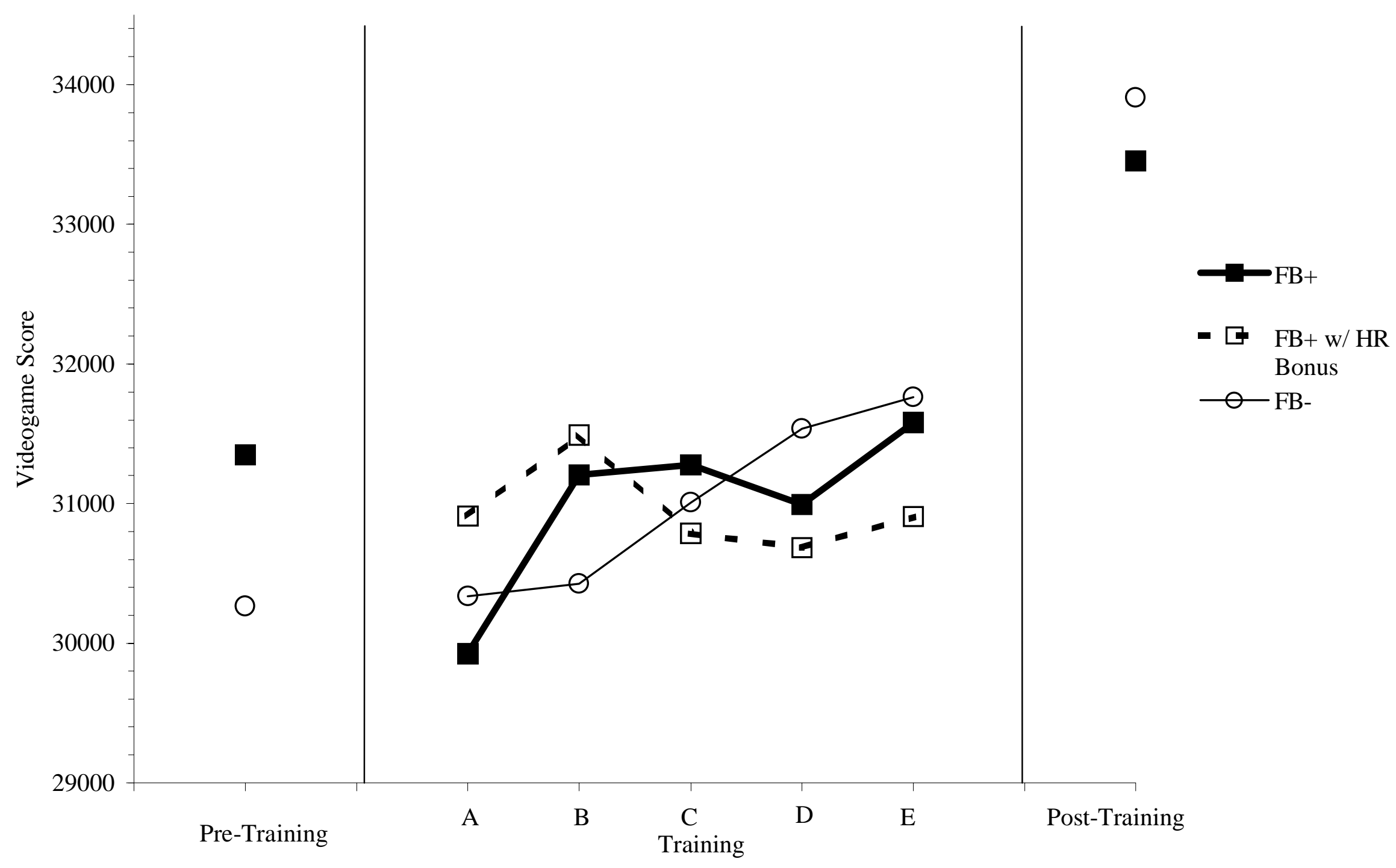


Figure 4.

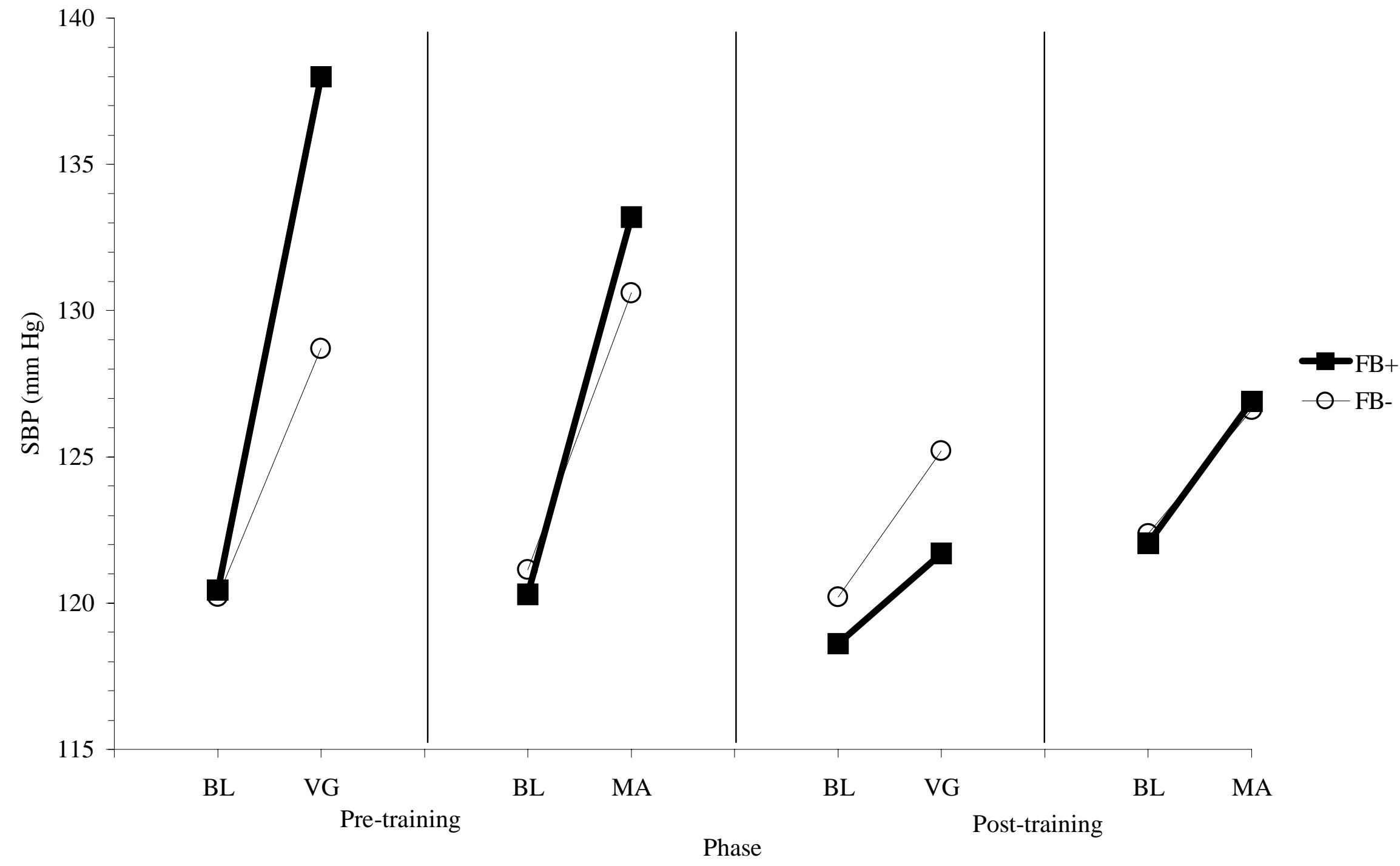


Figure 5.

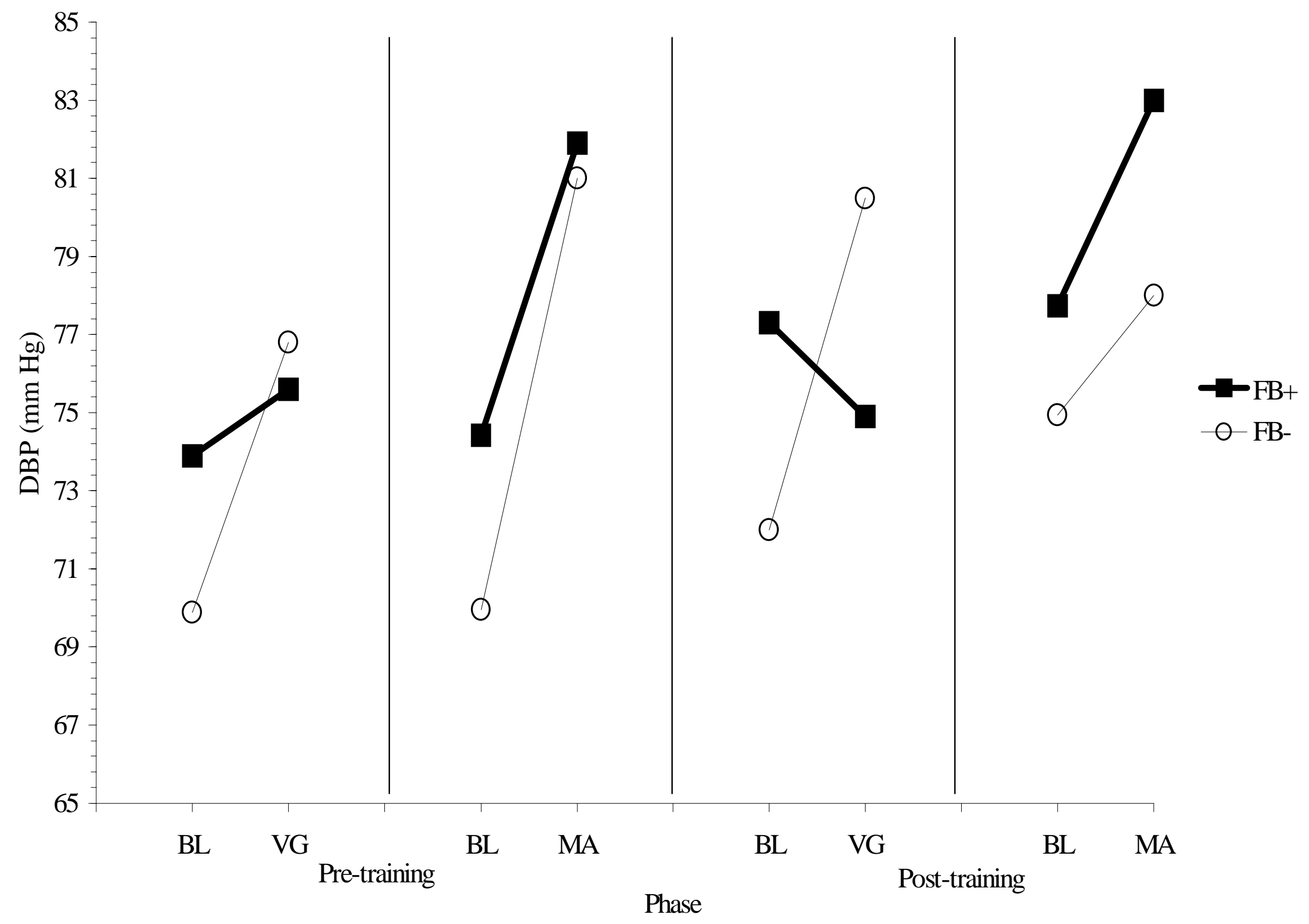


Figure 6.

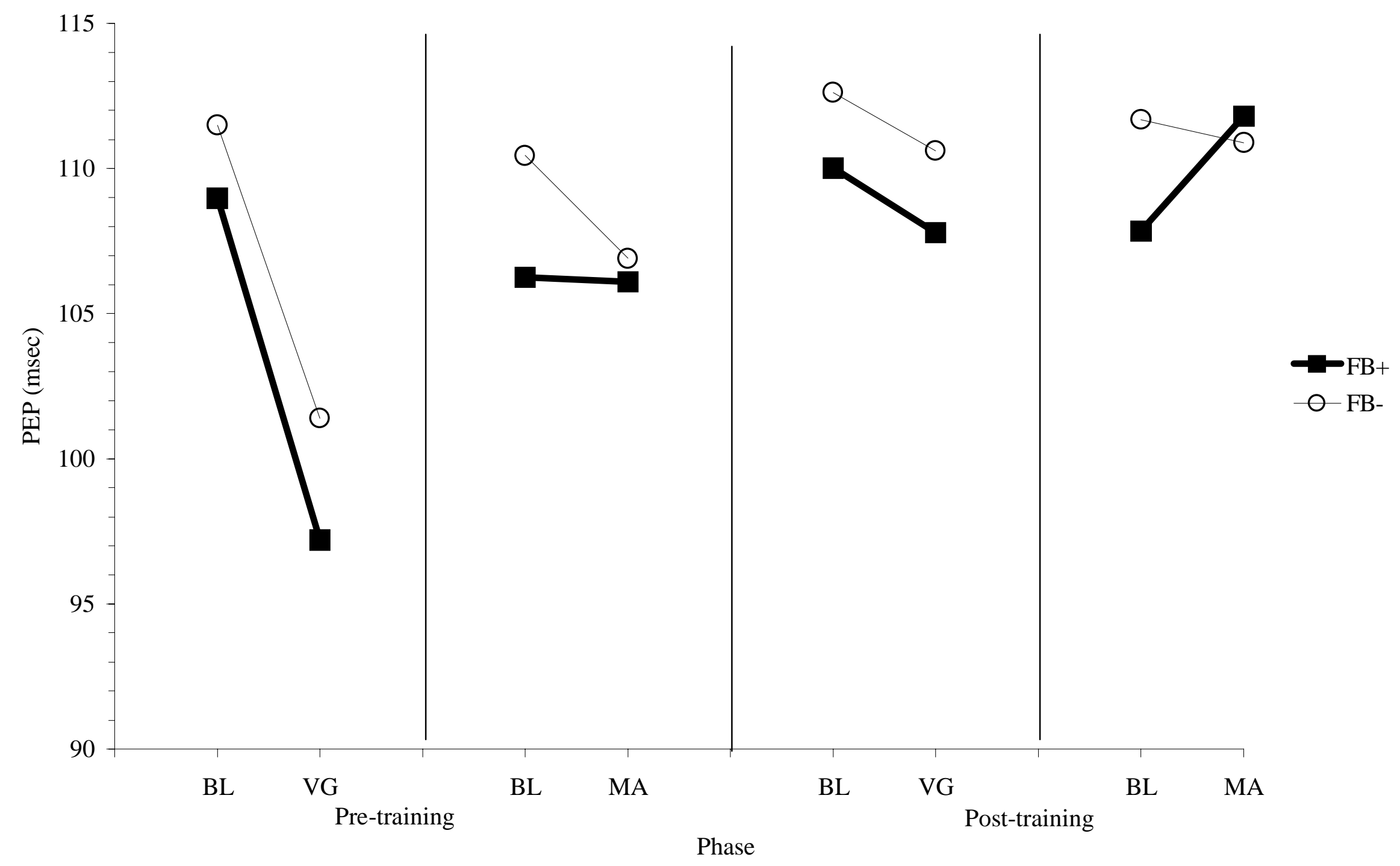


Figure 7.

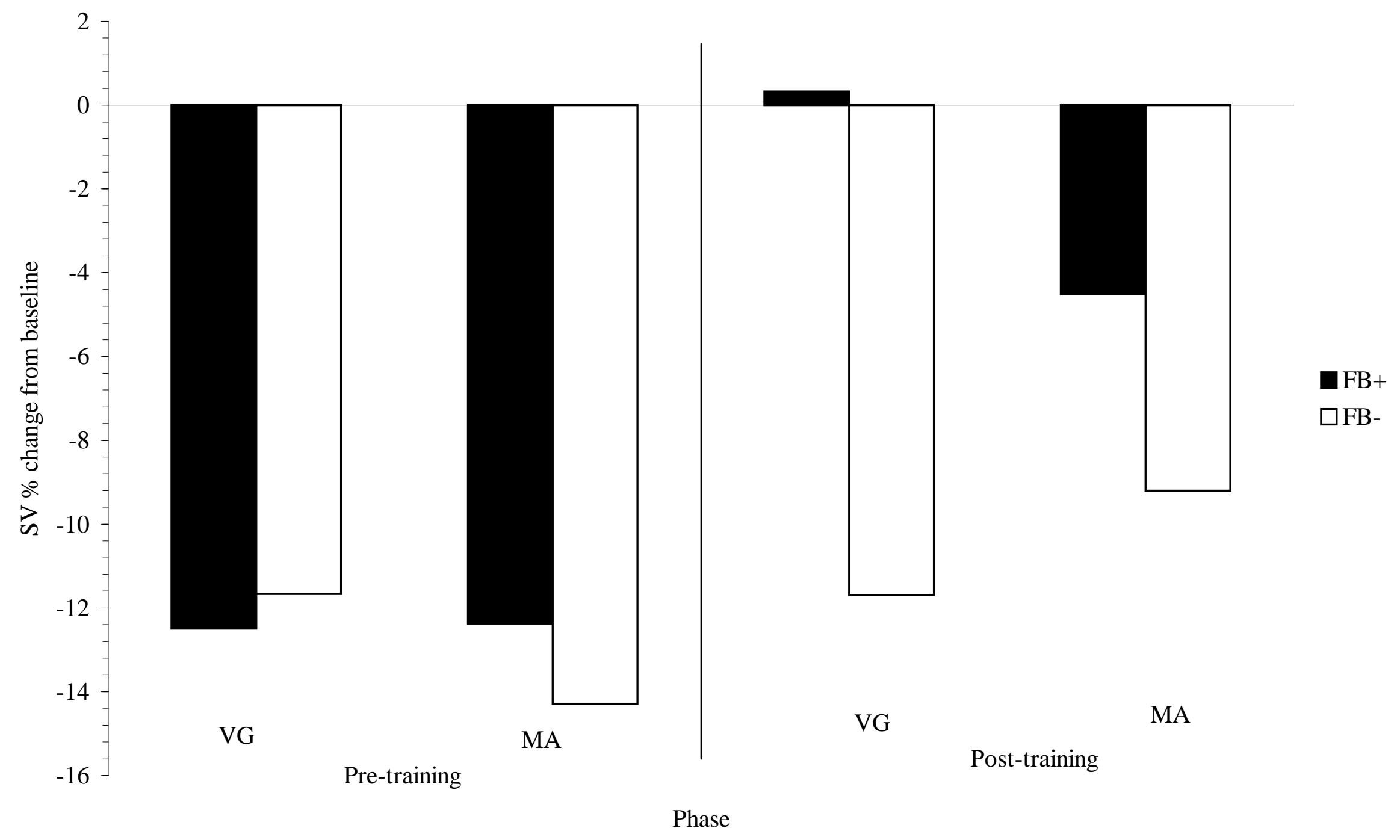


Figure 8 .

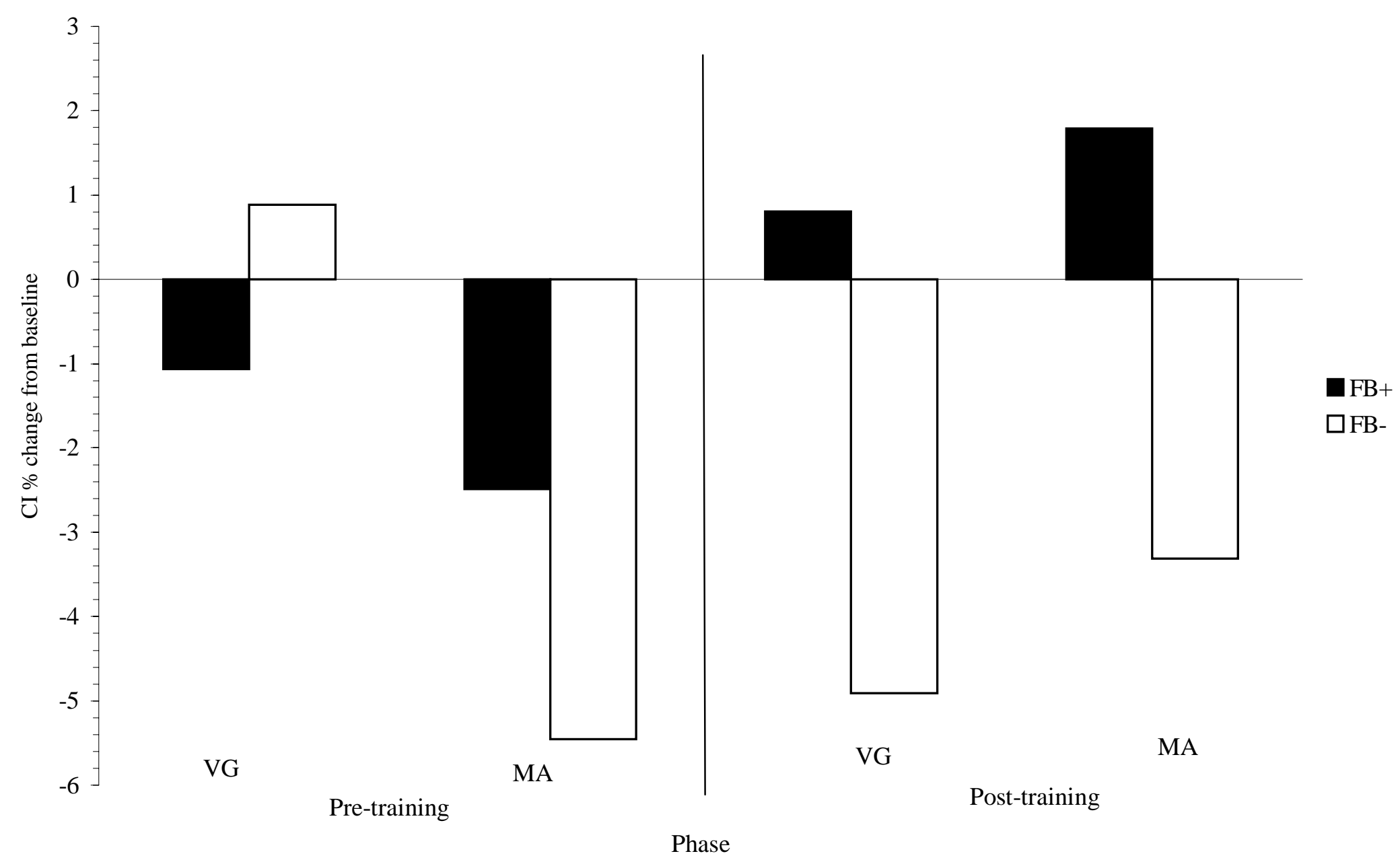


Figure 9.

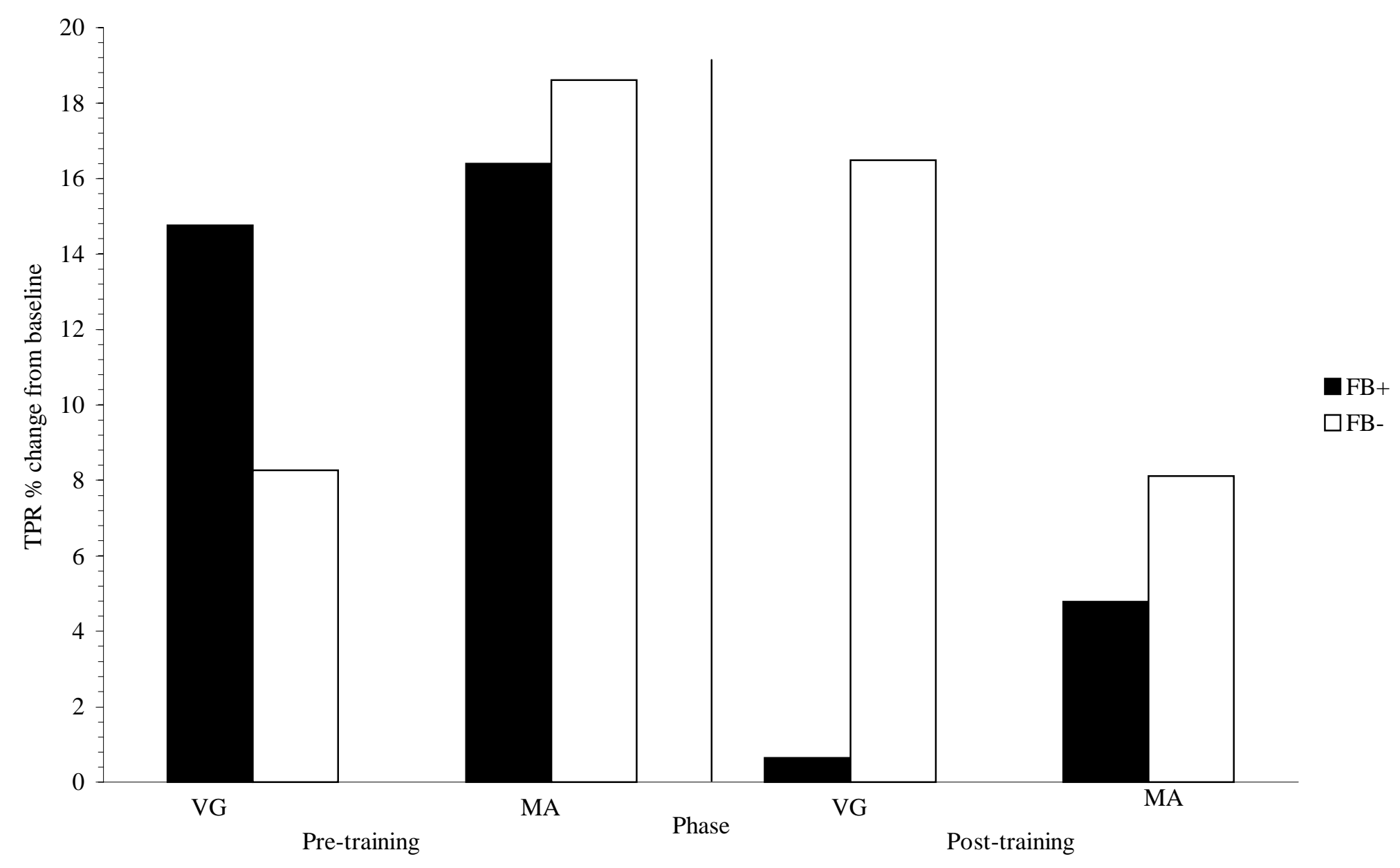


Figure 10.

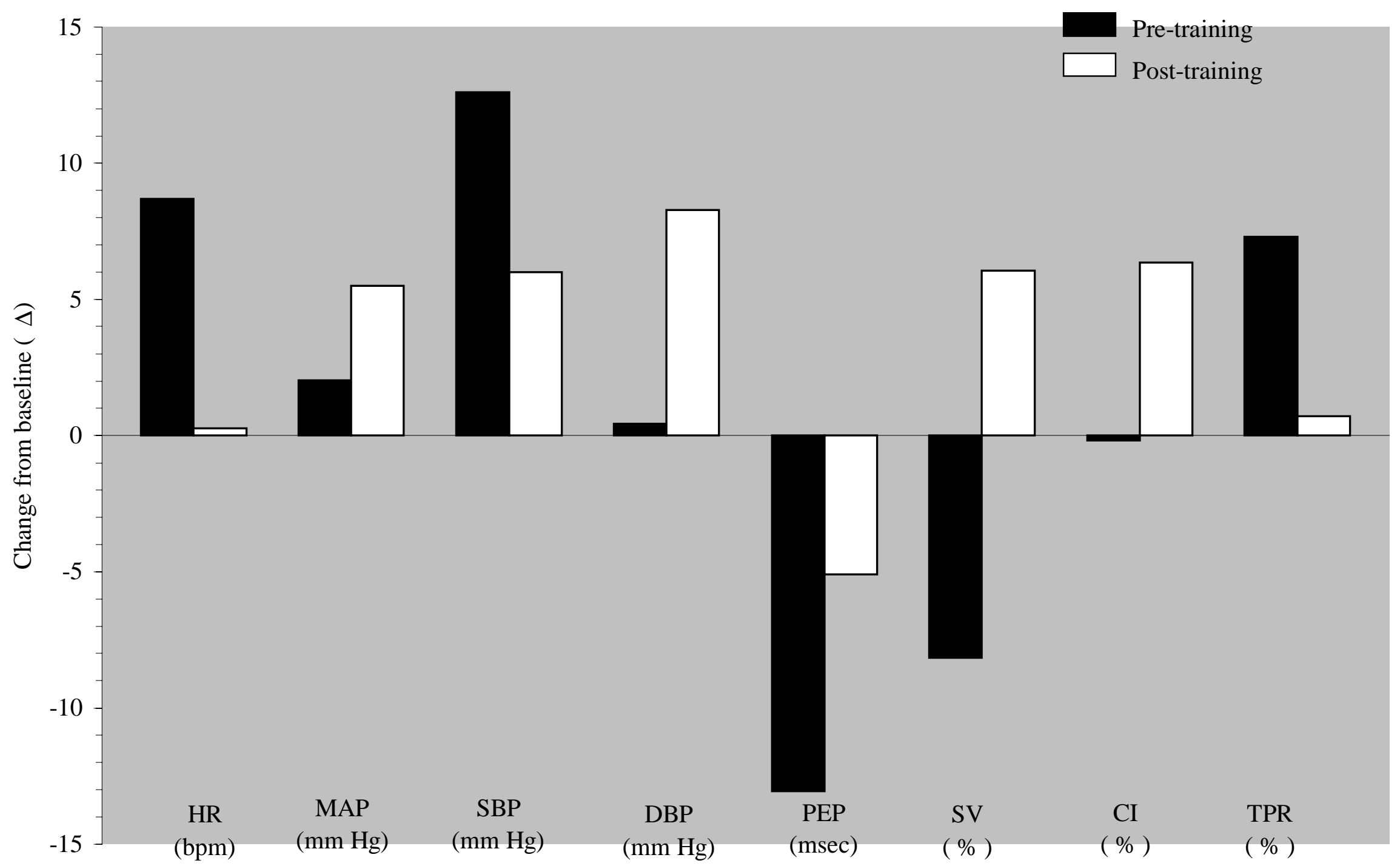


Figure 11.

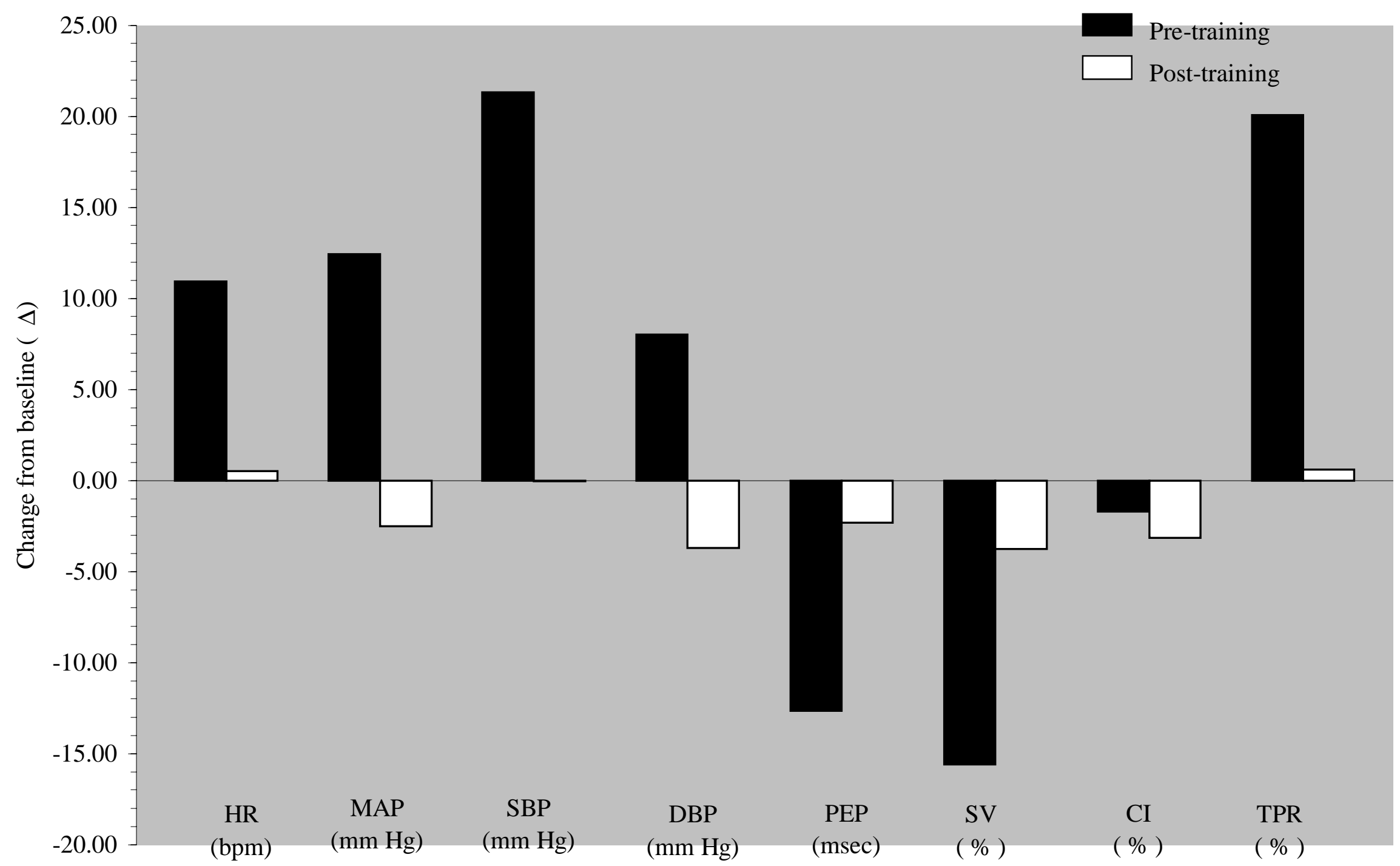




\section{CURRICULUM VITAE}

Name:

Business Address:

E-mail:

Graduate

8/96-Present

Undergraduate

8/89-5/93
Jeffrey Louis Goodie

West Virginia University

Department of Psychology

P.O. Box 6040

Morgantown, WV 26506-6040

jgoodie@wvu.edu

\section{EDUCATION}

West Virginia University

Clinical Psychology, Ph.D. Program

Behavioral Medicine research focus

Dickinson College

Bachelor of Arts degree in Psychology

Completed Pre-Medicine course requirements

Dean's List 1992-1993

\section{CLINICAL EXPERIENCES}

Practicum Student, Center for Pain Management, Ruby Memorial Hospital Morgantown, WV Practicum Student, Hopemont Hospital, Terra Alta, WV.

Practicum Student, Quin Curtis Center, West Virginia University, Morgantown, WV

Practicum Student, Louis A. Johnson Veterans Memorial Hospital, Clarksburg, WV

Mental Health/Mental Retardation Technician, Personal-Touch, Pittsburgh, PA

Research Associate, Western Psychiatric Institute and Clinic, Pittsburgh, PA

Volunteer, Cancer Caring Center, Pittsburgh, PA

Resident Adviser, Dickinson College, Carlisle, PA

\section{RESEARCH EXPERIENCES}

Primary Investigator, Thesis project examining changes in hemodynamic parameters during heart rate biofeedback using impedance cardiography, West Virginia University, Morgantown, WV.

Graduate Research Assistant, Neuropsychological assessment of adult residual attention deficit 
disorder, West Virginia University, Morgantown, WV.

Graduate Research Assistant, Daily stress and ambulatory blood pressure in individuals with essential hypertension, West Virginia University, Morgantown, WV.

Graduate Research Assistant, Examining cardiovascular reactivity to stress and family history of hypertension. West Virginia University, Morgantown, WV.

Co-Investigator, Decision making in older adults, West Virginia University, Morgantown, WV. Co-Investigator, Preliminary investigation of the reliability of the Polar Heart Rate Monitor to assess cardiovascular activity, West Virginia University, Morgantown, WV.

Research Specialist II, Studied the effects of psychosocial factors on ambulatory cardiovascular reactivity, University of Pittsburgh, Pittsburgh, PA.

\section{TEACHING EXPERIENCES}

Graduate Teaching Assistant, Behavioral Assessment, West Virginia University, Morgantown, WV

Graduate Teaching Assistant , Child Behavior Modification, West Virginia University, Morgantown, WV

Graduate Teaching Assistant, Introduction to Clinical Psychology, West Virginia University, Morgantown, WV

Graduate Laboratory Instructor, Experimental Analysis of Behavior, West Virginia University, Morgantown, WV

Undergraduate Teaching Assistant, Personality Psychology, Dickinson College, Carlisle, PA Undergraduate Tutor, Biology, Dickinson College, Carlisle, PA

\section{EDITORIAL ACTIVITIES}

1997

1998
Ad Hoc Editorial Reviewer, Journal of Behavioral Medicine

Ad Hoc Editorial Reviewer, Psychosomatic Medicine

\section{PUBLICATIONS}

Ruggerio, K., Goodie, J. L., \& Morris, T. (in press). Beyond summary scores and labels: The benefits of item analysis in group-design research. Behavior Therapy and Experimental Psychiatry,.

Kamarck, T., Shiffman, S., Smithline, L., Goodie, J., Paty, J., Gnys, M., \& Jong, J. (1998). The effects of task strain, social conflict, and emotional activation on ambulatory cardiovascular activity: Daily life consequences of 'recurring stress' in a multiethnic adult sample, Health Psychology, 17, 17-29.

Kamarck, T. Shiffman, S., Smithline, L., Goodie, J., Thompson, H., Ituarte, P., Jong, J., Pro, V., Paty, J., Kassel, J., Gnys, M., \& Perz, W. (1998). The diary of ambulatory behavioral states: A new approach to the assessment of psychosocial influences on ambulatory cardiovascular activity. In D. Krantz \& A. Baum (Eds.), Perspectives in Behavioral Medicine: 
Technology and Methodology in Behavioral Medicine. Hillsdale, NH: Lawrence Erlbaum.

Goodie, J. \& Kamarck, T. (1996). Use of the Accutracker DX to assess behavioral influences on ambulatory cardiovascular activity: A preliminary investigation. Blood Pressure Monitoring, 1,135-140.

\section{PUBLISHED ABSTRACTS AND PRESENTATIONS}

Drozdick, L. W., Goodie, J. L., James, J., \& Edelstein, B. (1998). Relation between the AFABS and measures of executive and cognitive functioning. Poster presentation at the Gerontolgical Society of America in Philadelphia, PA.

Goodie, J. L. \& Kalish, K. (1998). Functional assessment of nursing home residents. Presentation at the Association for the Advancement of Behavior Therapy in Washington, DC.

Larkin, K. T., Schauss, S. L., Elnicki, D. M., Goodie, J. L. (1998). Clinical indicators of "White Coat" hypertension. Presented at the Society for Behavioral Medicine Annual Meeting, in New Orleans, LA.

Goodie, J. L., Schauss, S., Larkin, K. T., Aragona, B. (1997). Validation of the Polar heart rate monitor for measuring heart rate responses to mental stress. Psychophysiology, 34, S38. Presented at the Society for Psychophysiological Research Annual Meeting, in Cape Cod, MA.

Kamarck, T. W., Shiffman, S. S., Smithline, L., Thompson, H., Goodie, J., Paty, Gnys, M., \& Kassel. (1997). The effects of psychosocial influences on ambulatory blood pressure: Contrasting different measurement and data analytic strategies. Psychophysiology, 34, S6. Presentation at the Society for Psychophysiological Research Annual Meeting, in Cape Cod, MA.

Raynor, D. A., Kamarck, T. W., Shiffman, S. S., Ituarte, P., Thompson, H., Smithline, L., Goodie, J., Paty, J., Gnys, M., \& Kassel, J. (1997). The effects of social influence on cardiovascular responsiveness in the natural environment. Psychophysiology, 34, S73. Presented at the Society for Psychophysiological Research Annual Meeting, in Cape Cod, MA.

Smithline, L., Kamarck, T. W., Shiffman, S. S., Thompson, H., Goodie, J., Paty, J., Gnys, M., \& Kassel, J. (1997). Job strain and ambulatory blood pressure in a healthy community sample: Failure to replicate. Psychophysiology, 34, S82. Paper presented at the Society for Psychophysiological Research, in Cape Cod Annual Meeting, MA.

Ciano-Federoff, L. M., Larkin, K. T., \& Goodie, J. L. (1997). Coping mechanisms as partial mediators between depression and health status. Paper presented at the Society of Behavioral Medicine Annual Meeting, in San Francisco, CA.

Gump, B., Kamarck, T., Shiffman, S., Smithline, L., Thompson, H., Goodie, J., Pro, V., Paty, J., Kassel, J., \& Gnys, M. (1997). Marital satisfaction and cardiovascular reactivity: 
Looking within the home. Paper presented at the Society of Behavioral Medicine Annual Meeting, in San Francisco, CA.

Smithline, L., Kamarck, T., Shiffman, S., Thompson, H., Goodie, J., Pro, V., Paty, J., Kassel, J., \& Gnys, M. (1997). The effects of hostility on social conflict and cardiovascular reactivity during daily life. Paper presented at the Society of Behavioral Medicine Annual Meeting, in San Francisco, CA.

Davig, J. P, Larkin, K. T. \& Goodie J. L. (1996). Does cardiovascular reactivity to stress measured in the laboratory generalize to thesis and dissertation meetings? Paper presented at the Association for the Advancement of Behavior Therapy Annual Meeting in New York, NY.

Ituarte, P., Kamarck, T. W., Shiffman, S., Goodie, J., Smithline, L., Pro, V., Gnuys, M., Paty, J. \& Kassel, J. (1996). Received support buffers the effects of daily stressors on wellbeing: An ecological momentary assessment approach. Paper presented at the Society of Behavioral Medicine Annual Meeting, in Washington, DC.

Kamarck, T. W., Shiffman, S., Manuck, S. B., Debski, T. T., Cerrone, P., Smithline, L., Goodie, J. Pro, V., Gnys, M., Paty, J., \& Kassel, J. (1996). Correspondence between laboratory and ambulatory measures of cardiovascular reactivity. Paper presented at the Society of Behavioral Medicine Annual Meeting, in Washington, DC.

Kamarck, T. W., Shiffman, S., Smithline, L., Goodie, J. Pro, V., Paty, J., Kassel, J. (1996). The effects of social behavior on ambulatory cardiovascular activity. Paper presented at the Society of Behavioral Medicine Annual Meeting, in Washington, DC.

Goodie, J. \& Kamarck, T. (1994). Validation of the Accutracker DX ambulatory blood pressure monitor. Paper presented at the Society for Psychophysiological Research Annual Meeting, in Atlanta GA. 